\title{
ATIVIDADE MÍNIMA DETECTÁVEL PARA RADIOISÓTOPOS EMISSORES DE RAIOS GAMA EM AMOSTRAS AQUOSAS
}

\author{
MARCIA INESS ROCHA SARTI
}

Orientador: VIRGILIO F. NASCIMENTO FILHO

Dissertação apresentada à Escola Superior de Agricultura "Luiz de Queiroz", da Universidade de São Paulo, para obtenção do título de Mestre em Energia Nuclear na Agricultura.

PIR A CICABA

Estado de São Paulo - Brasil

Novembro, 1980 
Aos meus pais,

Ao Antonio Carlos, Filipe e Milena,

$D E D I C O$ 


\section{AGRADECIMENTOS}

- Ao Prof. Virgílio F. Nascimento FO, pela orientação, dedicação e estí mulo no desenvolvimento deste trabalha,

- ao Dr. Admar Cervezzini, Diretor do Centro de Energia Nuclear na Agricultura, e ao Dr. Peter B. Vose, Diretor do Projeto UNDP/IAEA BRA/ 78/006, pelos recursos obtidos junto à Comissão Nacional de Energia Nuclear e Agência Internacional de Energia Atômica,

- do Centro de Energia Nuclear na Agricultura e à Escola Superior de Agricultura "Luiz de Queiroz", pela oportunidade de aperfeiçoamento,

- ao Plano de Formação e Aperfeicoamento de Pessoal de Nivel Superior PLANFAP/CNEN e Coordenação do Aperfeiçoconento do Pessoal de Nivel Superior - CAPES, pela concessão de bolsas de estudos,

- ao funcionārio José osório Bertoli, pela amizade, ajuda na realização de experimentos e serviços de datilografia, e

- a todos os funcionários do CENA, que de uma forma ou de outra, contri buĩram para a execução deste trabalho. 
Pāgina

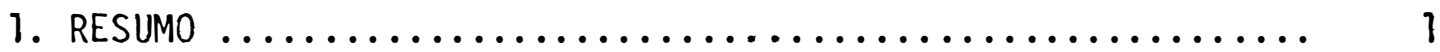

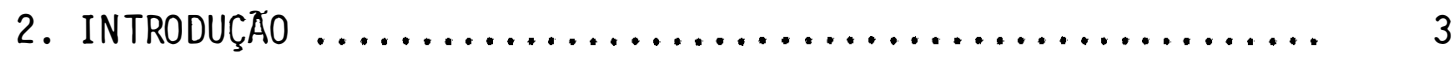

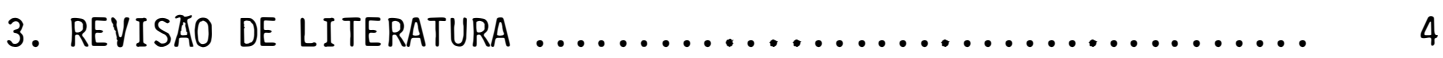

4. TEORIA $\ldots \ldots \ldots \ldots \ldots \ldots \ldots \ldots \ldots \ldots \ldots \ldots \ldots \ldots \ldots \ldots \ldots \ldots \ldots \ldots \ldots$

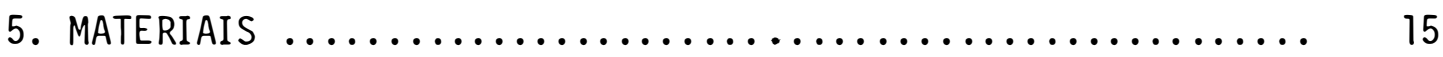

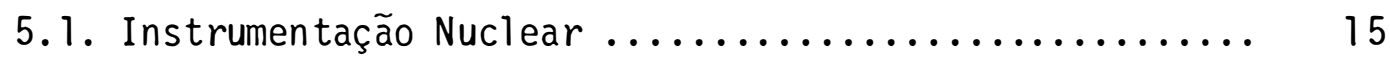

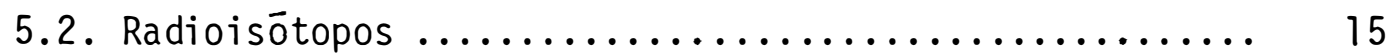

5.2.1. Amostras radioativas padronizadas .......... 15

5.2 .2 . Amostras radioativas não padronizadas ....... 18

5.2.3. Blindagem, beaker Marinelli e tubo de ensaio.. 18

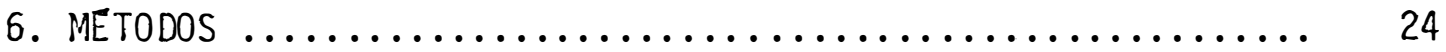

6.1. Eficiência de detecção de radioisōtopos em bastão

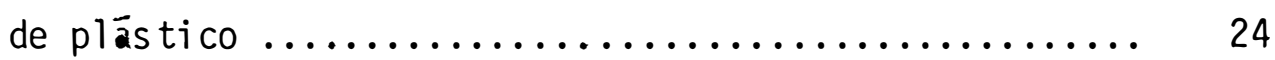

6.2. Eficiência de deteç̧ão de radioisōtopos em tubo de

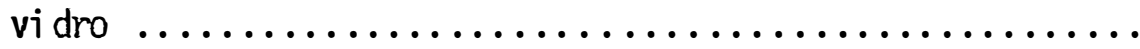

6.3. Eficiência de detecção de radioisōtopos em beaker

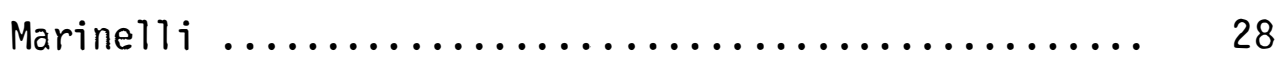

6.4. Atividade especîfica mínima detectável .......... 29

7. RESULTADOS E DISCUSSÃO $\ldots \ldots \ldots \ldots \ldots \ldots \ldots \ldots \ldots \ldots \ldots \ldots$

7.1. Eficiência de detecção de radioisōtopos em bastão

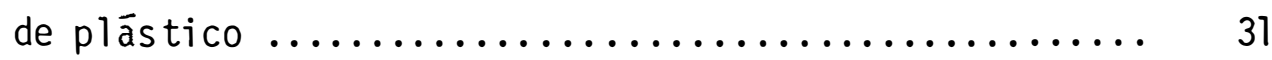

7.2. Eficiência de detecção de radioisōtopos em tubo de

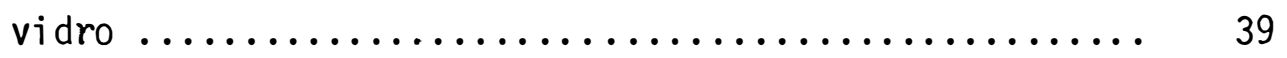

7.3. Eficiência de deteç̧ão de radioisōtopos em beaker

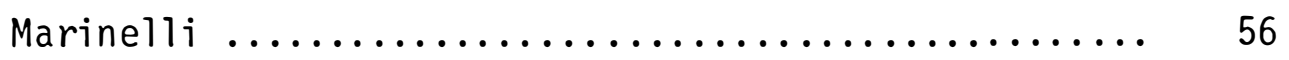

7.4. Atividade especîfica mīnima detectāvel .......... 66

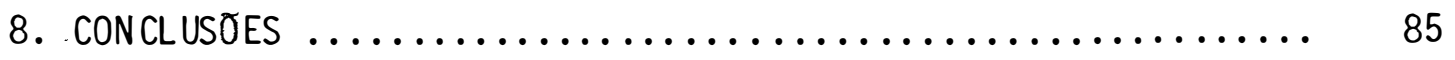

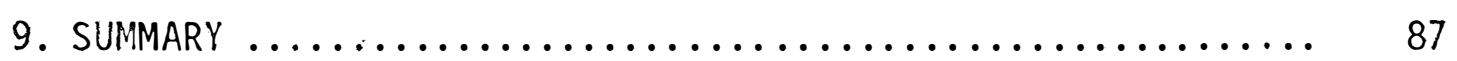

10. Literatura CITAdA $\ldots \ldots \ldots \ldots \ldots \ldots \ldots \ldots \ldots \ldots \ldots \ldots \ldots$ 
1 - Características físicas dos radioisōtopos utilizados nas amostras padronizadas (Neu England Nuclear, 1977)

2 - Características físicas dos radioisótopos utilizados nas amostras não padronizadas (NASCIMENTO Fo, 1977).

3 - Eficiência de deteç̧ão $\left(\varepsilon_{b}\right)$ em função da energia da radiação gama $(E \gamma)$, obti das com amostras padronizadas em bastões plāsticos ....................

4 - Razões (R) entre as taxas líquidas de contagem obtidas com amostras de mesma atividade, colocadas no tu bo de vidro - $5 \mathrm{ml}$, e no bastão plástico, em função da energia da radiação gama $(E \gamma) \ldots \ldots \ldots \ldots \ldots \ldots$

5 - Eficiēncia de detecção em função da energia da radia ção gama $(E \gamma)$, obtida com amostras radioativas de vá rios volumes em tubos de vidro $\left(\varepsilon_{t}\right)$ e em beaker Mari

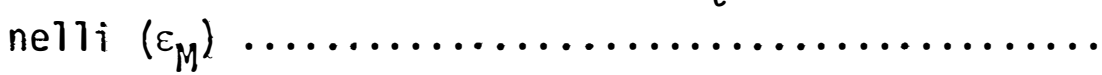

6 - Taxas relativas de contagem em função do volume da a mostra em tubos de vidro, tomando-se como unitária a taxa de contagem obtida com o volume de $25 \mathrm{ml}$. E tam bém apresentado o fator de geometria $\left(f_{t}\right)$ relativo ao tubo de vidro, baseando-se nos volumes de 5 e $25 \mathrm{ml}$.

7 - Eficiência relativa de detecção para camadas de 5 e $250 \mathrm{ml}$ de amostras radioativas colocadas em tubo de vidro e beaker Marinelli, respectivamente, tomando-se como unitária a eficiēncia de contagem da pri

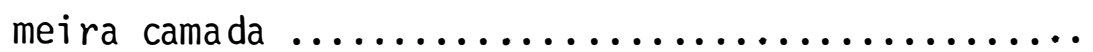

8 - Razão ( $R^{\prime}$ ) entre as taxas lĩquidas de contagem obtidas com amostras de mesma atividade, colocadas no beaker Marinelli - $2500 \mathrm{ml}$ e no tubo de vidro - $5 \mathrm{ml}$, em função da energia da radiação gama $(E \gamma) \ldots . . .$. 
9 - Taxas relativas de contagem em função do volume da amos tra em beaker Marinelli, tomando-se como unitāria a taxa de contagem obtida com o volume de $2500 \mathrm{ml}$. E tambēm apresentado o fator de geometria $\left(f_{M}\right)$ relativo ao beaker Marinelli, baseando-se nos volumes de 250 e

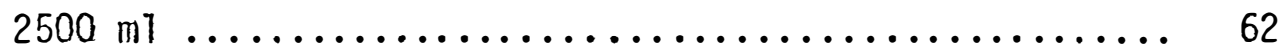


LISTA DE FIGURAS

Figura

1 - Amostra colocada no beaker Marinelli em volta do cristal cintilador sólido $\mathrm{NaI}(\mathrm{Tl})$. Para cálculo teórico da eficiência total de detecção, a amostra foi dividida

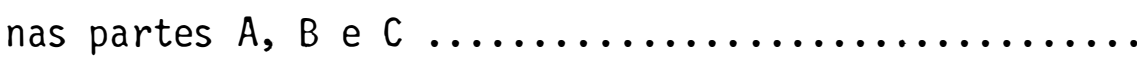

2 - Arranjo geométrico mostrando as variāveis nas três partes da amostra contida no beaker Marinelli, em volta do

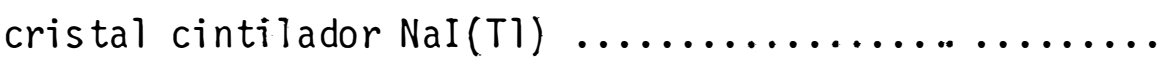

3 - Dimensões externas das fontes radioativas padronizadas e seladas em bastão plástico acrīilico, segundo catálogo

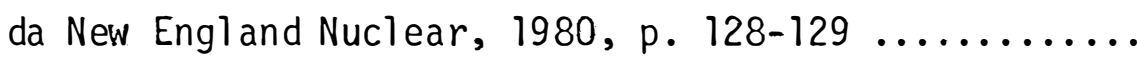

4 - Dimensões das fontes radioativas não padronizadas, em bastões de plástico acrîlico (dimensões em mi tîmetros). 26

5 - Espectro de energia do ${ }^{57} \mathrm{Co}$, obtido com a fonte padroni zada em bastão de plástico, visualizando-se a ārea do fotopico utilizada para o cālculo da eficiência de de-

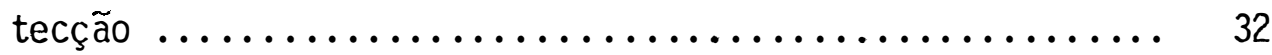

6 - Espectro de energia do ${ }^{13} \mathrm{Ba}$, obtido com a fonte padronizada em bastão de plástico, visualizando-se a ārea do fotopico utitizada para o cálculo da eficiência de

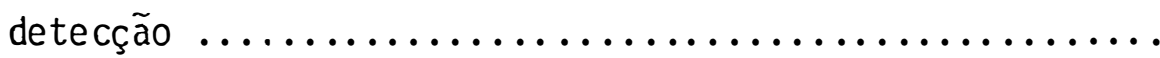

7 - Espectro de energia do ${ }^{137} \mathrm{Cs}$, obtido com a fonte padronizada em bastão de plástico, visualizando-se a ārea do fotopico utilizada para o cālculo da eficiēncia de

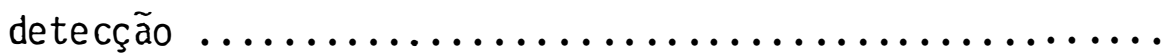

8 - Espectro de energia do ${ }^{54} \mathrm{Mn}$, obtido com a fonte padroni zada em bastão de plástico, visualizando-se a ārea do fotopico utilizada para o cālculo da eficiência de de-

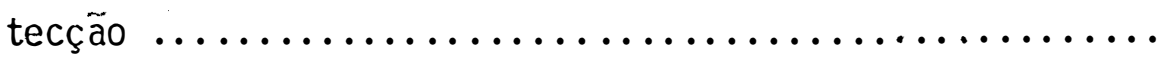


9 - Espectro de energia do ${ }^{60} \mathrm{Co}$, obtido com a fonte padroni zada em bastão de plástico, visualizando-se a ārea do fotopico utilizada para o cálculo da eficiência de de-

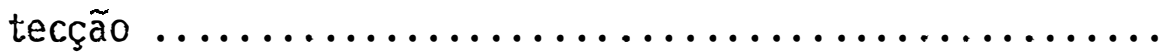

10 - Eficiência de deteç̧ão $\left(\varepsilon_{\mathrm{b}} \backslash\right.$ em função da energia da radiação gama $(E \gamma)$, obtida com amostras padronizadas em bastões de plāstico acrîlico .......................

11 - Espectro de energia do ${ }^{203} \mathrm{Hg}$, obtido com a fonte não pa dronizada em bastão de plástico, em tubo de vidro - 5 $\mathrm{ml}$ - e em beaker Marinelli - $2500 \mathrm{ml}$.................

12 - Espectro de energia do ${ }^{54} \mathrm{Mn}$, obtido com a fonte não padronizada em bastão de plástico, em tubo de vidro - 5 ml - e em beaker Marinelli ........................

13 - Espectro de energia do ${ }^{65} \mathrm{Zn}$, obtido com a fonte não padronizada em bastão de plástico, em tubo de vidro - 5 ml - e em beaker Marinelli - $2500 \mathrm{ml}$.................

14 - Razão(R) entre as taxas líquidas de contagem obtidas com amostras de mesma atividade colocadas no tubo de vi dro - $5 \mathrm{ml}$ - e no bastão plástico, em função da energia da rádiação gama $(E \gamma) \ldots \ldots \ldots \ldots \ldots \ldots \ldots \ldots \ldots . . . \ldots \ldots$

15 - Eficiência de detecção em função da energia da radiação gama $(E \gamma)$, obtidas com amostras radioativas de vārios volumes, colocadas em tubos de vidro $\left(\varepsilon_{t}\right)$ e em beaker

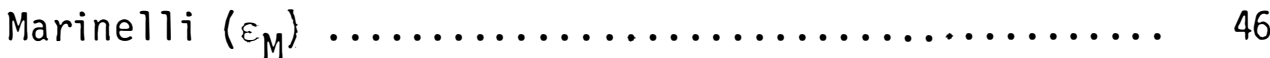

16 - Espectro de energia do ${ }^{131} \mathrm{I}$, obtido com a fonte não padronizada em bastão de plástico, em tubo de vidro - 5 $\mathrm{ml}$ - e em beaker Marine $11 \mathrm{i}$ - $2500 \mathrm{ml}$............... 48

17 - Espectro de energia do ${ }^{56} \mathrm{Mn}$, obtido com a fonte não padronizada em bastão de plástico, em tubo de vidro - 5 $\mathrm{ml}$ - e em beaker Marinelli - $2500 \mathrm{ml}$................ 
18 - Espectro de energia do ${ }^{24} \mathrm{Na}$, obtido com a fonte não padronizada em bastão plástico, em tubo de vidro - $5 \mathrm{ml}$ -

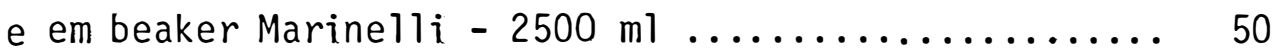

19 - Espectro de energia do ${ }^{42} \mathrm{~K}$, obtido com a fonte não padronizada em bastão plástico, em tubo de vidro - $5 \mathrm{ml}$ -

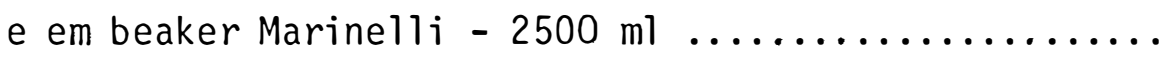

20 - Taxa relativa de contagem (mēdia de sete radioisótopos) em função do volume da amostra colocada em tubo de vidro, tomando-se como unitária a taxa de contagem obtida com o volume de $25 \mathrm{ml} \ldots \ldots \ldots \ldots \ldots \ldots \ldots \ldots \ldots \ldots$

21 - Eficiência relativa de detecção $\left(\varepsilon_{c t}\right)$ para camadas de 5 $\mathrm{ml}$ de amostras radioativas colocadas no tubo de vidro, tomando-se como unitāria a eficiēncia relativa de conta

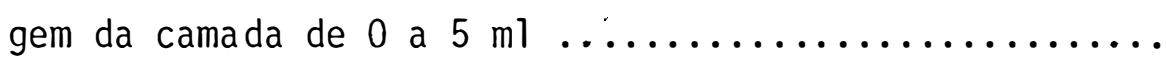

22 - Fator de geometria $\left(f_{t}\right)$ ou eficiência relativa de detec ção $\left(\varepsilon_{R t}\right)$ em função do volume da amostra (V) colocada em tubo de vidro tomando-se como unitária a eficiēncia relativa obtida com $5 \mathrm{ml} \ldots \ldots \ldots \ldots \ldots \ldots \ldots \ldots$

23 - Eficiência de detecção para alguns radioisótopos em tubo de vidro $\left(\varepsilon_{t V}\right)$ em função do volume da amostra $(V)$..

24 - Razão ( $R^{\prime}$ ) entre as taxas lĩquidas de contagem obtidas com amostras de mesma atividade colocadas em beaker Marinelli - $2500 \mathrm{ml}$ e em tubos de vidro - $5 \mathrm{ml}$, em função da energia da radiação gama $\left(E_{\gamma}\right) \ldots \ldots \ldots \ldots \ldots \ldots \ldots$

25 - Taxa relativa de contagem (média de sete radioisótopos) em função do volume da amostra colocada em beaker Marinelli, tomando-se como unitāria a taxa de contagem obti da com a amostra de $2500 \mathrm{ml} \ldots \ldots \ldots \ldots \ldots \ldots \ldots \ldots$

26 - Eficiência relativa de detecção $\left(\varepsilon_{c M}\right)$ para camadas de $250 \mathrm{ml}$ de amostras radioativas colocadas em beaker Mari nelli, tomando-se como unitāria a eficiēncia relativa de contagem da camada de 0 a $250 \mathrm{ml} \ldots \ldots \ldots \ldots \ldots \ldots$ 
27 - Fator de geometria $\left(f_{M}\right)$ e eficiencia relativa de detecção em função do volume da amostra colocada em beaker Marinelli, tomando-se como unitária a eficiência relati va obtida com $2500 \mathrm{ml}\left(\varepsilon_{R M}\right)$. E dada tambēm a eficiēncia relativa de deteç̧ão tomando-se como unitária a efi ciência relativa obtida com amostra de $250 \mathrm{ml}\left(\varepsilon_{\mathrm{RM}}^{\prime}\right) \ldots$

28 - Eficiēncia de detecção para alguns radioisōtopos em beaker Marinelli $\left(\varepsilon_{\text {MV }}\right)$ em função do volume da amostra . 68

29 - Atividade especîfica minima $(a, d p m / m l)$ para ${ }^{203} \mathrm{Hg}$, em função do tempo de deteç̧ão $\left(t_{B}\right.$, min), para se atingir coeficiente de variação de $1 \%$, para amostras de 5 e 25 ml colocadas em tubo de vidro, e de $2500 \mathrm{ml}$ em beaker Marinelli. Tempo de contagem da radiação de fundo $t_{F}=100$ e 1000 minutos $\ldots \ldots \ldots \ldots \ldots \ldots \ldots \ldots \ldots$.

30 - Atividade específica mínima ( $a, d p m / m l)$ para ${ }^{131} \mathrm{I}$, em função do tempo de deteç̧ão $\left(t_{B}\right.$, min), para se atingir coeficiente de variação de $1 \%$, para amostras de 5 e 25 $\mathrm{ml}$ colocadas em tubo de vidro, e de 500 e $2500 \mathrm{ml}$ em beaker Marinelli. Tempo de contagem da radiação de fundo $t_{F}=100$ e 1000 minutos $\ldots \ldots \ldots \ldots \ldots \ldots \ldots \ldots . .670$

31 - Atividade específica mínima ( $a, d p m / m l)$ para ${ }^{54} \mathrm{Mn}$, em função do tempo de detecção $\left(t_{B}\right.$, min), para se atingir coeficiente de variação de 1\%, para amostras de 5 e 25 ml colocada em tubo de vidro e de 500 e $2500 \mathrm{ml}$ em beaker Marinelli. Tempo de contagem da radiação de fungo $t_{F}=100$ e 1000 minutos $\ldots \ldots \ldots \ldots \ldots \ldots \ldots$.

32 - Atividade específica minima (a, dpm/ml) para ${ }^{65} \mathrm{Zn}$, em função do tempo de deteç̧ão $\left(t_{B}\right.$, min), para se atingir coeficiente de variação de $1 \%$ para amostras de 5 e 25 ml colocada em tubo de vidro, e de $2500 \mathrm{ml}$ em beaker Marinelli. Tempo de contagem da radiação de fundo $t_{F}=100$ e 1000 minutos $\ldots \ldots \ldots \ldots \ldots \ldots \ldots \ldots \ldots \ldots$ 
33 - Atividade específica mînima $(\mathrm{a}, \mathrm{dpm} / \mathrm{ml})$ para ${ }^{24} \mathrm{Na}$, em função do tempo de deteç̧ão $\left(t_{B}\right.$, min), para se atingir coeficiente de variação de $1 \%$, para amostras de 5 e 25 $\mathrm{ml}$ colocada em tubo de vidro, e de $2500 \mathrm{ml}$ em beaker Marinelli. Tempo de contagem da radiação de fundo $t_{F}=100$ e 1000 minutos $\ldots \ldots \ldots \ldots \ldots \ldots \ldots \ldots \ldots$

34 - Atividade específica mīnima $(a, d p m / m l)$ para ${ }^{42} \mathrm{~K}$, em função do tempo de detecção $\left(t_{B}\right.$, min), para se atingir coeficiente de variação de $1 \%$, para amostras de 5 e 25 ml colocada em tubo de vidro, e de $2500 \mathrm{ml}$ em beaker Marinelli. Tempo de contagem da radiação de fundo $t_{F}=100$ e 1000 minutos $\ldots \ldots \ldots \ldots \ldots \ldots \ldots \ldots \ldots$

35 - Atividade especīfica mínima detectável (a, dpm/ml) para ${ }^{203} \mathrm{Hg}$ em função do tempo de detecção ( $t_{B}$, min) para se atingir coeficiente de variação de 10\%, para amostras de 5 e $25 \mathrm{ml}$ colocadas em tubo de vidro, e de $2500 \mathrm{ml}$ em beaker Marinelli. Tempo de contagem da ra diação de fundo $t_{F}=100$ e 1000 minutos $\ldots \ldots \ldots . .$.

36 - Atividade específica mīnima detectável (a, dpm/ml) para ${ }^{131} \mathrm{I}$ em função do tempo de detecção ( $t_{B}$, min) para se atingir coeficiente de variação de $10 \%$, para amostras de 5 e $25 \mathrm{ml}$ colocadas em tubo de vidro, e de $2500 \mathrm{ml}$ em beaker Marinelli. Tempo de contagem da ra diação de fundo $t_{F}=100$ e 1000 minutos $\ldots . . . . . .$.

37 - Atividade específica mínima detectável (a, dpm/ml) para ${ }^{54} \mathrm{Mn}$ em função do tempo de deteç̧ão ( $t_{B}$, min) para se atingir coeficiente de variação de $10 \%$, para amostras de 5 e $25 \mathrm{ml}$ colocadas em tubo de vidro, e de $2500 \mathrm{ml}$ em beaker Marinelli. Tempo de contagem da ra diação de fundo $t_{F}=100$ e 1000 minutos $\ldots \ldots \ldots \ldots .$.

38 - Atividade específica mínima detectāvel (a, dpm/ml) para ${ }^{65} \mathrm{Zn}$ em função do tempo de detecção ( $t_{B}$, min) para se atingir coeficiente de variação de $10 \%$, para amostras de 5 e $25 \mathrm{ml}$ colocadas em tubo de vidro, .e de 
$2500 \mathrm{ml}$ em beaker Marinel1i. Tempo de contagem da ra diação de fundo $t_{F}=100$ e 1000 minutos $\ldots \ldots \ldots \ldots . .78$

39 - Atividade específica mīnima detectāvel (a, dpm/ml) para ${ }^{2} \mathrm{Na}$ em função do tempo de deteç̧ão ( $t_{B}$, min) para se atingir coeficiente de variação de $10 \%$, para amostras de 5 e $25 \mathrm{ml}$ colocadas em tubo de vidro, e de $2500 \mathrm{ml}$ em beaker Marinelli. Tempo de contagem da ra diação de fundo $t_{F}=100$ e 1000 minutos $\ldots \ldots \ldots \ldots$. .

40 - Atividade específica mīnima detectāvel (a, dpm/ml) para ${ }^{42} \mathrm{~K}$ em função do tempo de detecção ( $t_{B}$, min) para se atingir coeficiente de variação de $10 \%$, para amostras de 5 e $25 \mathrm{ml}$ colocadas em tubo de vidro, e de $2500 \mathrm{ml}$ em beaker Marinelli. Tempo de contagem da ra diação de fundo $t_{F}=100$ e 1000 minutos $\ldots \ldots \ldots . . . .80$

41 - Razão entre as atividades especīficas mīnimas detectãveis para amostras colocadas em tubo de vidro ( $a_{t}, 5$ e $25 \mathrm{ml})$ e beaker Marinelli $\left(a_{m}, 2500 \mathrm{ml}\right) \ldots \ldots \ldots \ldots$

42 - Razão entre as atividades especîficas mīnimeas detectā veis para amostras colocadas diretamente em beaker Marinelli - $2500 \mathrm{ml}\left(\mathrm{a}_{\mathrm{s}}\right)$ e apōs extração colocadas em tu bos de vidro $\left(a_{\mathrm{s}}^{\prime}\right)$ de 5 ou $25 \mathrm{ml} \ldots \ldots \ldots \ldots \ldots \ldots \ldots$ 


\section{LISTA DE FOTOGRAFIAS}

\section{Fotografia}

Pāgina

1 - Vista geral da blindagem e instrumentação nuclear

2 - Detalhe interno da blindagem, vendo-se o revestimento com lāminas de chumbo e cobre, e o beaker Marinelli sobre o detector ................. 22

3 - Detalhe da armação de plästico acrílico para suporte do sistema detector e beaker Marinelli .... 


\section{RESUMO}

Foi determinada a eficiência de deteç̧ão no fotopico para amostras aquosas de 5 a $25 \mathrm{ml}$ em tubo de vidro e de 250 a $2500 \mathrm{ml}$ em beaker Marinelli, em função da energia da radiação gama na faixa de 0,2 a 1,5 MeV, para cristal cintilador de $\mathrm{NaI}(\mathrm{Tl})$, de $3 \times 3^{\prime \prime}$, tipo poço (7/8" diämetro $\times 11 / 2 "$ de altura).

A eficiēncia de detecção para amostras de $25 \mathrm{ml}$ em tubo de vidro foi 1,4 vezes menor que para amostras de $5 \mathrm{ml}$, independentemente da energia da radiação gama. Para amostras de $2500 \mathrm{ml}$ e $500 \mathrm{ml}$, colo cadas em beaker Marinelli, a diminuição da eficiencia de deteç̧ão foi da mesma ordem.

Na faixa estudada de energia de radiação gama, a eficiência de detecção em beaker Marinelli - $2500 \mathrm{ml}$ foi de 4 a 8 vezes menor que a da deteç̧ão em tubo de vidro $-25 \mathrm{ml}$, e de 11 a 6 vezes em relação ao tubo de vidro $-5 \mathrm{ml}$.

A baixa eficiēncia de detecção em beaker Marinelli em relação ao tubo de vidro é compensada pelo grande volume empregado na me dida da atividade do radioisótopo. Considerando-se o mesmo tempo de detecção da radiação de fundo, tempo necessārio para detecção da amostra em beaker Marinelli - $2500 \mathrm{ml}$ para se atingir um dado coeficiente de variação, ē da ordem de 100 vezes menor do que quando se emprega tubo de vidro $-25 \mathrm{ml}$.

A atividade específica necessāria para se atingir um mesmo coeficiente de variação, ē 44 a 84 vezes menor quando se emprega beaker Marinelli - $2500 \mathrm{ml}$ do que tubo de vidro - $5 \mathrm{ml}$, utilizando-se mes mos tempos de detecção da amostra e radiação de fundo nas duas técnicas. Comparando-se a deteç̧ão em beaker Marinelli - $2500 \mathrm{ml}$ e tubo de vidro $25 \mathrm{ml}$, pode-se atingir 12 a 23 vezes. 
A redução do volume da amostra pelos métodos quĩmicos,com eficiência de $100 \%$, seria mais vantajosa para radioisótopos emissores de raios gama de baixa energia. Na faixa de 0,2 a $1,5 \mathrm{MeV}$, a concentração de $2500 \mathrm{ml}$ para $25 \mathrm{ml}$, atingiria atividades específicas 8,3 a 4,3 vezes menores do que a deteç̧ão direta em beaker Marinelli - $2500 \mathrm{ml}$; se a redução for para $5 \mathrm{ml}$, poderia atingir nĩveis 11,4 a 5,9 vezes menores do que a detecção direta. 


\section{INTRODUÇAOO}

0 estudo de comportamento dos elementos micronutrientes e dos poluentes na relação solo-planta-animal tem sido efetuado utilizando-se radioisötopos emissores de raios gama como traçadores. Tambēm têm sido utilizados radioisótopos naturais emissores de raios gama na avaliação da concentração de urānio, tōrio e potāssio em minerais e no solo.

A deteç̧ão por espectrometria gama com cristal cintilador sōlido NaI(TI) desses radioisōtopos em amostras de pequeno volume (5 $25 \mathrm{ml}$ ), algumas vezes não permi tem uma precisão adequada, e a falta de dados quantitativos para anālise pode levar à peráa total ou parcial do experimento. Quando possîvel, a utilização de maiores atividades no inîcio do experimento pode acarretar exposição pessoal às radiações, difi cultando a instalação do experimento e manuseio das amostras.

Em alguns experimentos, principalmente na nutrição animal e prospecção, é possĩvel a obtenção de amostras radioativas de grande vo lume (3 litros) e a falta de equipamentos que possam usar essas amostras faz com que a deteção seja feita utilizando-se pequena fração delas, acarretando incerteza nos resultados.

0 objetivo deste trabalho foi o de montar um sistema que permita trabalhar com amostras de pequeno e grande volume, determinar a eficiência e avaliar a sensibilidade de deteção (através da atividade mînima detectāvel! em função da energia dos raios gama emitidos pelos radioisōtopos. 


\section{REVISAO DE LITERATURA}

A eficiência de detecção para fontes puntuais para cris tais cintiladores sōlidos $\mathrm{NaI}(\mathrm{Tl})$, tipos plano e poço, tem sido avaliada teoricamente e experimentalmente por vārios autores. LAZAR et alii (1956) estimaram a eficiēncia de detecção para o fotopico na faixa de 0,15 a $2,76 \mathrm{MeV}$ para fontes puntuais e cristais planos de $11 / 2 \times 1$ " e $3 \times 3$ ", a partir da eficiencia total e da razão pico para total para alguns radioisōtopos emissores de um ünico raio gama. Para cristal de poço de $5 \times 5$ " $\left(5 / 8 \times 221 / 2^{\prime \prime}\right)$, COLBY e COBBLE (1959) determinaram a eficiência para 0 fotopico para amostra puntual colocada no fundo do poço, na faixa de 0,28 a 1,33 MeV, enquanto que GUNNINK e STONER (1961) determinaram a eficiēncia incidente para fotopico para cristais de $3 \times 3^{\prime \prime}$, tipos plano e poço $\left(13 / 16 \times 129 / 32^{\prime \prime}\right)$, utilizando fontes puntuais padronizadas pelas técnicas $4 \pi$ e coincidência $4 \pi \beta-\gamma$.

Alguns autores elaboraram equações teōricas para o cālcu10 da eficiência total e para fotopico, para fontes e cristais de diversas formas. Assim, VERHEIJKE (1962) apresenta valores da eficiencia total de deteç̧ão para fonte puntual colocada a diversas alturas do fundo de um cristal de poço $3 \times 3^{\prime \prime}(7 / 8 \times 1$ 1/2") em função da energia da ra diação gama, na faixa de 0,05 a 5 MeV. HOLMBERG e RIEPPO (1973) e RIEPPO et alii (1975) apresentam valores teóricos de eficiência para fotopicona faixa de 0,01 a $3 \mathrm{MeV}$ para amostras sem absorção, água e osso, de 0,1 e $3,5 \mathrm{~cm}$ de altura, colocadas no poço de cristais cintiladores de $2 \times 2^{\prime \prime}$ (1 1/8" $\left.\times 11 / 2^{\prime \prime}\right)$ e $3 \times 3^{\prime \prime}\left(11 / 8^{\prime \prime} \times 11 / 2^{\prime \prime}\right)$, enquanto que RIEPPO e BLOMSTER (1976) apresentam os valores para amostra em forma de disco de $2 \times 7 \mathrm{~cm}$, colocada a $10 \mathrm{~cm}$ de um cristal plano de $3 \times 3^{\prime \prime}$. 0 efeito das dimensões do poço de cristal cintilador sobre a eficiência para fotopico na faixa de 0,01 MeV a 1 MeV foi estudado teoricamente por HOLMBERG e RIEPPO (1977), considerando cristais de $2 \times 2$ e $3 \times 3^{\prime \prime}$, com poço de 0,51,66 e $4 \mathrm{~cm}$ de diämetro e 4,45 de altura, e amostra de 0,1 e $3,5 \mathrm{~cm}$ de 
altura.

Para amostras de grande volume Marinelli sugeriu envolver detectores Geiger-Muller com a amostra (HILL et alii, i950), e atualmente refere-se a beaker Marinelli a técnica de se utilizar beaker de fundo reentrante, onde $\bar{e}$ colocado o cristal cintilador. Para este tipo de geo metria, VERHEIJKE (1970) apresenta um modelo teórico para determinação da eficiência total de deteç̧ão, na faixa de 0,05 a $5 \mathrm{MeV}$, para cristais cintiladores tipo plano de $3 \times 3$ e $4 \times 4^{\prime \prime}$, e amostras aquosas de 1,44 3,8 e 7,4.5 litros. Utilizando valores de razão pico para total, determi nados experimentalmente por HEATH (1964) e CHRISTALLER (1967), estimou os valores de eficiência para fotopico e determinou experimentalmente os va lores para alguns radioisōtopos.

IDDINGS et alii (1979) apresentam tambēm um modelo teōrico para estimativa da eficiência para fotopico, determinando-a experimen talmente para alguns radioisótopos em solução aquosa, colocados em beaker Marinelli de 1 litro e detectados com cristal plano de $4 \times 4$ ".

A utilização de beaker Marinelli em conjunto com detectores semicondutores de $\mathrm{Ge}(\mathrm{L} i)$, são apresentadas por alguns autores. COSTRELL et alii (1980) apresenta uma fonte padronizada, de $450 \mathrm{ml}$, selada em beaker Marinelli, contendo vārios radioisōtopos emissores de raios ga ma na faixa de 0,08 a 1,33 MeV, e também uma curva de eficiēncia para fo topico para um detector cilíndrico de $53 \times 52 \mathrm{~mm}\left(117 \mathrm{~cm}^{3}\right)$.

Poucos autores têm feito comparação entre uma técnica tra dicional de medida e aquela empregando amostras de grande volume. Assim, BERGER e GOANS (1979) sugerem na monitoração ambiental de ${ }^{131}$ I em leite, a utilização de frascos de fundo reentrante com capacidade de 4,54 li tros de amostra e detector de $\mathrm{NaI}(\mathrm{Tl})$, de $3 \times 3^{\prime \prime}$, tipo plano. Desse modo, a atividade mínima detectável é 2,5 pCi/litro, com 15 minutos de deteç̧ão, superando a técnica de se utilizar detector semicondutor e 1 1itro da amostra (20 pCi/ml em 15 minutos de detecção). Apesar da técnica de separação com resina trocadora de ions ser mais sensível, é demorada, requerendo maior tempo de preparo de amostra e gastos com reagentes químicos (TAKAGI et alii, 1978). Esta técnica de detecção direta de emis sores de raios gama em amostras colocadas em beaker Marinelli também tem sido utilizada na estimativa da atividade de ${ }^{1{ }^{3}} \mathrm{Cs}$ em leite (HORWITZ, 1975; BARATTA e KNOWLES, Jr., 1973) e em alimentos para animais (WARD et alii, 1968). A determinação direta de ${ }^{137} \mathrm{Cs}$ em solos e vegetação da Ma 
lásia foì feita por LOWE (1975), utilizando-se 1 a $3 \mathrm{~kg}$ de solo e 100 a 600 gramas de matéria seca vegetal em beaker Marinelli de 2,4 litros e detector semi-condutor de Ge $(L i)$ de $47 \mathrm{~cm}^{3}$, com resolução de 2,11 kev.

MÜLLER e HAASBROEK (1969), empregando a metodologia des crita por VASSILAKI et alii (1965), estimaram a concentração de potāssio total no solo, detectando o radioisótopo natural ${ }^{40} \mathrm{~K}(1,46 \mathrm{MeV}) \mathrm{em}$ amostras de 9,5 a $10,3 \mathrm{~kg}$ colocadas em beaker Marinelli, eliminando-se as interferências do ${ }^{214} \mathrm{Bi}(1,76 \mathrm{MeV})$ e ${ }^{208} \mathrm{Tl}(2,62 \mathrm{MeV})$, das séries radioativas naturais do urānio e tório, respectivamente. Também utili zando beaker Marinelli com $2 \mathrm{~kg}$ de solo e cristal cintilador NaI(Tl) de $5 \times 4 "$, GUSTAFSON e BRAR (1964) determinaram a concentração de urânio $\left({ }^{214} \mathrm{Bi}\right)$, tório $\left({ }^{208} \mathrm{Tl}\right)$ e potássio $\left({ }^{40} \mathrm{~K}\right)$, e a atividade de alguns produtos de fissão nuclear $\left({ }^{95} \mathrm{Zr} /{ }^{9} \mathrm{Nb},{ }^{103} \mathrm{Ru},{ }^{106} \mathrm{Ru} /{ }^{106} \mathrm{Rh},{ }^{1{ }^{37} \mathrm{Cs}},{ }^{140} \mathrm{Ba} /\right.$ ${ }^{140} \mathrm{La},{ }^{141} \mathrm{Ce} \mathrm{e}{ }^{144} \mathrm{Ce} /{ }^{144} \mathrm{Pr}$ ) com o objetivo de se calcular a taxa de ex posição proveniente do solo.

Outros autores têm utilizado amostras cilinndricas de grande volume colocadas diretamente sobre a face plana de cristais cin tiladores sólidos para avaliação da atividade de alguns radioisōtopos e concentração de potássio total em amostras de solo e de interesse geológico. Desse modo, TALIBUDEEN e YAMADA (1966) utilizaram 500 gra mas de solo e cristais cintiladores NaI(TI) de $13 / 4 \times 2$ " e $3 \times 3 "$, na avaliação da concentração de potássio em solos, analisando-se a interferência dos radioisótopos pertencentes às séries radioativas naturais do urânio e tório na deteç̧ão do ${ }^{40} \mathrm{~K}$, e para a avaliação da concentração de urânio, tório e rádio em rochas fosfatadas, MENZEL (1968) utili zou amostras de 150 gramas colocadas sobre um cristal cintilador $\mathrm{NaI}$ (T1) de $3 \times 3^{11}$, tipo plano, para detectar as radiações gama de 185 $\left({ }^{235} \mathrm{U}\right)+187 \mathrm{keV}\left({ }^{26} \mathrm{Ra}\right), 239\left({ }^{212} \mathrm{~Pb}\right.$, sērie do $\left.{ }^{232} \mathrm{Th}\right)+242 \mathrm{keV}\left({ }^{214} \mathrm{~Pb}\right.$, série do $\left.{ }^{226} \mathrm{Ra}\right)$ e $295 \mathrm{keV}\left({ }^{214} \mathrm{~Pb}\right)$. Utilizando amostras de 300 gramas, HANSEN e HUNTINGTON (1969) es tudaram a movimentação de tório em solos da Califórnia detectando $0{ }^{232} \mathrm{Th},{ }^{226} \mathrm{Ra}$ e ${ }^{40} \mathrm{~K}$ em um perfil de solo da mesma região por espectrometria gama, e ${ }^{232} \mathrm{U},{ }^{234} \mathrm{U},{ }^{238} \mathrm{U},{ }^{230} \mathrm{Th}$ e ${ }^{233} \mathrm{Th}$ por espectrometria alfa.

CIVETTA et alii (1969) estimaram a radioatividade do ${ }^{40} \mathrm{~K}$ em amostras de origem geológica, utilizando-se amostras cilindricas de 5,30 e $50 \mathrm{~cm}^{3}(3,5 \mathrm{~cm}$ de diâmetro) colocadas entre dois cristais cintiladores $\mathrm{NaI}(\mathrm{Tl})$ de $3 \times 3^{\prime \prime}$, tipo plano, opostos. Esta mesma 
técnica jā fora utilizada porLLOYD et alizi (1968) na detecção de vārios radioisōtopos em amostras de 4 litros de solo colocadas entre dois cristais cintiladores de $8 \times 4 "$, tipo plano, estudando a influencia da densidade do solo nessas determinações.

Alguns autores têm descrito sistemas sofisticados com detectores operando em coincidência ou anticoincidência, com a finalida de de se diminuir o nîvel da radiação de fundo e a região Compton (WATT e RAMSDEN, 1964). NIELSEN e KORNBERG (1965) e NIELSEN e PERKINS(1967) descrevem um sistema onde a amostra de até $925 \mathrm{~cm}^{3}\left(6 \times 2^{\prime \prime}\right)$ pode ser co locada entre dois cristais cintiladores $\mathrm{NaI}(\mathrm{Tl})$ de $11 \times 6 "$ ", tipo plano, opostos, e envoltos por um cilindro cintillador plástico operando em anticoincidencia. SONNTAG (1967) descreve outro sistema onde um cristal cintil ador $\mathrm{NaI}(\mathrm{Tl})$ de $4 \times 4 "$, tipo plano, opera em anticoincidência com um anel de detectores Geiger-Müller, e ainda com a possibilidade de um outro cristal cintil ador de $3 \times 1$ 1/2", tipo plano, operar em coincidên cia com o primeiro. A amostra, de até 2 litros, é colocada em beaker Marinelli em volta do primeiro detector. Outros sistemas são dados por ADAMS e GASPARINI (1970), WOGMAN et alii (1969), WOGMAN (1976), BRAU ER et alii $(1970,1972,1975)$ e HUNT et alii (1978). 


\section{TEORIA}

Os modelos matemáticos elaborados por VERHEIJKE (1962, 1970), HEATH (1957) e CROUTHAMEL et alii (1975), entre outros, para a es timativa da eficiência total de detecção ou para fotopico em função da energia da radiação gama são um tanto complexos e elaborados sob condi ções ideais. Para detecção em beaker Marinelli, VERHEIJKE (1970) apre senta um modelo para a estimativa da eficiēncia total de detecção para cristal sōlido. Neste modelo, a amostra contida no beaker Marinelli foi dividida em trés partes: (A) um cilindro sobre o detector com o mesmo raio $\underline{r}$ do detector e altura $\underline{h}_{2}-\underline{h}_{1} ;(B)$ um anel ao redor do detector com a mesma altura $\underline{t}$ do detector e tendo raios interno e externo $\underline{R}_{1}$ e $\underline{R}_{2}$ do beaker Marinelli; e (C) um anel ao redor do volume da parte $A$, considera do como a diferença de dois anéis $\underline{C}_{2}-\underline{C}_{1}$, tendo alturas e raios exter nos $\underline{h}_{2}$ e $\underline{R}_{2}, \underline{h}_{1}$ e $\underline{R}_{1}$, respectivamente, e com raio interno $\underline{r}$, conforme mos tra a figura 1. Para uma fonte puntual, colocada em qualquer posição den tro dessas três partes (figura 2) a eficiência total de detecção é da da por:

$$
T_{p}(E \gamma)=\frac{1}{4 \pi} \int_{0}^{2 \pi} d \varphi \int_{0}^{\pi}\left[1-e^{-\tau(E \gamma) \cdot x}\right] e^{-\mu(E \gamma) \cdot y} \cdot \operatorname{sen} \theta \cdot d \theta
$$

sendo: $T_{p}(E \gamma)=$ eficiēncia total de detecção para o raio gama de energia EY.

$\tau, \mu=$ coeficiente de atenuação do cristal cintilador $N a I(T l) e$ da ägua, respectivamente,

$x=$ percurso do raio gama através do cristal cintilador, e

$y=$ percurso do raio gama através da amostra, paredes do bea ker. e do material que envolve o cristal. 


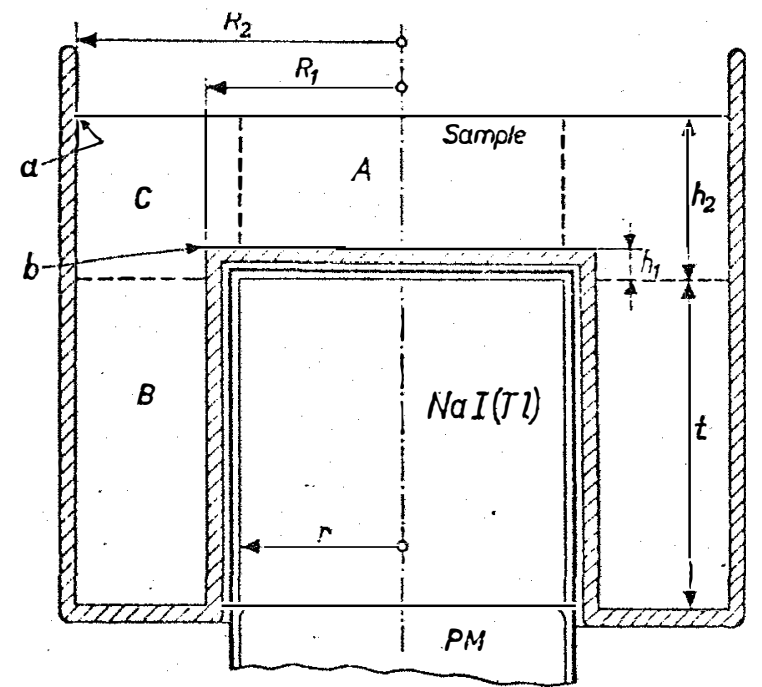

Figura 1 - Amostra colocada no beaker Marinelli em volta do cristal cintilador sōlido NaI(TI). Para cálculo teórico da efí ciência total de detecção, a amostra foi dividida nas partes $A, B$ e $C$.

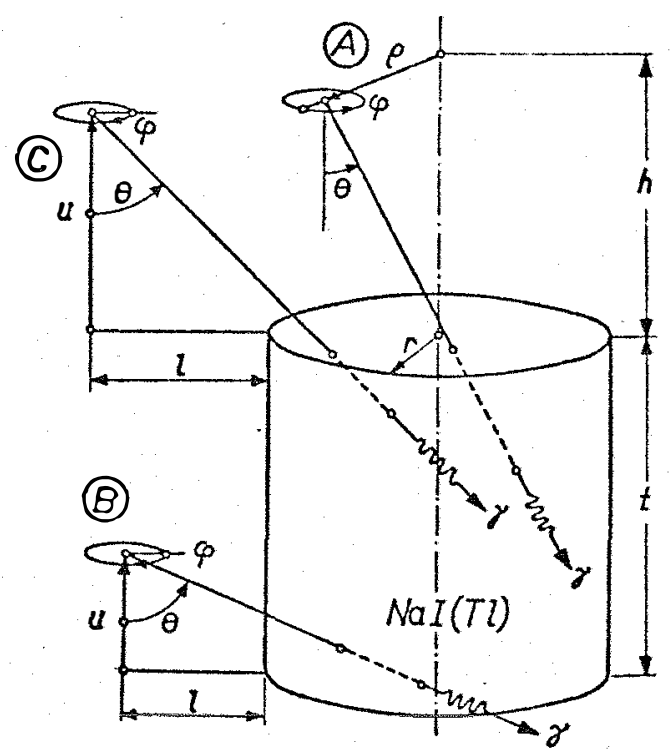

Figura 2 - Arranjo geométrico mostrando as variāveis nas três partes da amostra contida no beaker Marinelli, em volta do cristal cintilador $\mathrm{NaI}(\mathrm{Tl})$. 
As integrais de volume de $T_{p}\left(E_{\gamma}\right)$ sobre as três partes, de nominadas por $A\left(E_{\gamma}\right), B\left(E_{\gamma}\right)$ e $C\left(E_{\gamma}\right)=C_{2}\left(E_{\gamma}\right)-C_{1}\left(E_{\gamma}\right)$, resolvidas por interação numérica por VERHEIJKE, dão a eficiēncia total para a amostra no beaker Marinelli:

$$
T\left(E_{\gamma}\right)=\frac{A\left(E_{\gamma}\right)+B\left(E_{\gamma}\right)+C\left(E_{\gamma}\right)}{V} .
$$

onde:

$$
V=\pi\left[R_{2}^{2}\left(t+h_{2}\right)-R_{1}^{2}\left(t+h_{1}\right)\right]
$$

sendo: $V=$ volume da amostra no beaker Marinelli.

Com os dados de HEATH (1964) e CHRISTALLER (1967) sobre a razão pico para total para fontes puntuais e cristal cintilador plano, VERHEIJKE estimou a eficiēncia de detecção para fotopico, e utilizando fontes padronizadas determinou experimentalmente essa eficiência para al guns radioisótopos. No modelo descrito, foi assumido cristal plano, e não cristal de poço, como foi o utilizado neste trabalho, e a utilização de razão pico para total obtidos para cristais planos não são adequados para cristal de poço. Além disso, a construção da blindagem, suportes de detector e beaker Marinelli podem afetar os resultados devido ao espalha mento da radiação gama. Desse modo, foi estabelecido um modelo e uma se quēncia experimental, permitindo a obtenção da eficiēncia de detecção pá ra amostras radioativas colocadas em tubo de ensaio e dentro do poço de cristal cintilador, e tambēm para amostras colocadas no beaker Marineili e em volta do cristal.

Atravēs do uso de amostras padronizadas, de atividade conhecida, pode-se calcular a eficiēncia de detecção para fotopico em função da energia da radiação gama pela equação:

$$
\varepsilon=\frac{R_{L}}{N}=\frac{R_{L}}{A \cdot f}
$$

onde: $\varepsilon=$ eficiēncia de detecção para fotopico para uma dada energia de radiação gama,

$R_{L}=$ taxa de contagem no fotopico (contagens/minuto),

$N=$ número de raios gama emitidos por minuto,

$A=$ atividade da amostra, em desintegrações por minuto,

$f=$ intensidade de emissão de raios gama . 
Com 0 auxĩlio de soluções radioativas padronizadas, a efi ciência de deteç̧ão em função da energia e do volume, no caso do tubo de vidro como no beaker Marinelli, seria determinada diretamente através da equação 4. Estas soluções padröes são caras e necessitam ser importa das; além disso, os radioisōtopos de interesse biológico têm normalmente meia-vida curta e a aquisição dessas soluções serviria para um único experimento. Devido a isto, o uso de soluções radioativas não padroniza das é economicamente mais conveniente, mas há necessidade de uma série de passos para se chegar a meta final, que é a determinação experimental da eficiência de deteç̧ão para fotopico em função da energia da radiação gama e do volume das amostras colocadas em tubos de vidro $\left(\varepsilon_{t V}\right)$ e em beaker Marinelli $\left(\varepsilon_{M V}\right)$.

$$
\begin{aligned}
& \varepsilon_{t V}=\varepsilon_{t V}\left(E_{\gamma}, V\right) \\
& \varepsilon_{M V}=\varepsilon_{M V}\left(E_{\gamma}, V\right)
\end{aligned}
$$

0 primeiro passo é adquirir um conjunto de fontes padroni zadas, de radioisötopos com meia-vida longa e passivveis de serem usadas em outros experinientos. Normalmente essas fontes são seladas em bastões plásticos e tidas como puntuais, e com elas poder-se-ia determinar a efi ciência de detecção $\varepsilon_{b}$ em função da energia da radiação gama:

$$
\varepsilon_{b}=\varepsilon_{b}\left(E_{\gamma}\right)
$$

atravēs do emprego da equação 4 .

0 segundo passo seria a determinação da eficiência de deteç̧ão no tubo de vidro para um determinado volume ( $5 \mathrm{ml}$, por exemplo). Usando-se bastões de plástico e tubos de vidro com $5 \mathrm{ml}$ contendo amos tras de mesma atividade, tem-se pela equação 4 :

$$
\begin{aligned}
& \varepsilon_{b}=\frac{C_{b}}{A \cdot f} \\
& \varepsilon_{t 5}=\frac{C_{t 5}}{A \cdot f} \\
& \varepsilon_{t 5}=\frac{C_{t 5}}{C_{b}} \cdot \varepsilon_{b}
\end{aligned}
$$


ou

$$
\varepsilon_{t 5}=R \cdot \varepsilon_{b}
$$

sendo: $R=C_{t 5} / C_{b}=$ razão entre as taxas de contagem obtidas no tubo de vidro com $5 \mathrm{ml}$ e no bastão plástico.

Esta razão $\underline{R}$ deve depender da energia da radiação, e portanto a eficiência de detecção de raios gama em função da energia, para amostras de $5 \mathrm{ml}$ colocadas em tubo de vidro, é dada pela equação:

$$
\varepsilon_{t 5}=R\left(E_{\gamma}\right) \cdot \varepsilon_{b}\left(E_{\gamma}\right)
$$

Deve ser notado que a atividade deve ser a mesma, mas não hā necessidade de se conhecer o seu valor. Portanto, um mesmo volume da solução radioativia não padronizada é pipetado para o bastão de plāstico e para o tubo de vidro, e neste tubo o volume é completado até o volume desejado (5 $\mathrm{ml}$ ).

Para se ter a eficiēncia de detecção em certos volumes, transferem-se para tubos de vidro os volumes desejados $(5 \mathrm{ml}, 10 \mathrm{ml}, \ldots$. até $25 \mathrm{ml}$ ) de uma solução radioativa não padronizada e faz-se a detecção. Aplicando a equação 4 neste caso, tem-se:

$$
\begin{aligned}
& \varepsilon_{t 5}=\frac{c_{t 5}}{A_{5} \cdot f} \\
& \varepsilon_{t V}=\frac{c_{t V}}{A_{V} \cdot f}
\end{aligned}
$$

Sendo

$$
A_{V}=A_{5} \cdot\left(\frac{V}{5}\right)
$$

pode-se escrever que

$$
\varepsilon_{t V}=\frac{C_{t V}}{A_{5} \cdot\left(\frac{V}{5}\right) \cdot f}
$$

e tambēm

$$
\varepsilon_{\mathrm{tV}}=\frac{C_{\mathrm{tV}}}{C_{\mathrm{t} 5}} \cdot\left(\frac{5}{V}\right) \cdot \varepsilon_{\mathrm{t} 5}
$$

A razão entre as taxas de contagem obtidas com 0 tubo de vidro contendo a amostra de volunie qualquer $\underline{V}$ e com a amostra de $5 \mathrm{ml}$, representa sim plesmente um fator de geometria para o tubo de vidro.

$$
f_{t}=\frac{c_{t V}}{c_{t 5}} \cdot \frac{5}{V}
$$

0 valor deste fator de geometria deve depender tambëm da 
energia da radiação gama, alēm do volume da amostra. Logo, pode-se escrever de modo geral:

$$
\varepsilon_{t V}=f_{t}\left(E_{\gamma}, V\right) \cdot \varepsilon_{t 5}
$$

Substituindo o valor de $\varepsilon_{t 5}$ dado pela equação 12 , tem-se:

$$
\varepsilon_{t V}=R\left(E_{\gamma}\right) \cdot f_{t}\left(E_{\gamma}, V\right) \cdot \varepsilon_{b}\left(E_{\gamma}\right)
$$

No caso de deteç̧ão em beaker Marinelli, a eficiência pode ser determinada, detectando-se a mesma atividade em tubo de vidro e no beaker. Pipetando-se um mesmo volume de solução radioativa não padro nizada para um tubo de vidro e para um beaker Marinelli, e completando se o volume para 5 e $2500 \mathrm{ml}$, respectivamente, a eficiēncia de detecção em tubo de vidro seria dada pela equação 9 e para o beaker Marinelli seria:

Portanto

$$
\varepsilon_{M 2500}=\frac{C_{M 2500}}{A \cdot f}
$$

ou

$$
\varepsilon_{M 2500}=\frac{C_{M 2500}}{C_{t 5}} \cdot \varepsilon_{t 5}
$$

$$
\varepsilon_{M 2500}=R^{\prime} \cdot \varepsilon_{t 5}
$$

sendo: $R^{\prime}=C_{M 2500} / C_{t 5}=$ razão entre as taxas de contagem obtidas no beaker Marinelli com $2500 \mathrm{ml}$ e no tubo de vidro com $5 \mathrm{ml}$. Esta razão $\underline{\text { R' }}$ deve também depen der da energia da radiação gama e substituindo o valor da eficiēncia de deteç̧ão em tubo de vidro com $5 \mathrm{ml}\left(\varepsilon_{\mathrm{t} 5}\right)$ em relação a do bastão plástico $\left(\varepsilon_{b}\right)$, dada pela equação 12 , tem-se:

$$
\varepsilon_{M 2500}=R^{\prime}\left(E_{\gamma}\right) \cdot R\left(E_{\gamma}\right) \cdot \varepsilon_{b}\left(E_{\gamma}\right)
$$

Do mesmo modo que no tubo de vidro a eficiência de detecção para outros volumes no beaker Marinelli pode ser estimada transferin do-se volumies desejados $(250,500, \ldots$ até $2500 \mathrm{ml})$ de uma solução radioativa não padronizada e fazendo-se a deteç̧ão em seguida. A eficiência de detecção para $2500 \mathrm{ml}$ e para qualquer volume é dada então pelas equações : 


$$
\begin{aligned}
& \varepsilon_{M 2500}=\frac{C_{M 2500}}{A_{2500 \cdot f}} \\
& \varepsilon_{M V}=\frac{C_{M V}}{A_{V} \cdot f}
\end{aligned}
$$

sendo

$$
A_{V}=A_{2500} \cdot\left(\frac{V}{2500}\right)
$$

pode-se escrever $C_{M V}=\frac{C_{M V}}{C_{M 2500}} \cdot\left(\frac{2500}{V}\right) \cdot \varepsilon_{M 2500}$

A razão entre as taxas de contagem obtidas com o beaker Marinelli com a amostra de volume qualquer $\underline{V}$ e com a amostra de $2500 \mathrm{ml}$, representa também um fator de geometria para o beaker Marinelli:

$$
f_{M}=\frac{C_{M V}}{C_{M 2500}} \cdot \frac{2500}{V}
$$

0 valor deste fator de geometria deve depender também da energia da ra diação gama, além do volume da amostra, de modo semelhante ao fator de geometria para o tubo de vidro. Logo pode-se escrever de modo geral:

$$
\varepsilon_{M V}=f_{M}\left(E_{\gamma}, V\right) \cdot \varepsilon_{M 2500}
$$

substituindo o valor de $\varepsilon_{M 2500}$ dado peta equação 24 , tem-se:

$$
\varepsilon_{M V}=R^{\prime}\left(E_{\gamma}\right) \cdot R\left(E_{\gamma}\right) \cdot f_{M}\left(E_{\gamma}, V\right) \cdot \varepsilon_{b}\left(E_{\gamma}\right)
$$




\section{MATERIAIS}

5.1. Instrumentação Nuclear

0 espectrômetro gama multicanal usado neste trabalho é composto de:

- conjunto selado modelo 12 W12 fabricado pela Harshaw Chemical Company, constituĩdo de um cristal cintilador $\mathrm{NaI}(\mathrm{Tl})$ de $3 \times 3$ polegadas, tipo poço ( $7 / 8$ polegadas de diāmetro e 1 1/2 polega das de profundidade) e uma vālvula fotomultiplicadora tipo 8054 ,

- divisor de tensão e pré-amplificador, marca ORTEC, modelo 266,

- fonte de al ta voltagem marca ORTEC, modelo 456, fixada em 1000 volts,

- amplificador e analisador monocanal, marca ORTEC, modelo 490 B,

- analisador multicanal, marca NORTHERN, modelo NS-633, com 256 canais analisadores;

- impressora de dados,marca Teletype,

- registrador gräfico X-t, marca Moseley.

5.2. Radioisōtopos

5.2.1. Amostras radioativas padronizadas

As amostras radioativas utilizadas como padrões foram adquiridas da New England Nuclear (Gamma Reference Rod Sour ce Set - Catālogo no NES-100S) e as características físicas desses radioisōtopos são dadas na Tabela 1. Essas fon tes são seladas em bastões de plástico acrílico, e as dimensões externas e um desenho esquemático são fornecidos pelo fabricante (figura 3 ). 


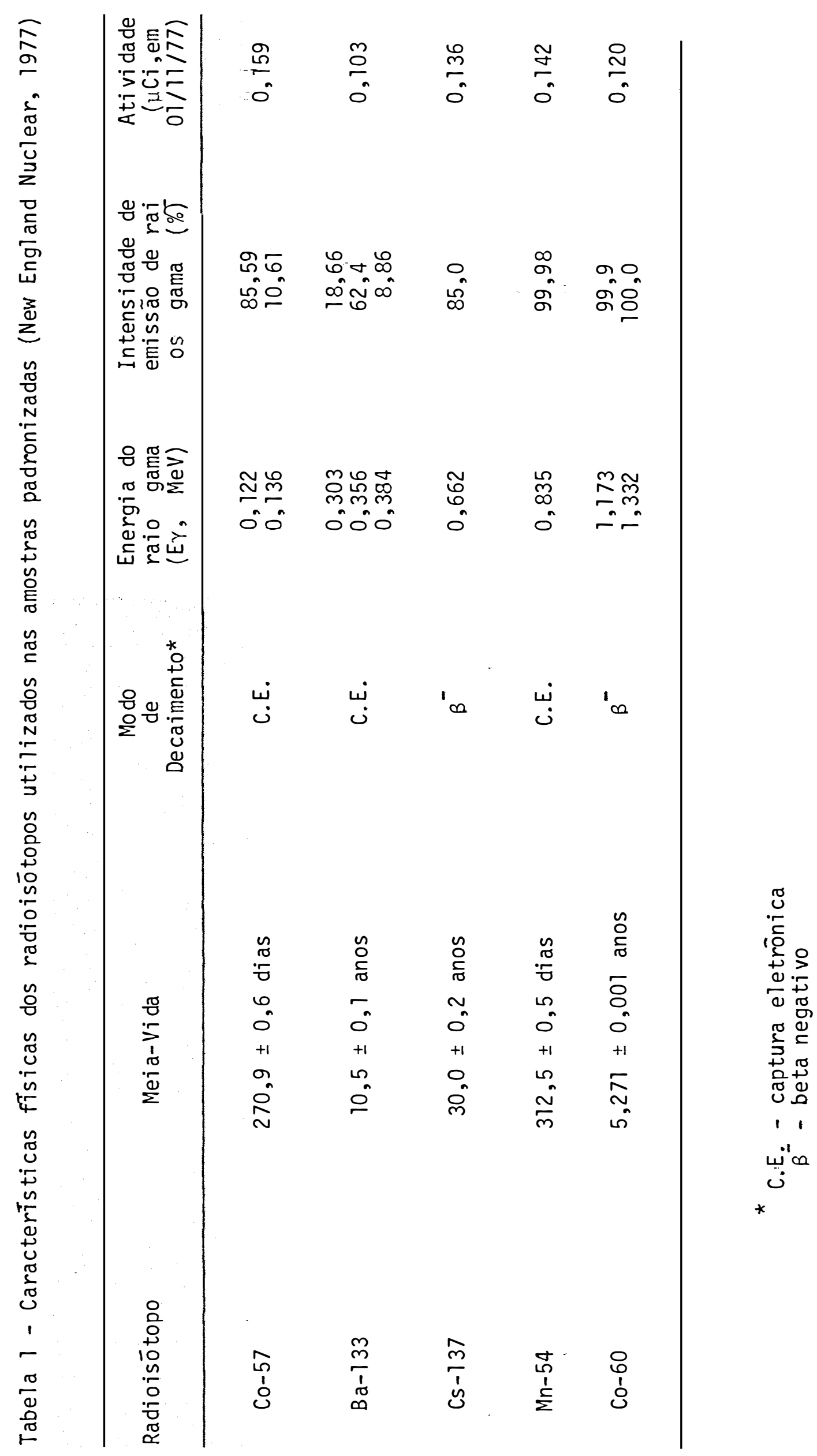



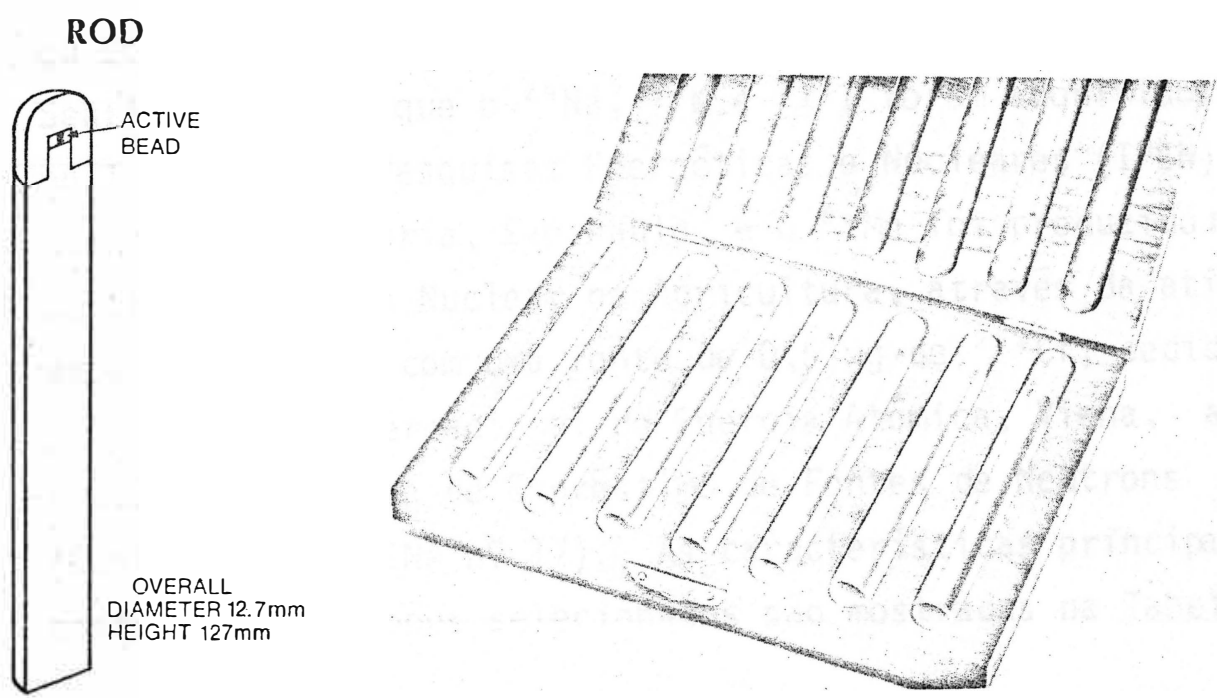

GAMMA REFERNCE SOURCE SETS

Seven relatively long-lived gama emitting $(30 . \mathrm{KeV}$ to 2.6 $\mathrm{MeV}$ ) nuclides in either rod or disc form are packaged with certificates of calibration in a walnut storage case.

\section{SPECIFICATIONS}

NEN's rod and disc sources have the radioactivity as point sources precisely located on the axis: $6 \mathrm{~mm}$ from the rounded end of the rod source, and $1.5 \mathrm{~mm}$ from either surface of a disc source.

Rod Dimensions: $12.7 \mathrm{~mm}$ diameter

$$
127 \mathrm{~mm} \text { length }
$$

Disc Dimensions: $25 \mathrm{~mm}$ diameter $3.2 \mathrm{~mm}$ thick

Figura 3 - Dimensões externas das fontes radioativas padronizadas e seladas em bastão plástico acrílico, segundo catálogo da New England Nuclear, 1980, p. 128-129. 
5.2.2. Amostras radioativas não padronizadas

$\mathrm{Na}$ escolha dos radioisōtopos foram levados em considera ção dois aspectos: o espectro de energia de raios gama, de forma a permitir uma boa discriminação do fotopico de maior intensidade, e a meia-vida, para evitar problemas de contaminação do beaker Marinelli. Dentro desses dois aspectos, enquadraram-se $0{ }^{24} \mathrm{Na},{ }^{42} \mathrm{~K},{ }^{54} \mathrm{Mn},{ }^{56} \mathrm{Mn},{ }^{6} \mathrm{Zn}$, ${ }^{131} \mathrm{I}$ e ${ }^{203} \mathrm{Hg}$. Os radioisótopos de meia-vida mais longa, ou seja ${ }^{54} \mathrm{Mn},{ }^{65} \mathrm{Zn}$ e ${ }^{203} \mathrm{Hg}$, foram adquiridos da AmershamSearle, enquanto que $0{ }^{24} \mathrm{Na},{ }^{42} \mathrm{~K}$ e ${ }^{131} \mathrm{I}$ foram adquiridos no Instituto de Pesquisas Energēticas e Nucleares (IPEN), Cidade Universitāria, São Paulo, e o ${ }^{56} \mathrm{Mn}$ foi produzido no Centro de Energia Nuclear na Agricultura, através da ativação neutrōnica com uma fonte de $0,5 \mu \mathrm{g}$ de ${ }^{252} \mathrm{Cf}$, cedida pela Agëncia Internacional de Energia Atômica, Viena, atravēs do Programa de Empréstimo de Fontes de Neutrons (Contrato AIEA-CENA no 17). As características principais destes radioisōtopos selecionados são mostradas na Tabela

2 .

5.2.3. Blindagem, beaker Marinelli e tubo de ensaio

A blindagem é de ferro fundido, formando um cilindro de 10 $\mathrm{cm}$ de espessura, $46 \mathrm{~cm}$ de diāmetro externo e $50 \mathrm{~cm}$ de altu ra. E fechado na parte inferior por uma tampa de $10 \mathrm{~cm}$ e na parte superior por uma tampa móvel de $26 \mathrm{~cm}$ de espessura, permitindo fácil acesso ao interior da blindagem (fo tografia 1). Internamente foi fei to um revestimento utilizando uma lâmina de chumbo de 2,5 mm de espessura para diminuir o nível de radiação espalhada proveniente do ferro e uma lâmina de $1 \mathrm{~mm}$ de cobre para diminuir 0 das radia ções gama e raios- $X$ de baixas energias provenientes do chumbo (fotografia 2). Dentro da blindagem também foi co locada uma armação de plástico acrīlico e PVC com a função. de suportar o conjunto detector e o beaker Marinelli (foto grafia 3).

Os beakers Marinelli, fabricados pela Hubert Lando, Jr., Inc. (425 Merrick Ave., Westbury, NY 11590) são de polieti leno de $3,4 \mathrm{~mm}$ de espessura e externamente tem $17 \mathrm{~cm}$ de 


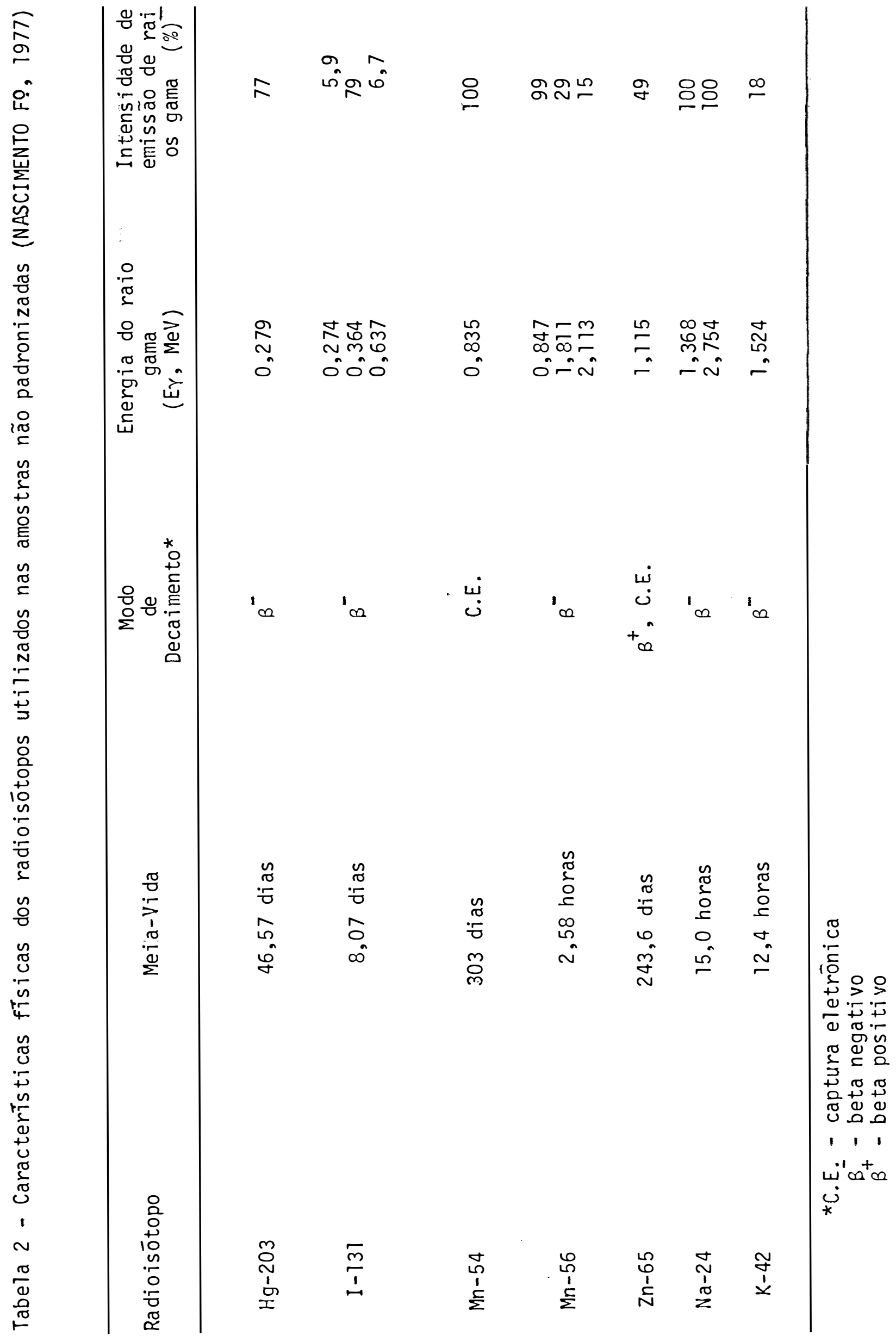


diâmetro e 21,5 cm de altura. A cavidade interna que $\mathrm{fi}$ ca em contacto com o cristal cintilador tem $8,35 \mathrm{~mm}$ de di âmetro e $8,35 \mathrm{~cm}$ de altura.

Os tubos de ensaio são de vidro comum de $1,2 \mathrm{~mm}$ de espessura, com dimensões externas de $2,55 \mathrm{~cm}$ de diâmetro e 8,4 $\mathrm{cm}$ de altura, fundo chato, ajustando-se perfeitamente ao poço do cristal cintilador. 


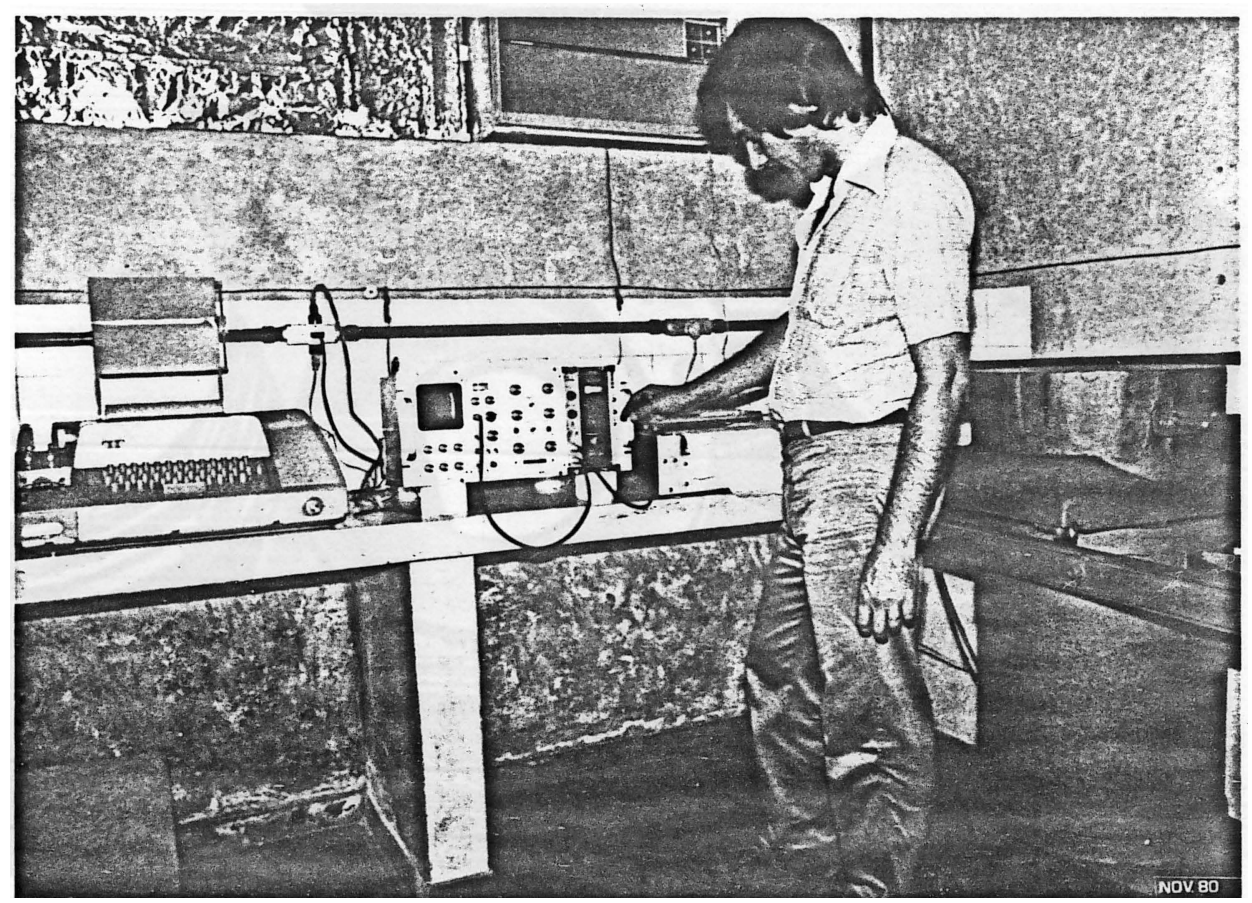

Fotografia 1 - Vista geral da blindagem e instrumentação nuclear. 


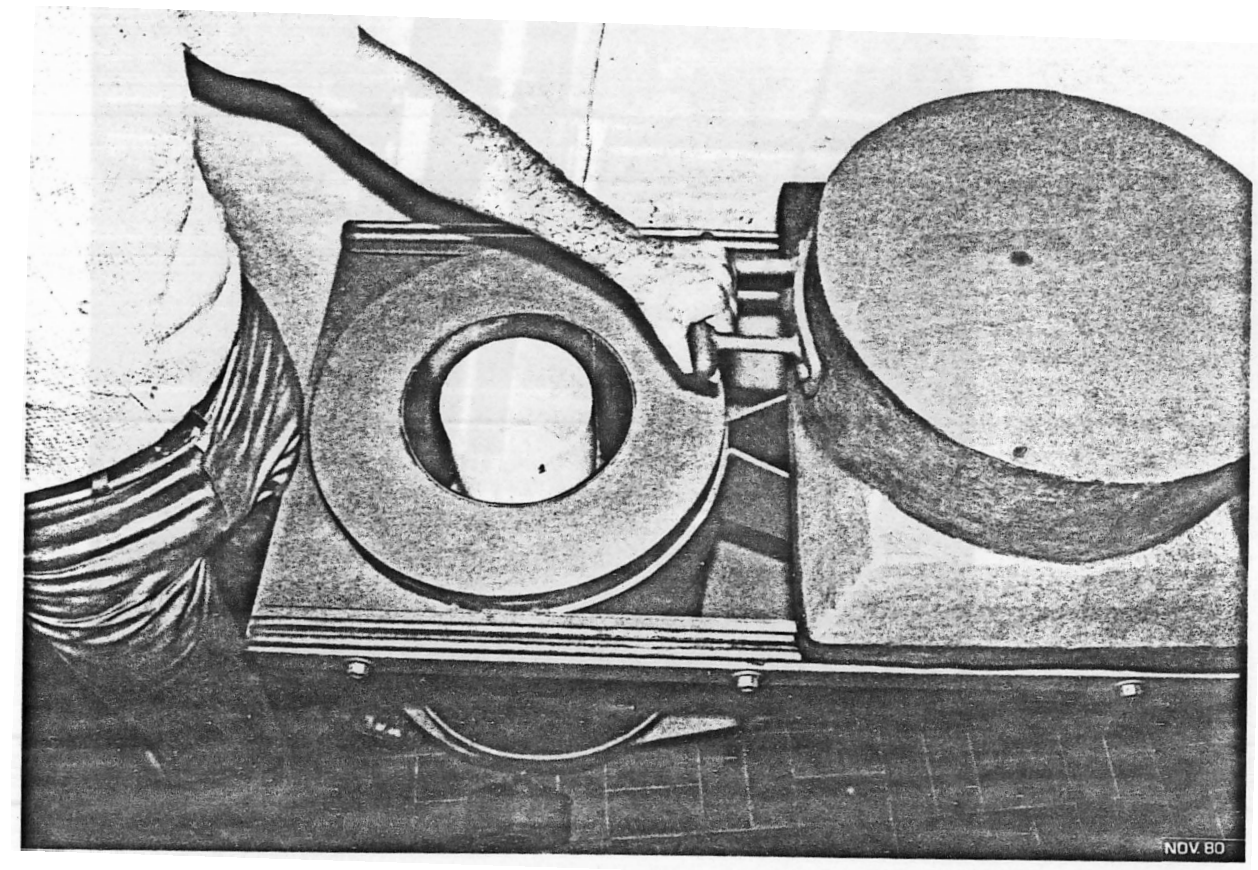

Fotografia 2 - Detalhe interno da blindagem, vendo-se 0 revestimento com lâminas de chumbo e cobre, e o beaker Marinelli sobre o detector. 


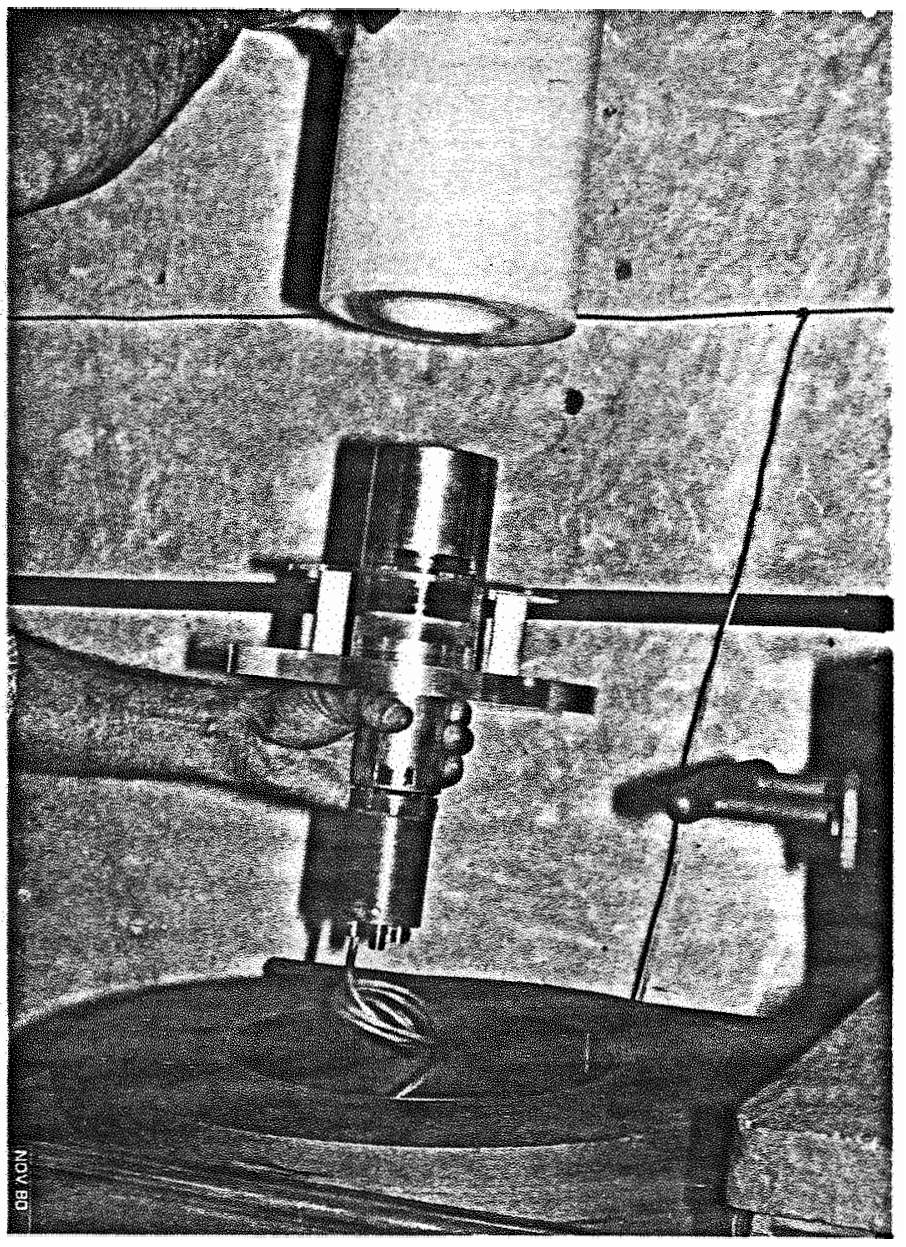

Fotografia 3 - Detalhe da armação de plástico acrîlico para suporte do sistema detector e beaker Marinelli. 


\section{METODOS}

6.1. Eficiência de detecção de radioisōtopos em bastão de plástico A eficiência para fotopico $(\varepsilon)$ em. função da energia, pode ser estimada, partindo-se da sua definição, isto ē, a razão entre 0 no de raios gama detectados ou a taxa líquida de contagem no fotopico $\left(R_{L}\right)$ e o no de raios gama emitidos $(N)$ pela fonte radio ativa:

$$
\varepsilon=\frac{R_{L}}{N}=\frac{R_{L}}{A \cdot f}
$$

sendo: $N=$ nümero de raios gama emitidos por minuto

$A=$ atividade $=$ nümero de desintegrações por minuto (dpm)

$f=$ intensidade de emissão ou nūmero de raios gama emitidos por desintegração.

O nümero de raios gama emitidos por minuto (N) é calculado a par tir da atividade atual $(A)$. Por sua vez, esta atividade atual é calculada pela equação que descreve o decaimento radioativo:

$$
A=A_{0} \cdot e^{-0,693 \cdot t / T}
$$

onde: $A, A_{0}=$ atividade atual e inicial $(\mathrm{dpm})$, respectivamente,

$t=$ tempo decorrido, $e$

$T=$ meia-vida física do radioisōtopo.

Para a obtenção do número de raios gama ou taxa líquida de con tagem no fotopico para um determinado radioisótopo, é preciso em primeiro lugar fazer-se o levantamento do espectro de amplitude dos pulsos eletrōnicos produzidos pela interação dos raios gama com o cristal cintilador. Devido a proporcionalidade existente entre a energia da radiação e a amplitude do pulso, este espec - 
tro è também chamado de espectro de energia (MONTANHEIRO et ali $i$, 1977).

Este espectro de energia é obtido através de um analisador multi canal, onde cada canal acumularā um certo número de contagens de. vido a uma determinada energia dissipada no detector. Os dados de contagem em cada canal são transferidos a uma impressora de dados ou a um registrador gráfico. Plotando-se esses dados em papel milimetrado, ou seja, taxa de contagem versus canal (energia) pode-se definir claramente o fotopico de maior intensidade de cada radioisōtopo.

A taxa de contagem líquida, que é o número de raios gama detec tados, é obtida calculando-se a ārea sob este fotopico; lembrando-se de fazer as devidas correções referentes a radiação de fun do e a ārea do trapézio sob a curva, conforme mostram as figuras 5 a 9.

6.2. Eficiēncia de detecção de radioisōtopos em tubo de vidro Nesta fase do trabalho procura-se verificar se a curva de efi ciência de detecção vs energia da radiação, feita com os bastões, poderia ser utilizada, quando fossem feitas leituras nos tubos de vidro.

Is to foi feito confeccionando-se bastões de plástico acrîlico, de dimensões prōximas às das amostras radioativas padrões (Fig. 4). Nestes bastões foram injetados $30 \mu$ l de amostra e mesmo volume foram colocados em três tubos de vidro e acrescentou-se $5 \mathrm{ml}$ de àgua destilada em cada tubo. Neste experimento foram utilizados somente os radioisōtopos ${ }^{20}{ }^{3} \mathrm{Hg},{ }^{54} \mathrm{Mn}$ e ${ }^{65} \mathrm{Zn}$, abrangendo uma faixa de energia de raios gama de 0,28 a 1,115 MeV, e foram feitas 3 repetições por radioisōtopo.

Sendo iguais as atividades contidas no bastão e no tubo de vidro, as taxas de contagem serão respectivamente:

$$
\begin{gathered}
C_{b}=\varepsilon_{b} \cdot A \cdot f \\
C_{t 5}=\varepsilon_{t 5} \cdot A \cdot f \\
\text { e consequentemente } \varepsilon_{t 5}=\frac{C_{t 5}}{C_{b}} \cdot \varepsilon_{b}
\end{gathered}
$$




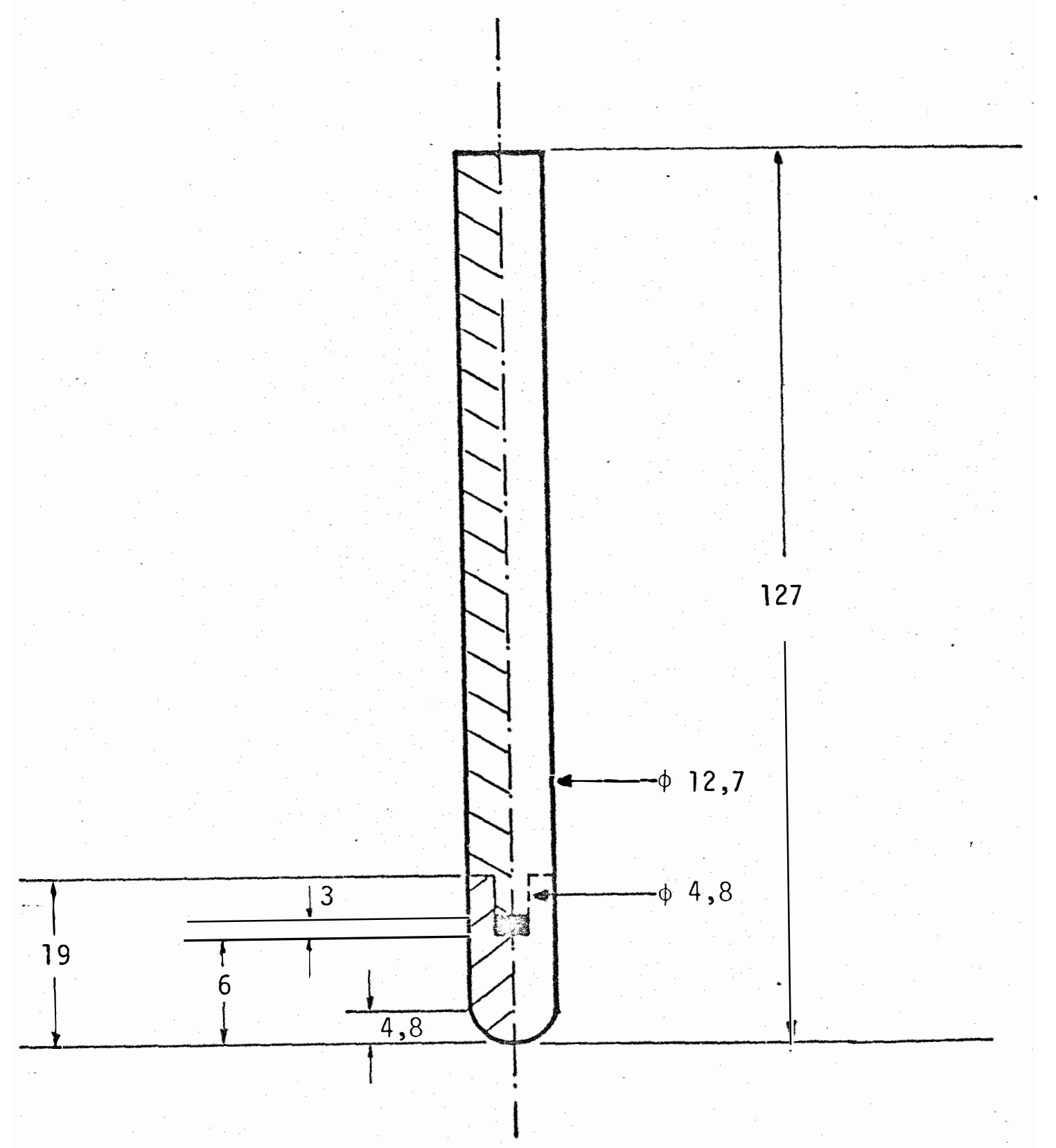

Figura 4 - Dimensões das fontes radioativas não padronizadas, em bastões. de plástico acrîlico (dimensões em milimetros). 
Fazendo-se

$$
\frac{c_{t 5}}{c_{b}}=R
$$

tem-se

$$
\varepsilon_{t 5}=R \cdot \varepsilon_{b}
$$

Portanto, conhecendo-se a razão $R$ entre as taxas de contagem no tubo de vidro e no bastão em função da energia da radiação gama, pode-se estimar a eficiência de detecção de radioisōtopos em amostras líquidas de $5 \mathrm{ml}$, quando colocadas em tubos de vidro.

Procurou-se tambēm determinar as eficiēncias de detecção para ra dioisótopos em solução aquosa em tubos de vidro com outros volumes. Para isso foram preparadas soluções radioativas de ${ }^{24} \mathrm{Na}$, ${ }^{42} \mathrm{~K},{ }^{54} \mathrm{Mn},{ }^{56} \mathrm{Mn},{ }^{65} \mathrm{Zn},{ }^{131} \mathrm{I}$ e ${ }^{203} \mathrm{Hg}$, e foram feitas detecções co locando-se 5 em $5 \mathrm{ml}$ dessas soluções em tubos de vidro, atē atin gir o volume de $25 \mathrm{ml}$. Desse modo, a eficiência de detecção em tubo de vidro em função do volume da amostra radioativa pode ser calculada pela equação:

$$
\varepsilon_{t V}=\frac{C R_{V}}{C R_{5}}-\left(\frac{5}{V}\right) \varepsilon_{t 5}
$$

onde: $\varepsilon_{t V}=$ eficiência de deteç̧ão em tubo de vidro para qualquer volume da amostra radioativa,

$C R_{V}, C_{5}=$ taxa de contagem relativa obtida com a amostra de qualquer volume e com $5 \mathrm{ml}$, respectivamente, $\mathrm{V}=$ volume da amostra radioativa, em $\mathrm{ml}$, e

$\varepsilon_{t 5}=$ eficiēncia de detecção em tubo de vidro para amostra de $5 \mathrm{ml}$.

Chamando

$$
\frac{C R_{V}}{C R_{5}} \cdot \frac{5}{v}=f_{t}
$$

sendo $f_{t}=$ fator de geometria relativo ao tubo de vidro, tem-se:

$$
\varepsilon_{t V}=f_{t} \cdot \varepsilon_{t 5}
$$

Convēm ressaltar que este fator de geometria $f_{t}$, representa a eficiencia relativa de deteç̧ão para detecção em tubo de vidro $\left(\varepsilon_{R t}\right)$, tomando-se como unitāria a eficiência de detecção obtida com a amostra de $5 \mathrm{ml}$. 
6.3. Eficiēncia de deteç̧ão de radioisōtopo em beaker Marinelli

Conhecendo-se a eficiēncia de detecção em tubo de vidro para uma determinada energia da radiaçäo gama, pode-se estimar a eficiēncia em beaker Marinelli, detectando-se amostra de mesma atividade. Assim, foram preparados tubos de vidro com $5 \mathrm{ml}$ e beaker $\mathrm{Ma}$. rinelli com $2500 \mathrm{ml}$ de solução radioativa, mas contendo a mesma atividade. Neste experimento foram utilizados os radioisōtopos ${ }^{24} \mathrm{Na},{ }^{42} \mathrm{~K},{ }^{54} \mathrm{Mn},{ }^{56} \mathrm{Mn},{ }^{65} \mathrm{Zn},{ }^{131} \mathrm{I}$ e ${ }^{203} \mathrm{Hg}$.

Do mesmo modo que o item anterior, as taxas de contagem obtidas no tubo de vidro com $5 \mathrm{ml}$ e no Marinelli com $2500 \mathrm{ml}$ serão dadas, respectivamente, por:

$$
\begin{aligned}
& C_{t 5}=\varepsilon_{t 5} \cdot A . f \\
& C_{M 2500}=\varepsilon_{M 2500} \cdot \text { A.f }
\end{aligned}
$$

Sendo iguais as atividades, pode-se escrever:

$$
\varepsilon_{M 2500}=\frac{C_{M 2500}}{C_{t 5}} \cdot \varepsilon_{t 5}
$$

e fazendo-se

$$
\frac{C_{M 2500}}{C_{t 5}}=R^{\prime}
$$

tem-se

$$
\varepsilon_{M 2500}=R^{\prime} \cdot \varepsilon_{t 5}
$$

Desse modo, conhecendo-se a razão entre as taxas de contagem no beaker Marinelli e no tubo de vidro e também a eficiēncia de detecção para amostra de $5 \mathrm{ml}$ em tubo de vidro ein função da ener gia da radiação gama, pode-se estimar a eficiência na detecção em beaker Marinelli para amostra de $2500 \mathrm{ml}$.

Do mesmo modo que o item anterior, procurou-se determinar a eficiēncia de deteç̧ão para amostras de outros volumes em beaker Ma rinelli. Para isso, foram preparadas soluções radioativas de ${ }^{24} \mathrm{Na},{ }^{42} \mathrm{~K},{ }^{54} \mathrm{Mn},{ }^{56} \mathrm{Mn},{ }^{65} \mathrm{Zn},{ }^{131} \mathrm{I}$ e ${ }^{203} \mathrm{Hg}$ e foram feitas detec ções colocando-se 250 em $250 \mathrm{ml}$ dessas soluções no beaker Mari nelli, até atingir o volume de $2500 \mathrm{ml}$. Tambērn normalizou-se as 
taxas de contagem, assumindo como unitária a taxa de contagem ob tida com $2500 \mathrm{ml}$. Assim, a eficiēncia de detecção em beaker Marinelli em função do volume da amostra radioativa, pode ser calculada pela equação:

$$
\varepsilon_{M V}=\frac{C R_{V}}{C R_{2500}} \cdot \frac{2500}{V} \cdot \varepsilon_{M 2500}
$$

onde :

$$
\begin{aligned}
\varepsilon_{M V}= & \text { eficiēncia de detecção em beaker Marinelli pa } \\
& \text { ra qualquer volume da amostra radioativa, } \\
C_{V}, C_{2500=} & \text { taxa de contagem relativa, obtida com a amos- } \\
& \text { tra de qualquer volume e com a de } 2500 \mathrm{ml} \text {, res } \\
& \text { pectivamente, } \\
= & \text { volume da amostra radioativa, em ml, } \\
= & \text { eficiēncia de detecção em beaker Marinelli pa } \\
& \text { ra amostra de } 2500 \mathrm{ml} .
\end{aligned}
$$

Chamando

$$
\frac{\mathrm{CR}_{\mathrm{V}}}{\mathrm{CR}_{2500}} \cdot \frac{2500}{\mathrm{~V}}=\mathrm{f}_{\mathrm{M}}
$$

sendo $f_{M}=$ fator relativo ao beaker Marinelli, tem-se

$$
\varepsilon_{M V}=f_{M} \cdot \varepsilon_{M 2500}
$$

Deve-se tambēm notar que este fator de geometria $f_{M}$ representa a eficiência relativa de deteç̧ão para o beaker Marinelli $\left(\varepsilon_{R M}\right)$, to mando-se como unitāria a eficiēncia de detecção feita com $2500 \mathrm{ml}$.

\subsection{Atividade específica mínima detectāvel}

Para uma medida da atividade de uma amostra radioativa, a taxa îquida de contagem $\left(R_{L}\right)$, o seu desvio padrão $\left(S_{L}\right)$ e o coefici ente de variação (CV) são dados pelas equações:

$$
\begin{gathered}
R_{L}=R_{B}-R_{F} \\
S_{L}=\sqrt{S_{B}{ }^{2}+S_{F}{ }^{2}}=\sqrt{\frac{R_{B}}{t_{B}}+\frac{R_{F}}{t_{F}}}
\end{gathered}
$$




$$
C V=\frac{S_{L}}{R_{L}}
$$

sendo: $R_{B}, S_{B}=$ taxa bruta de contagem e desvio padrão, devido a amostra e a radiação de fundo,

$R_{F}, S_{F}=$ taxa de contagem e desvio padrão da radiação: de fundo (cpm), e

$t_{B}, T_{F}=$ tempos de detecção da amostra radioativa e da ra diação de fundo (minutos), respectivamente.

Substituindo o valor de $R_{B}$ (dado pela equação 49) na equação 50 , pode-se escrever para o coeficiente de variação:

$$
C V=\frac{\sqrt{\frac{R_{L}+R_{F}}{t_{B}}+\frac{R_{F}}{t_{F}}}}{R_{L}}
$$

Rearranjando os termos, tem-se que:

$$
R_{L}=\frac{1+\sqrt{1+4 \cdot C V^{2} \cdot t_{B} \cdot R_{F}\left(1+\frac{t_{B}}{t_{F}}\right)}}{2 \cdot C V^{2}}
$$

Por outro lado, a taxa líquida de contagem é dada pela equação:

$$
R_{L}=a \cdot V \cdot f \cdot \varepsilon
$$

sendo: $a$ = atividade específica da amostra $(\mathrm{dpm} / \mathrm{ml})$.

Portanto:

$$
a=\frac{1+\sqrt{1+4 \cdot C V^{2} \cdot t_{B} \cdot R_{F}\left(1+\frac{t_{B}}{t_{F}}\right)}}{2 \cdot V \cdot f \cdot \varepsilon \cdot C V^{2}}
$$

Analisando a equação 55, a representa a atividade específica mínima que deve ter uma amostra radioativa para que sua estimativa seja feita com um coeficiente de variação CV desejado, detectando-se um volume $\underline{V}$ da amostra e a radiação de fundo pelos tempos $t_{B}$ e $t_{F}$, respectivamente, e conhecendo-se de antemão a taxa de radiação de fundo $\left(R_{F}\right)$, a intensidade de emissão de raios gama (f) e a eficiência de detecçāo $(\varepsilon)$. 


\section{RESULTADOS E DISCUSSAOO}

7.1. Eficiência de detecção de radioisōtopos em bastão de plástico

Foram levantados os espectros de todos os radioisótopos com 0 in tuito de se definir convenientemente as āreas sob o fotopico ( $f \underline{i}$ guras 5 a 9). Depois de feita a correção da radiação de fundo e da ārea de fotopico sob a curva, obteve-se as taxas de contagem 1 iquidas, as quais relacionadas com o número de raios gama emiti dos pelos radioisōtopos, forneceram as eficiências de deteç̧ão (equação 31) mostradas na Tabela 3. Plotando-se os dados de efi ciência vs energia da radiação em papel semi-logaritmo, obteve se a figura 10. Nesta figura observa-se que os pontos estão pra ticamente alinhados e através da regressão linear obteve-se uma equação para a eficiência no bastão $\left(\varepsilon_{b}\right)$ em função da energia da radiação gama $\left(E_{\gamma}\right.$, MeV)

$$
\begin{aligned}
& \varepsilon_{b}=1,1152 \cdot e^{-2,2255 E_{\gamma}} \\
& r=0,9972(\text { sig. } 1 \%)
\end{aligned}
$$

Mas a curva que melhor se adaptaria segundo PRICE (1958), basean do no fato que o coeficiente de absorção de massa devido ao efei to fotoelétrico ser proporcional a $Z \cdot E_{\gamma}{ }^{-3,5}$, onde $Z \bar{e}$ o número atômico médio do cristal cintilador, seria:

$$
\begin{aligned}
& \varepsilon_{b}=0,21033+0,000406 \cdot E_{\gamma}-3,5 \\
& r=0,8622(\operatorname{sig} .5 \%)
\end{aligned}
$$

Procurou-se também ajustar estes dados a uma curva exponencial e 


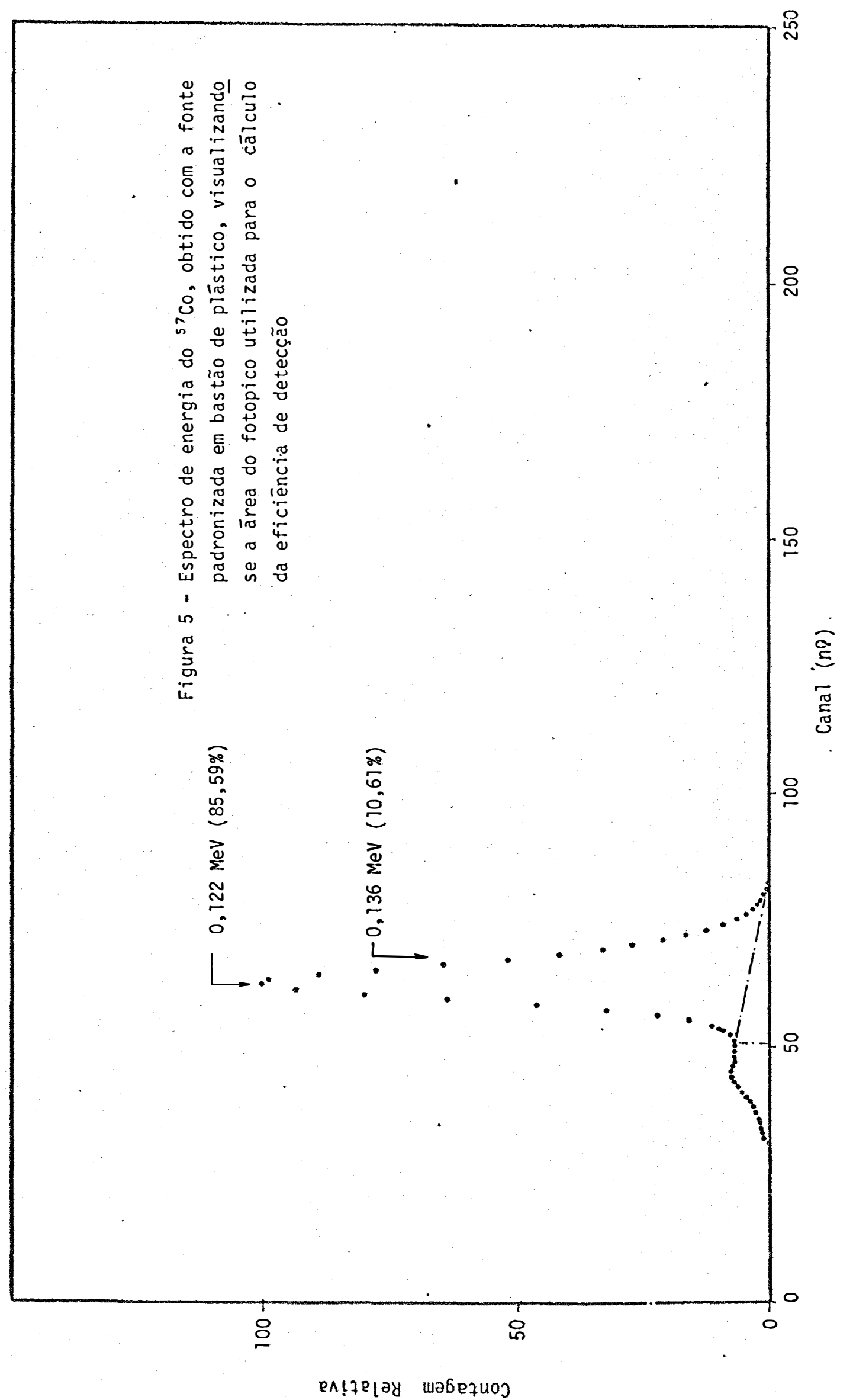




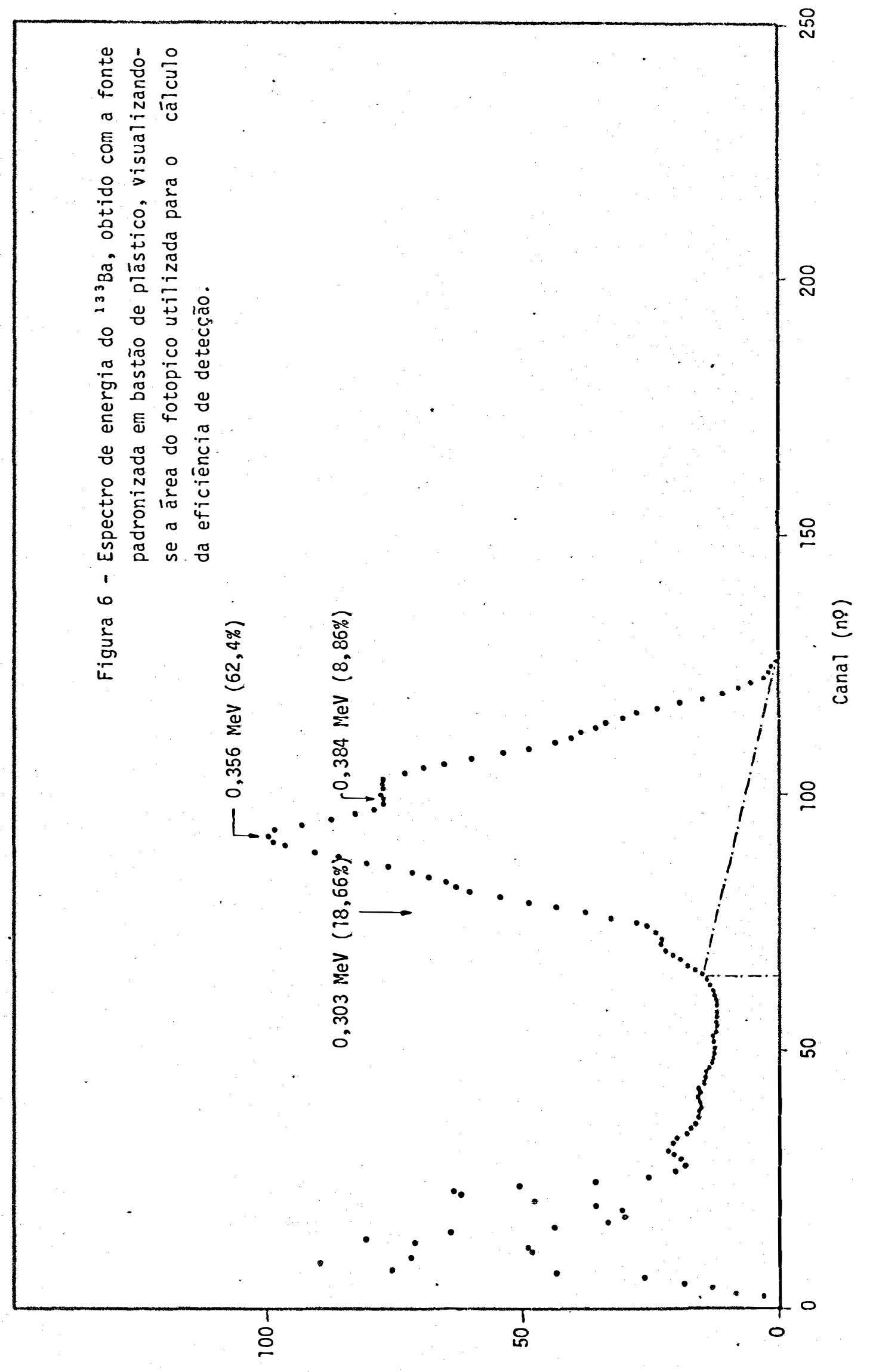

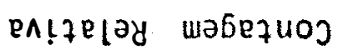




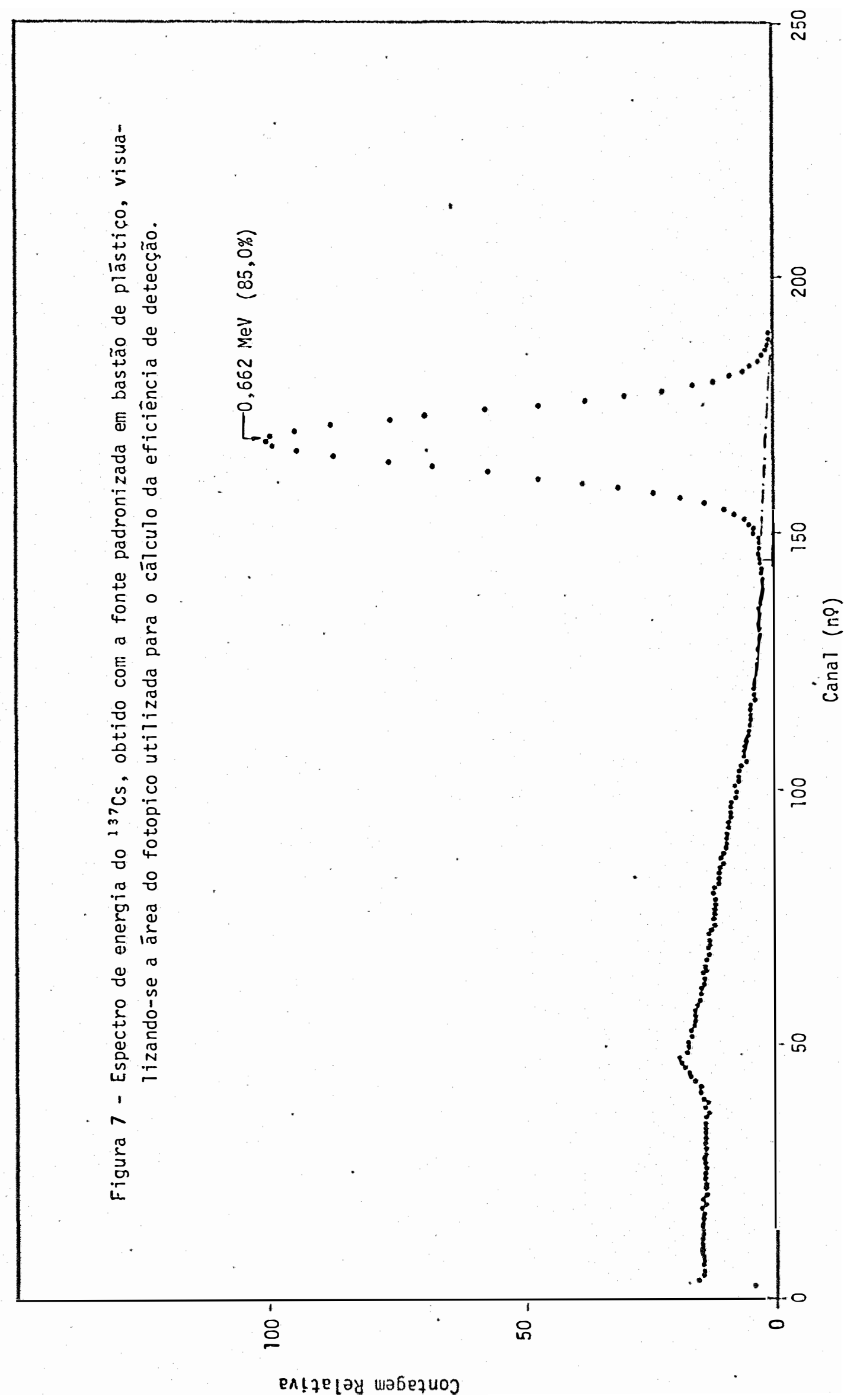




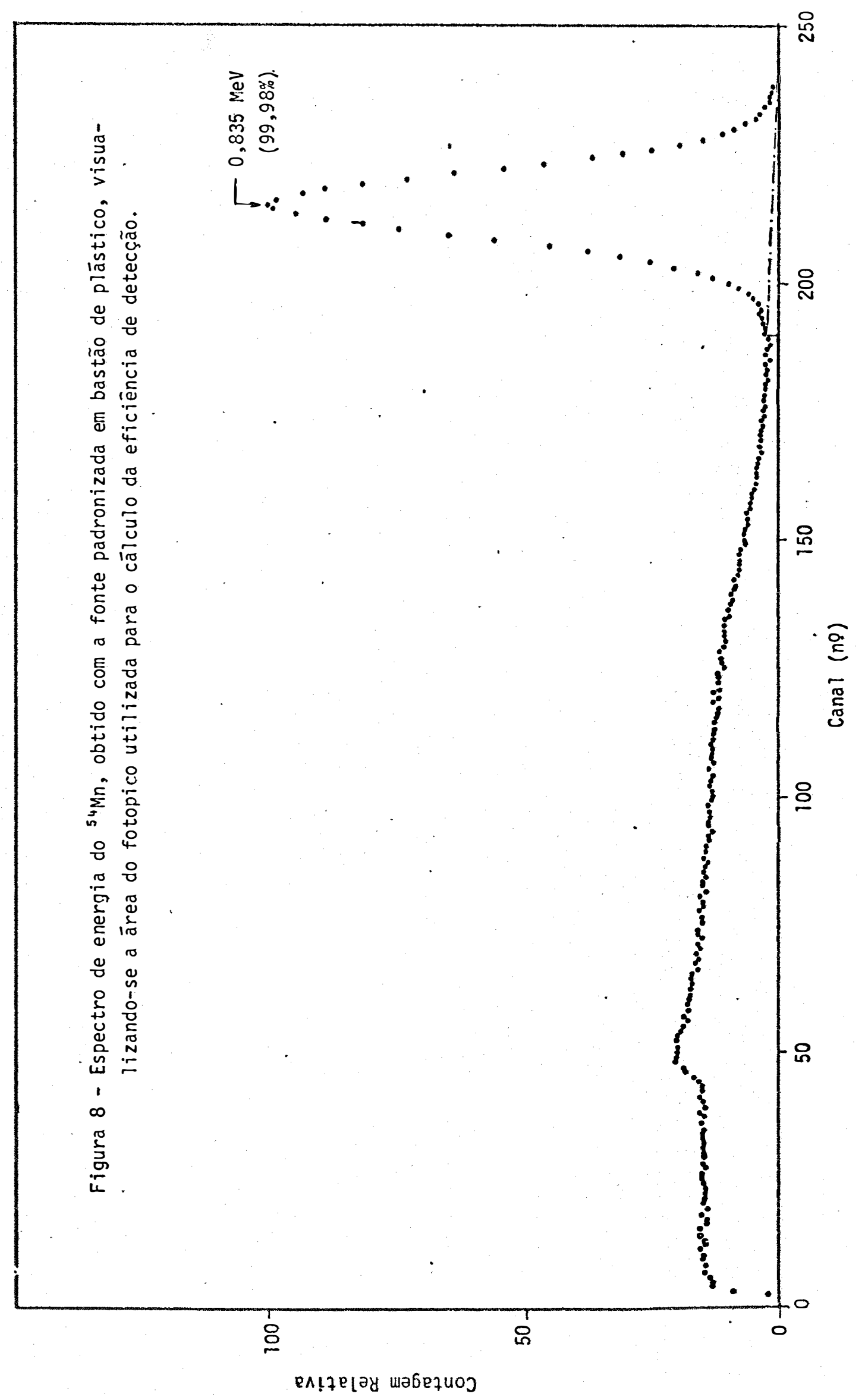




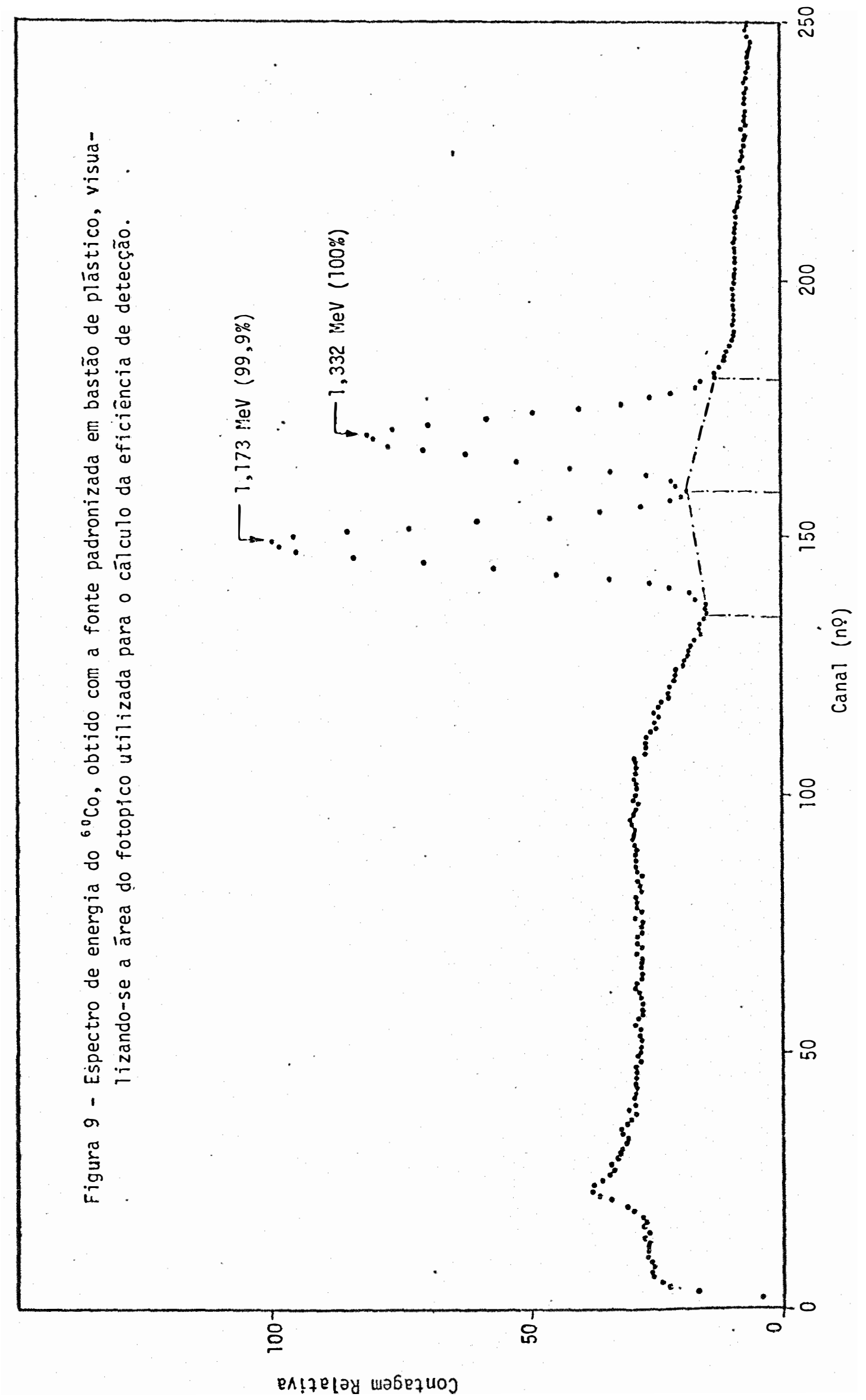




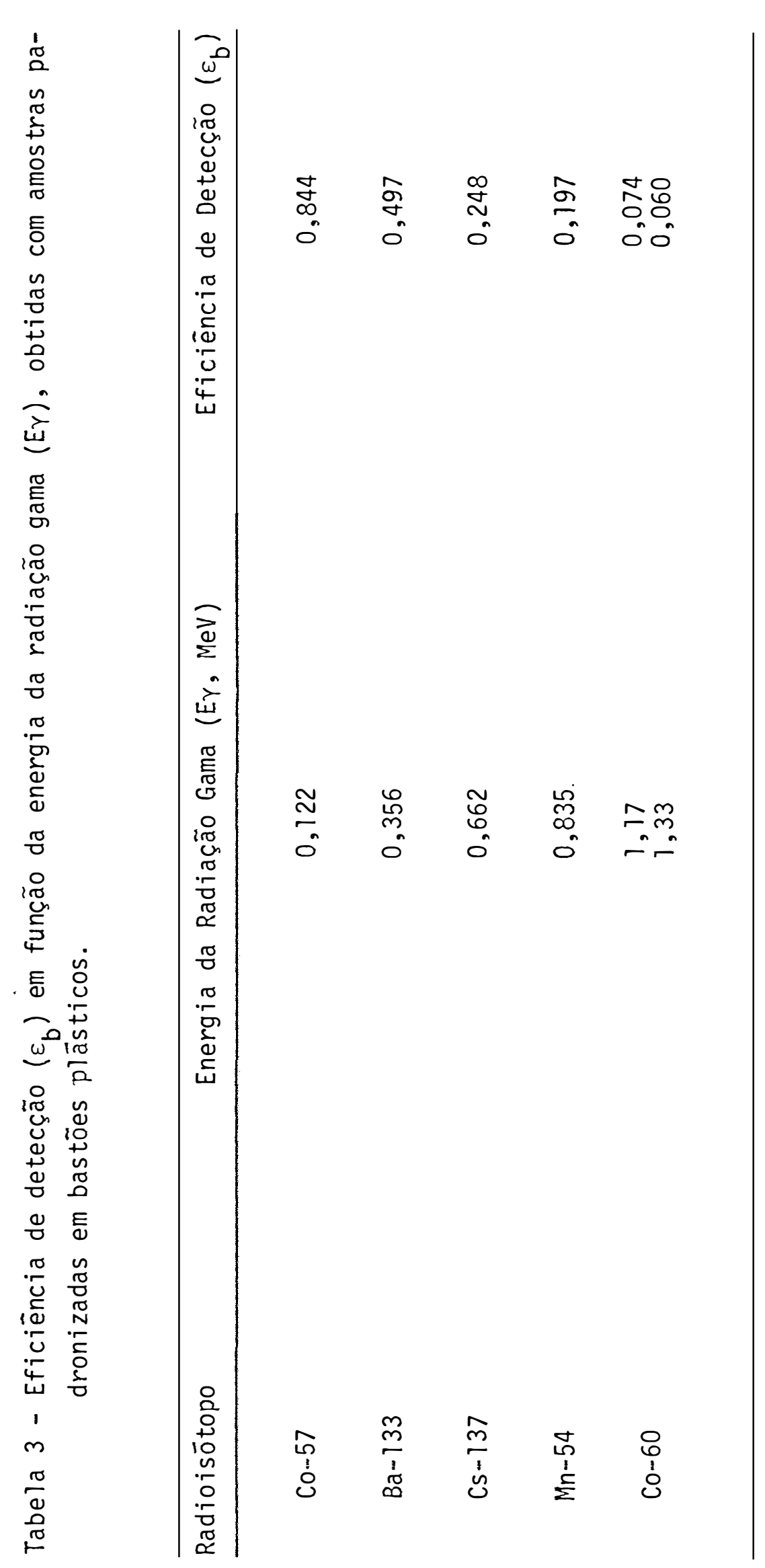




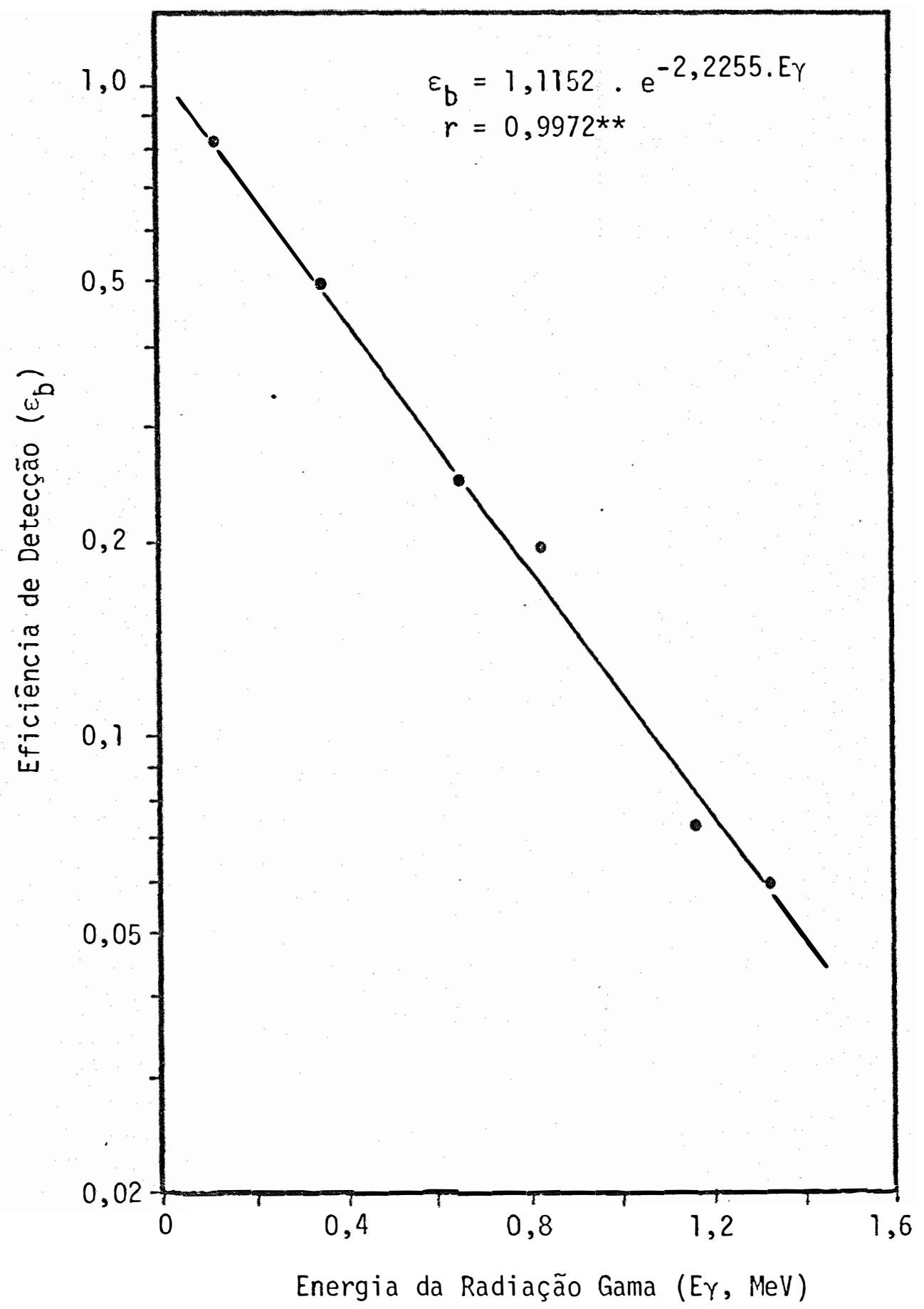

Figura 10 - Eficiência de deteç̧ão $\left(\varepsilon_{b}\right)$ em função da energia da radiação gama $(E Y)$, obtida com amostras padronizadas em bastōes de plästico acrîlico. 
a equação obtida foi :

$$
\begin{aligned}
& \varepsilon_{b}=0,1167 \cdot E_{\gamma}-1,0904 \\
& r=0,9415(\operatorname{sig} \cdot 1 \%)
\end{aligned}
$$

Comparando-se o coeficiente de correlação linear nos três casos, observa-se que o da primeira equação apresentou o maior valor, significando que aqueles dados se ajustam melhor segundo aquela equação.

7.2. Eficiência de detecção de radioisōtopos em tubo de vidro Foram levantados os espectros de energias das amostras radioativas colocadas em bastões de plástico e em tubo de vidro - $5 \mathrm{ml}$, definindo-se em seguida as āreas sob os fotopicos. Para as amos tras em tubos de vidro - $5 \mathrm{ml}$, os espectros do ${ }^{203} \mathrm{Hg},{ }^{54} \mathrm{Mn}$ e ${ }^{65} \mathrm{Zn}$, são mostrados nas figuras 11,12 e 13, respectivamente.

A razão $\underline{R}$ (equação 36 ) entre as taxas de contagem obtidas para amostras de mesma atividade em tubos de vidro $(5 \mathrm{ml})$ e no bastão, para os radioisótopos ${ }^{203} \mathrm{Hg},{ }^{54} \mathrm{Mn}$ e ${ }^{65} \mathrm{Zn}$, encontra-se na tabela 4 e representada na figura 14. Relacionando-se o valor da razão das taxas de contagem em função da energia da radiação gama, ob teve-se a equação:

$$
\begin{aligned}
& R=0,9753+0,09959 \cdot E_{\gamma} \\
& r=0,9997(\operatorname{sig} \cdot 5 \%)
\end{aligned}
$$

podendo-se concluir que a eficiēncia de detecção em tubo de vi dro (5 ml) é praticamente a mesma do bastão, mas a equação acima foi utilizada nos cálculos posteriores.

Substituindo-se o valor de $\underline{R}$ (equação 59) e $\varepsilon_{b}$ (equação 58) na equação 37 , tem-se:

ou

$$
\varepsilon_{t 5}=\left(0,9753+0,09959 E_{\gamma}\right) \cdot 1,1152 \cdot e^{-2,2255 E_{\gamma}}
$$

$$
\varepsilon_{t 5}=\left(1,08765+0,1111 E_{\gamma}\right) e^{-2,2255 E_{\gamma}}
$$

a qual fornece a eficiência de detecção no tubo de vidro de $5 \mathrm{ml}$ 


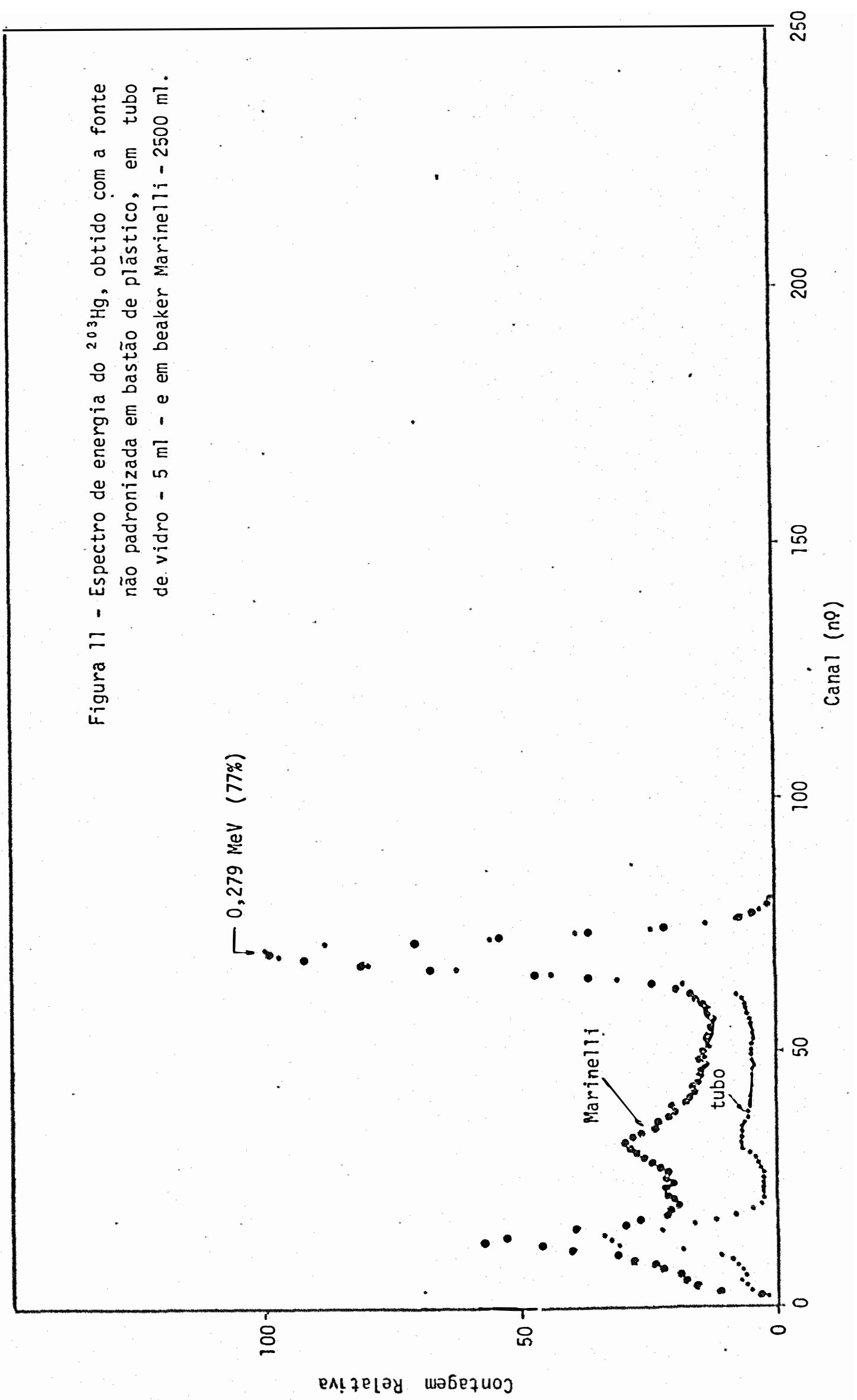




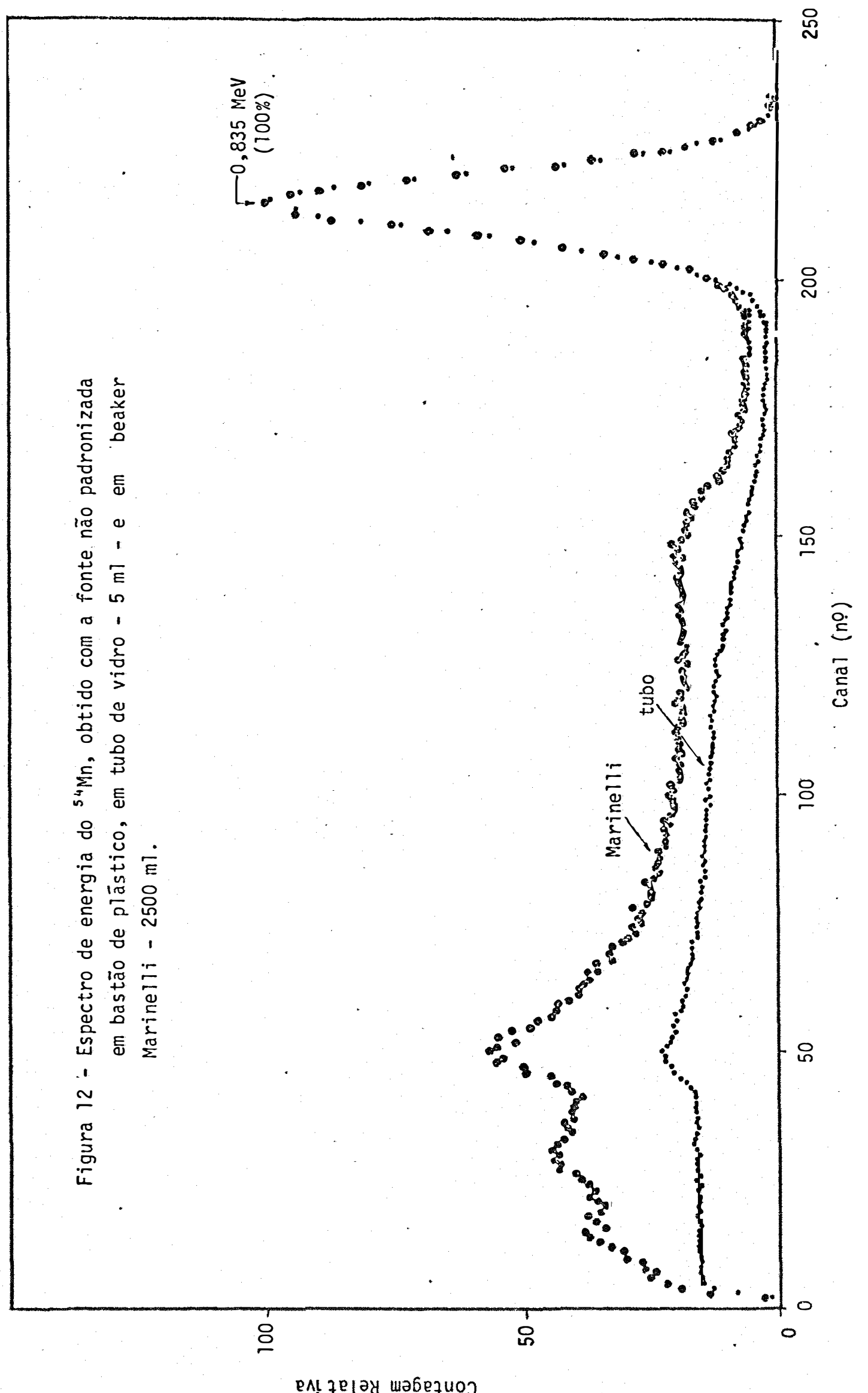

eA! felay ma6equos 


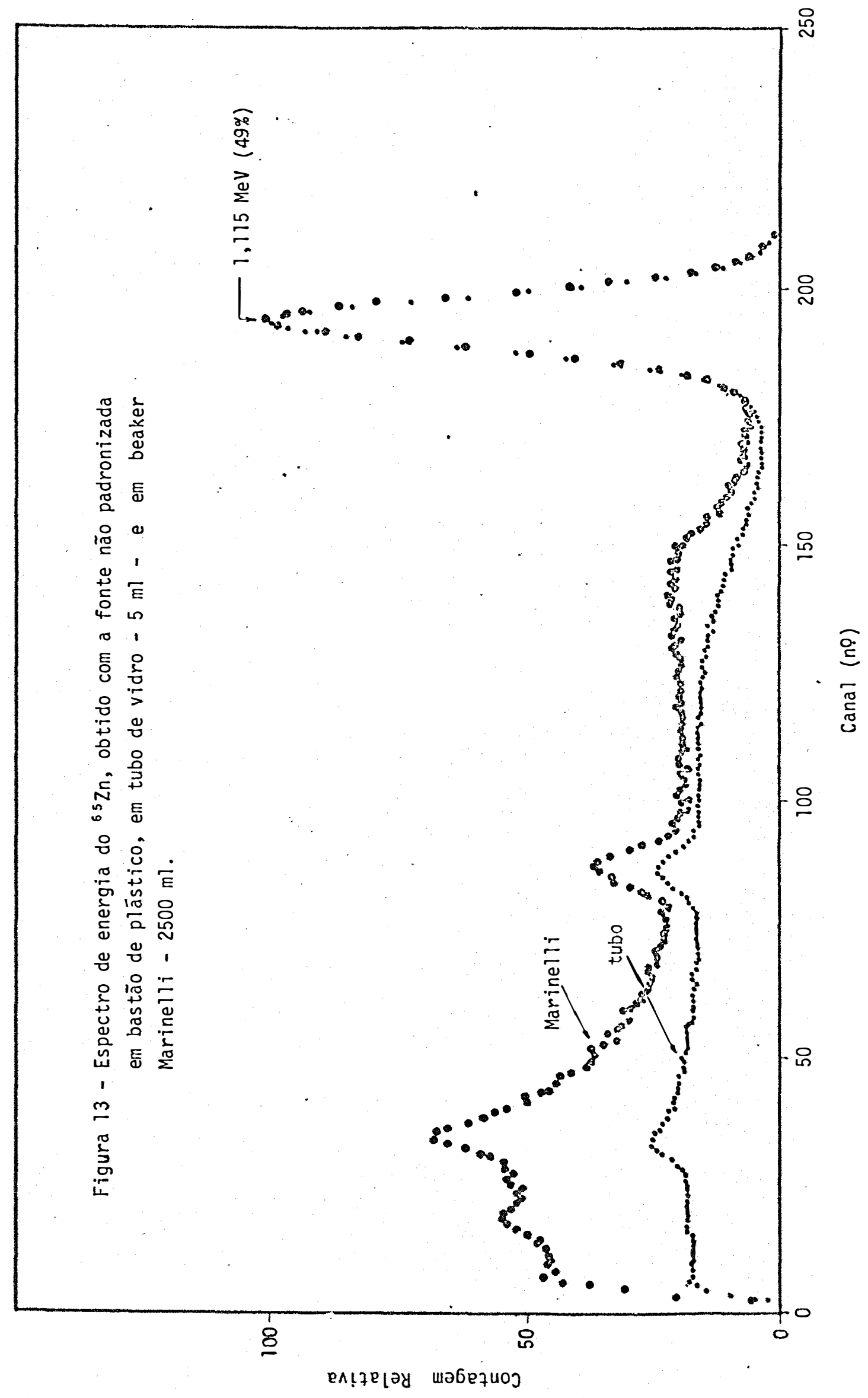


Tabela 4 - Razões ( $R$ ) entre as taxas liquidas de contagem obtidas com amos tras de mesma atividade, colocadas no tubo de vidro - $5 \mathrm{ml}$ e no bastão plástico, em função da energia da radiação gama $(E \gamma)$.

\begin{tabular}{lcc}
\hline Radioisótopo & Energia da Radiação $(E \gamma, M e V)$ & $R$ \\
\hline Hg-203 & 0,279 & 1,0027 \\
Mn-54 & 0,835 & 1,0595 \\
Zn-65 & 1,115 & 1,0856 \\
& & \\
\hline
\end{tabular}




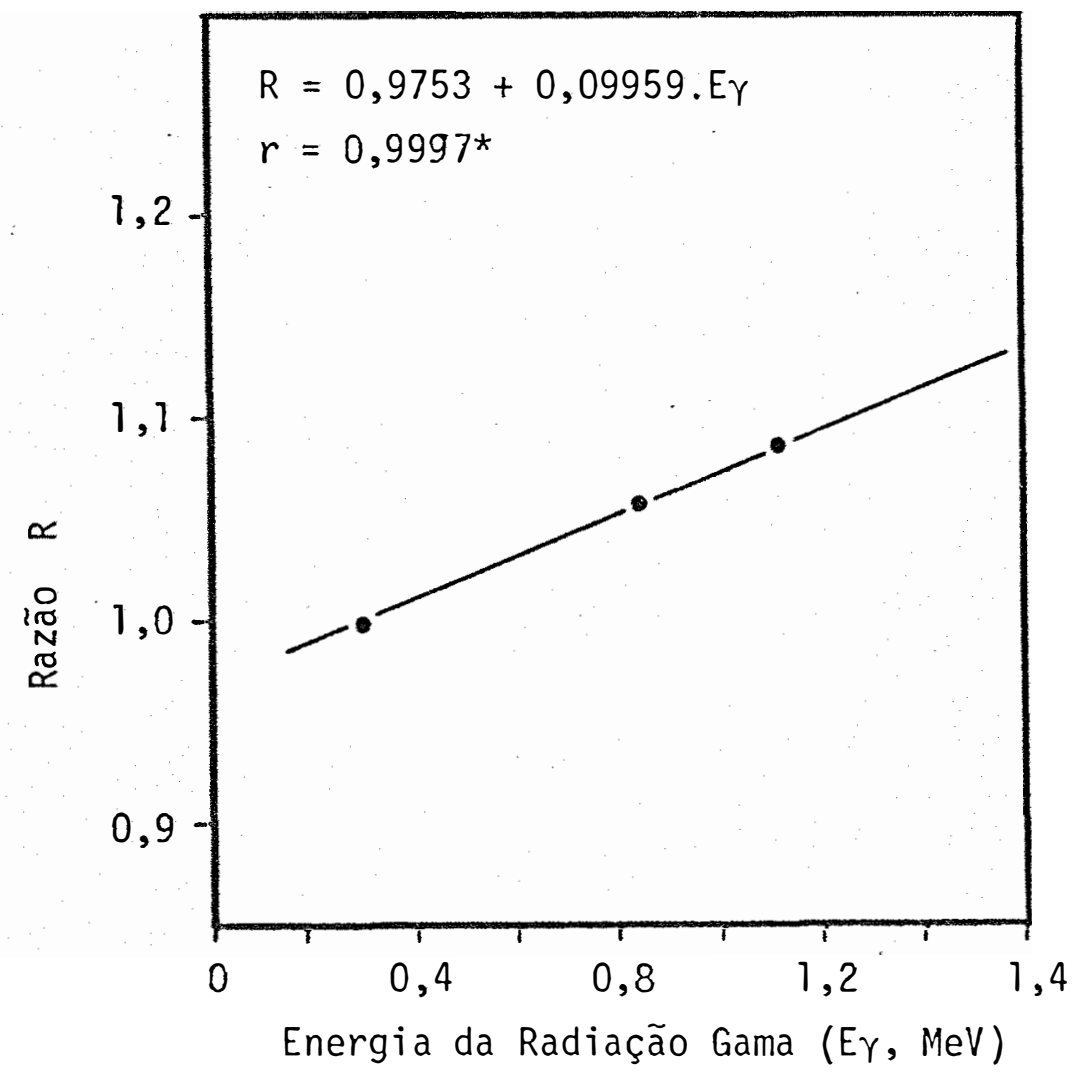

Figura 14 - Razão (R) entre as taxas líquidas de contagem obtidas com amostras de mesma atividade colocadas no tubo de vidro $5 \mathrm{ml}$ - e no bastão plāstico, em função da energia da radiação gama (EY). 
em função da energia da radiação gama emi tida pelo radioisōtopo, e é representada na figura 15. Na tabela 5 são apresentadas as eficiēncias para alguns radioisōtopos de interesse, estimadas de acordo com a equação 61 .

Os espectros de energiapara ${ }^{132} \mathrm{I},{ }^{56} \mathrm{Mn},{ }^{24} \mathrm{Na} \mathrm{e}^{42} \mathrm{~K}$, em tubos de vidro com $5 \mathrm{ml}$ de solução radioativa são dados nas figuras 16 a 19 , respectivamente. Os dados das taxas relativas de contagem para os volumes de 5 a $25 \mathrm{ml}$, de 5 em $5 \mathrm{ml}$, para os radioisótopos ${ }^{24} \mathrm{Na},{ }^{42} \mathrm{~K},{ }^{54} \mathrm{Mn},{ }^{56} \mathrm{Mn},{ }^{65} \mathrm{Zn},{ }^{131} \mathrm{I}$ e ${ }^{203} \mathrm{Hg}$, são mostrados na tabe la 6 , e visualizados na figura 20.

Nota-se que as taxas relativas obtidas nos diversos volumes inde pendem da energia da radiação gama. Com os valores médios de cá da volume, foi obtida uma relação entre a taxa relativa de conta gem em função do volume da amostra colocada no tubo de vidro:

$$
\begin{gathered}
C R_{V}=-2,8980 \cdot 10^{-2}+6,6029 \cdot 10^{-2} \mathrm{~V}-9,9171 \cdot 10^{-4} V^{2} \\
\left.r^{2}=0,9997 \text { (sig. } 1 \%\right)
\end{gathered}
$$

Com o auxîlio dessa equação pode-se estimar a contribuição de cada $5 \mathrm{ml}$ da amostra adicionados ao tubo de vidro à taxa de contagem, e com isto estimar a eficienncia relativa de detecção de cada "camada" $\left(\varepsilon_{c t}\right)$ de $5 \mathrm{ml}$ tomando-se como unitāria a dos pri meiros $5 \mathrm{ml}$. Deve ser notado que esta eficiēncia independe da energia da radiação gama, e pode ser expressa pela equação:

$$
\varepsilon_{c t}=\frac{C R_{V}-C R_{V-5}}{C R_{5}}
$$

sendo: $\varepsilon_{c t}=$ eficiência relativa de detecção no tubo de vidro pa ra camada de $5 \mathrm{ml}$ da amostra, compreendida entre 0 volume $V$ e $V-5 \mathrm{ml}$.

$$
C R_{V}, C R_{V-5} \text { e } C R_{5}=\text { taxas relativas de contagem devido aos }
$$
volumes $V, V-5$ e $5 \mathrm{ml}$ da amostra, respectivamente.

Os dados da eficiéncia de detecção de cada camada de $5 \mathrm{ml}$ para 0 tubo de vidro são mostrados na tabela 7 e figura 21 . Enquanto que os primeiros $5 \mathrm{ml}$ são detectados com uma eficiência relativa de $100 \%$, os ūltimos $5 \mathrm{ml}$ (de 20 a $25 \mathrm{ml}$ ) são detectados com apenas $38,71 \%$ de eficiēncia. Deve tambëm ser notado que o decréscimo 


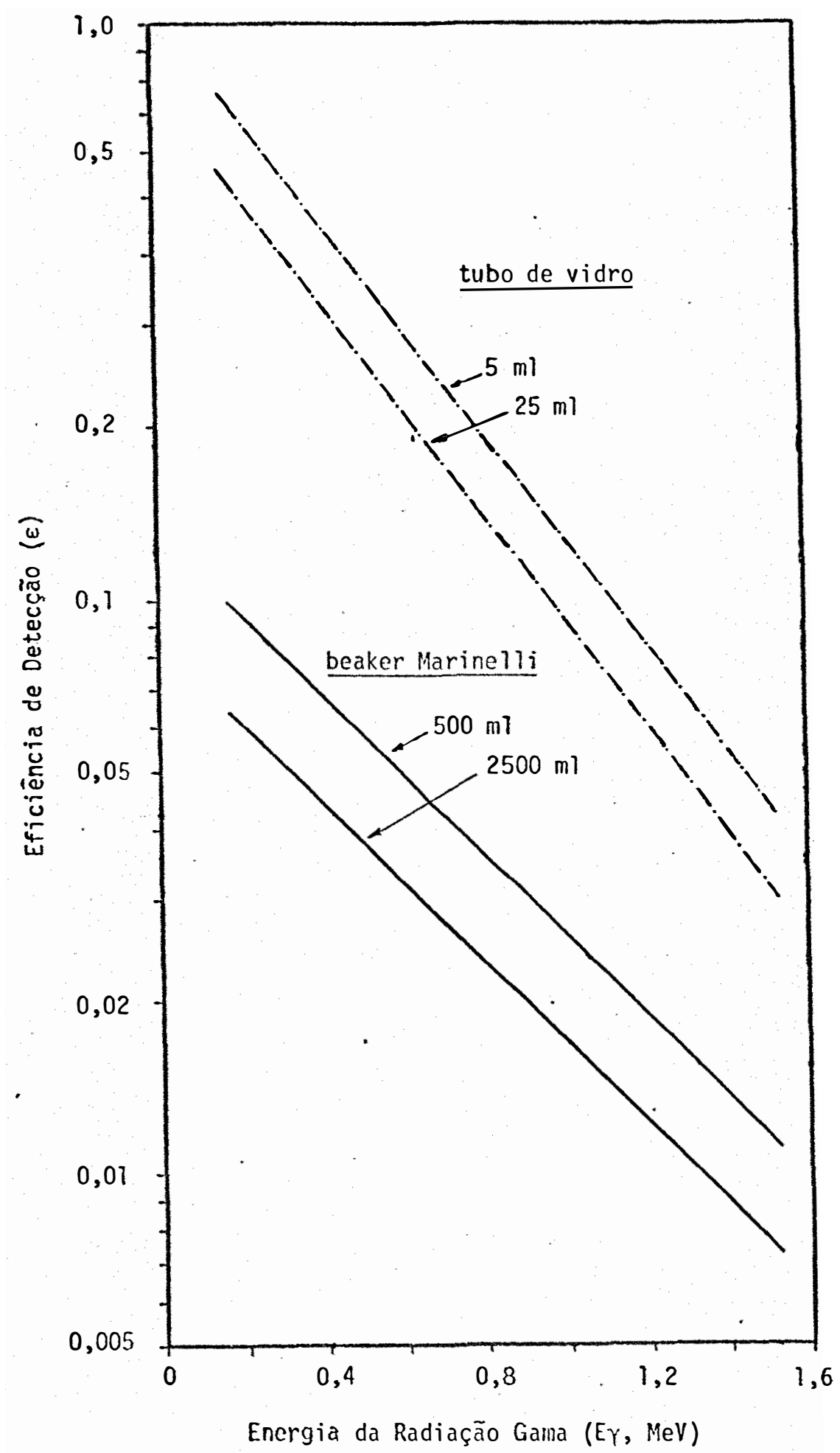

Figura 15 - Eficiência de detecção em função da energia da radiação gama (EY), obtidas com aniostras radioativas de värios volumes, co locadas en tubos de vidro $\left(\varepsilon_{t}\right)$ e em beaker Marinelli $\left(\varepsilon_{M}\right)$. 


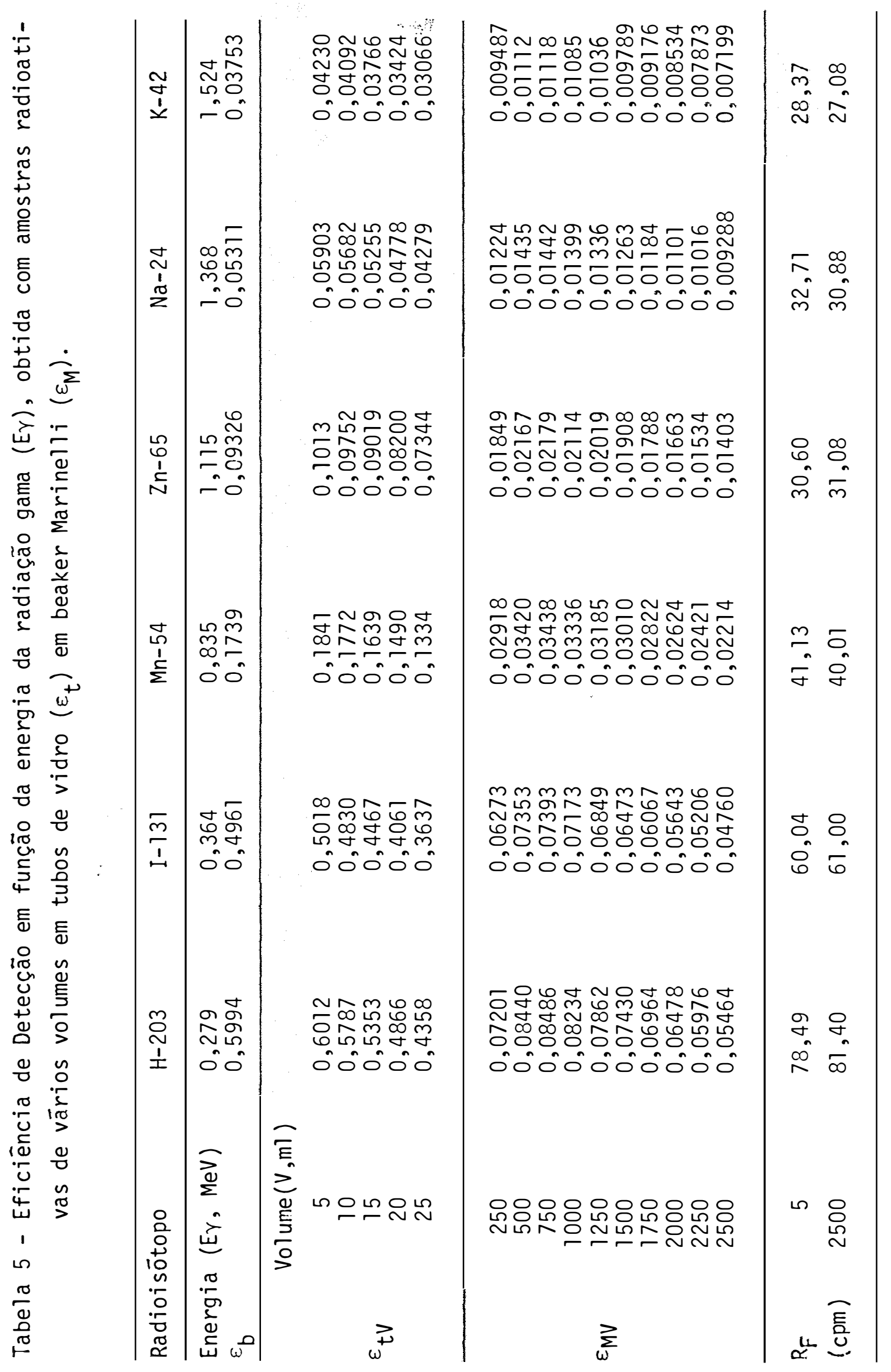




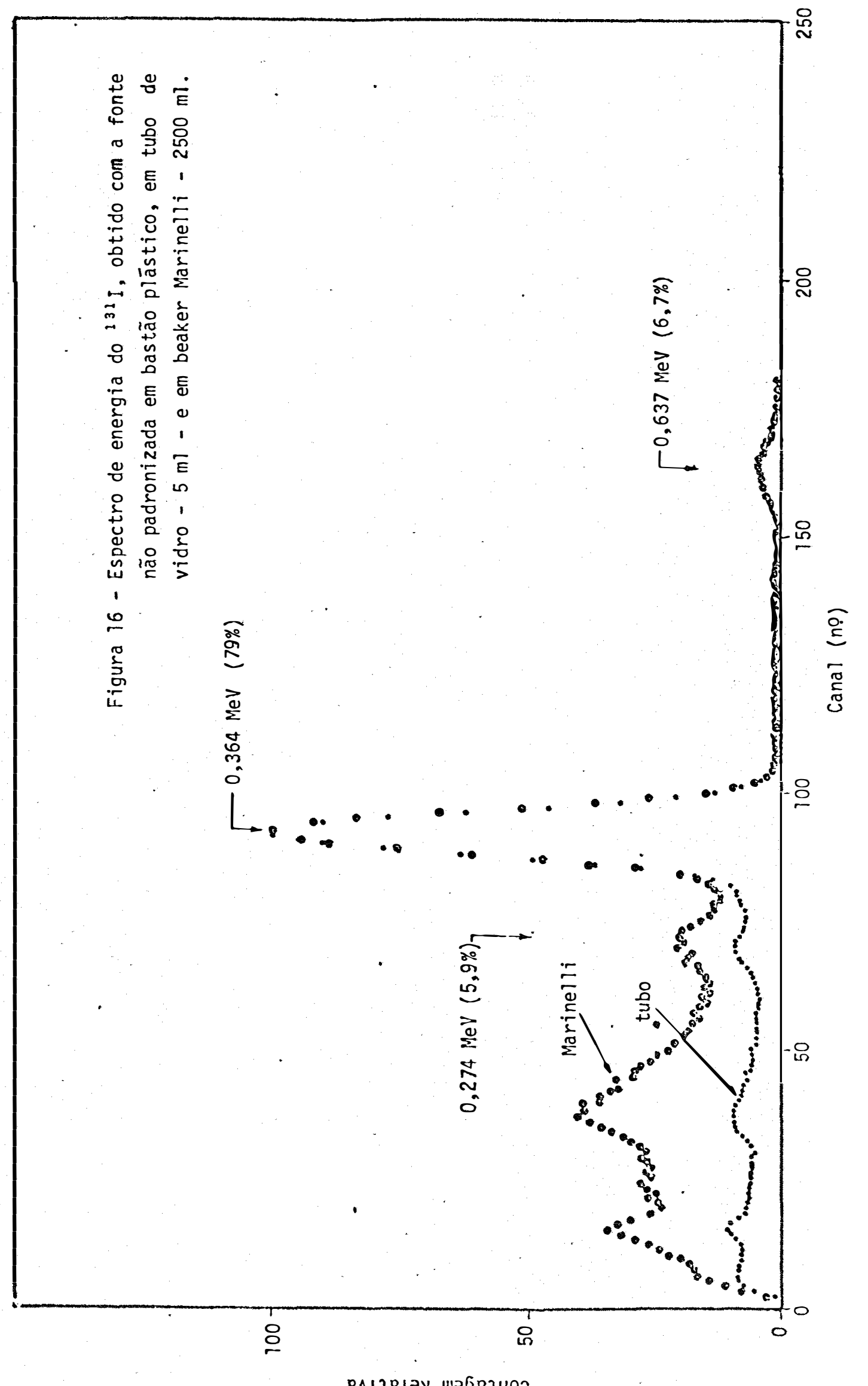

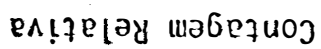




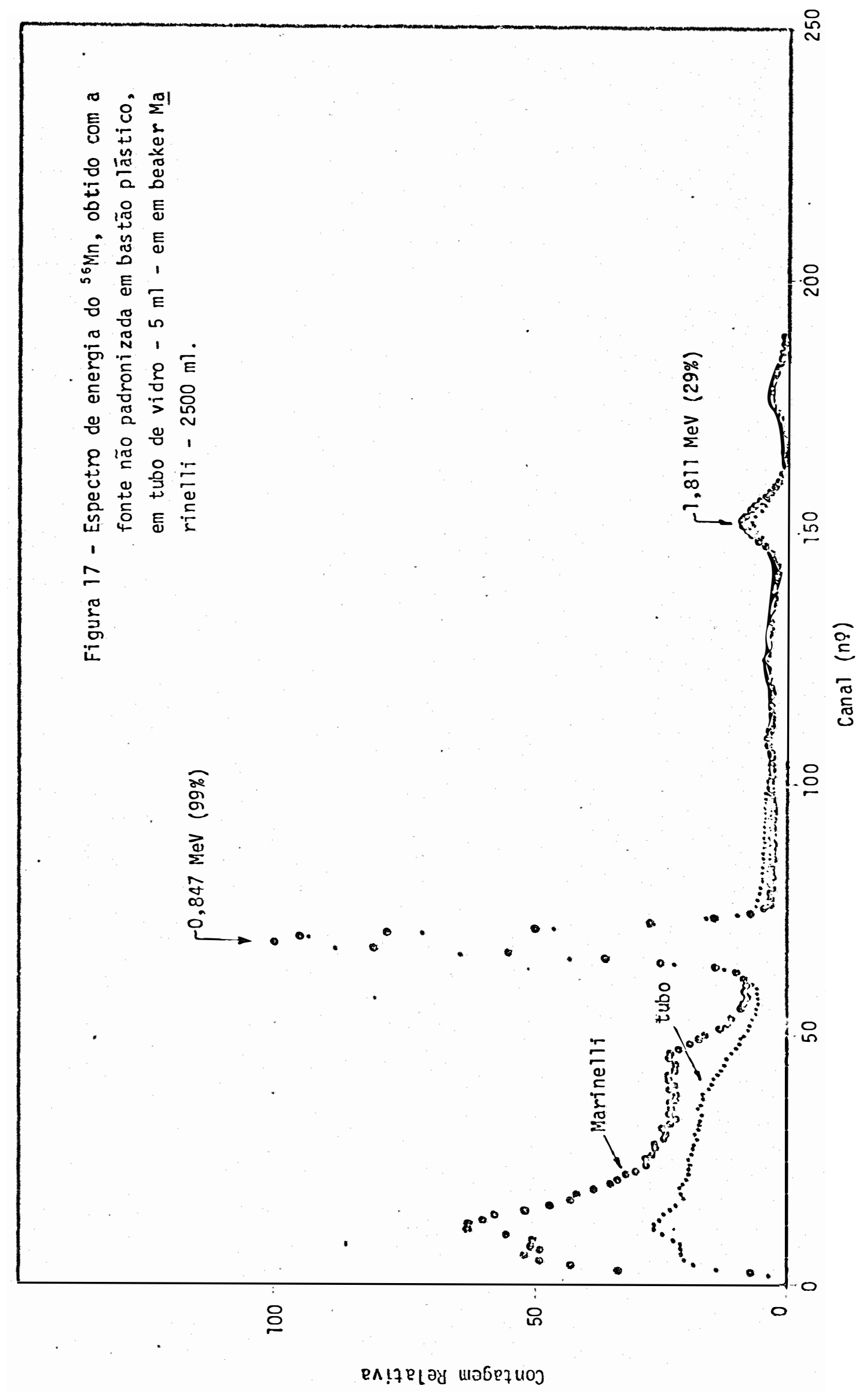




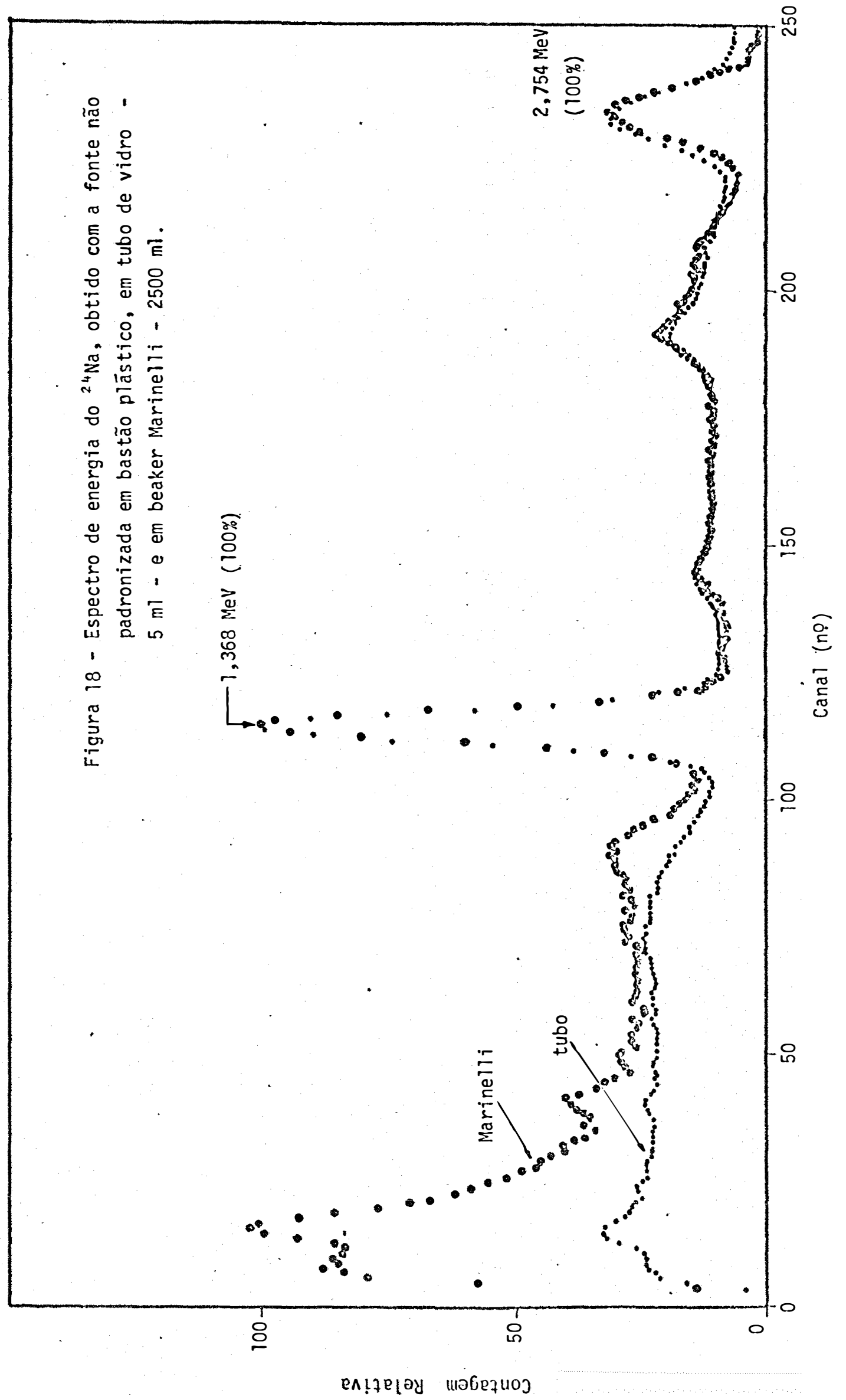




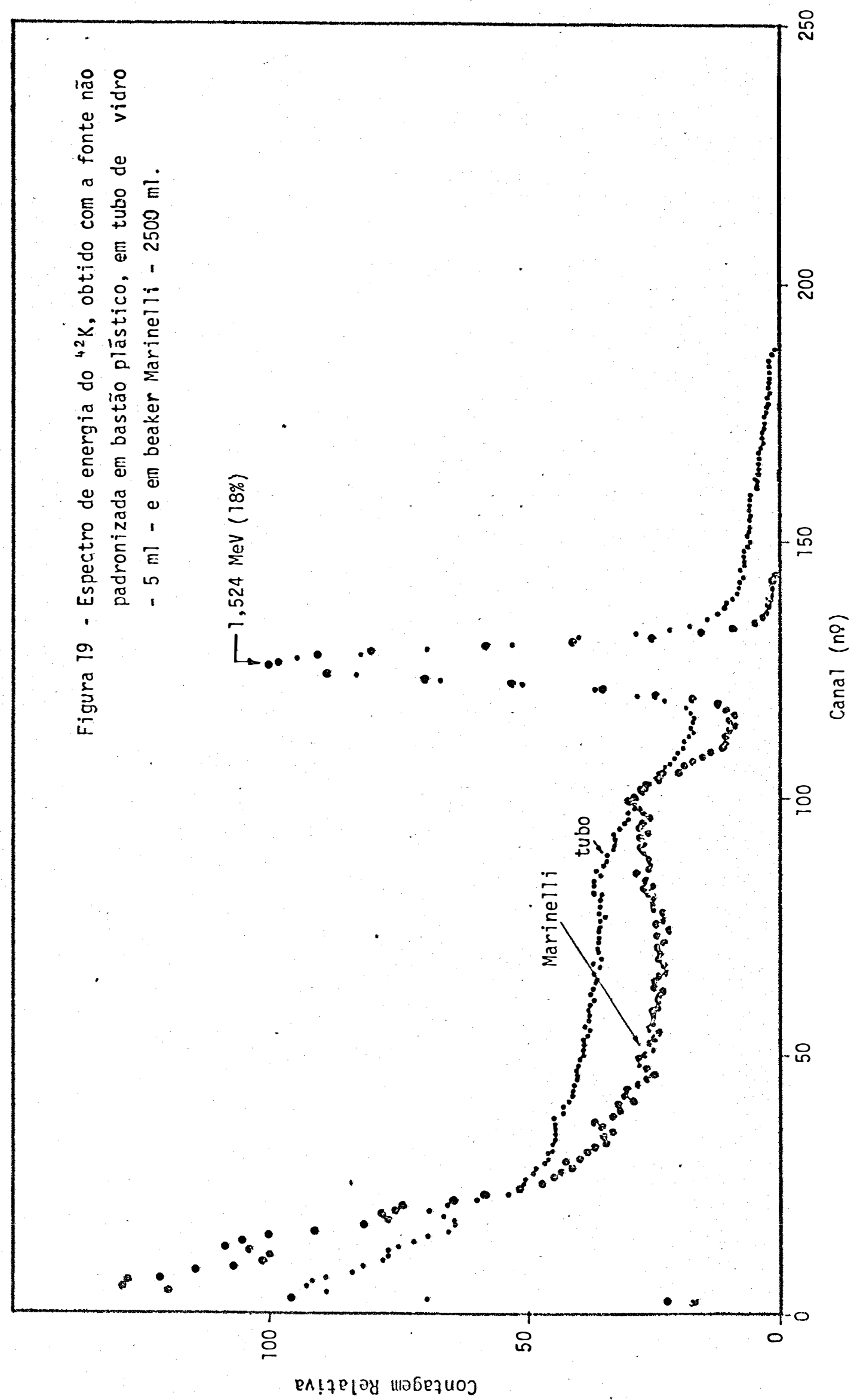


Tabela 6 - Taxas relativas de contagem em função do volume da amostra em tubos de vidro, tomando-se como unitāria a taxa de contagem obtida com o volume de $25 \mathrm{ml}$. E também apresentado o fator de geometria $\left(f_{+}\right)$relativo ao tubo de vidro, baseando-se no volume de $5 \mathrm{ml}$.

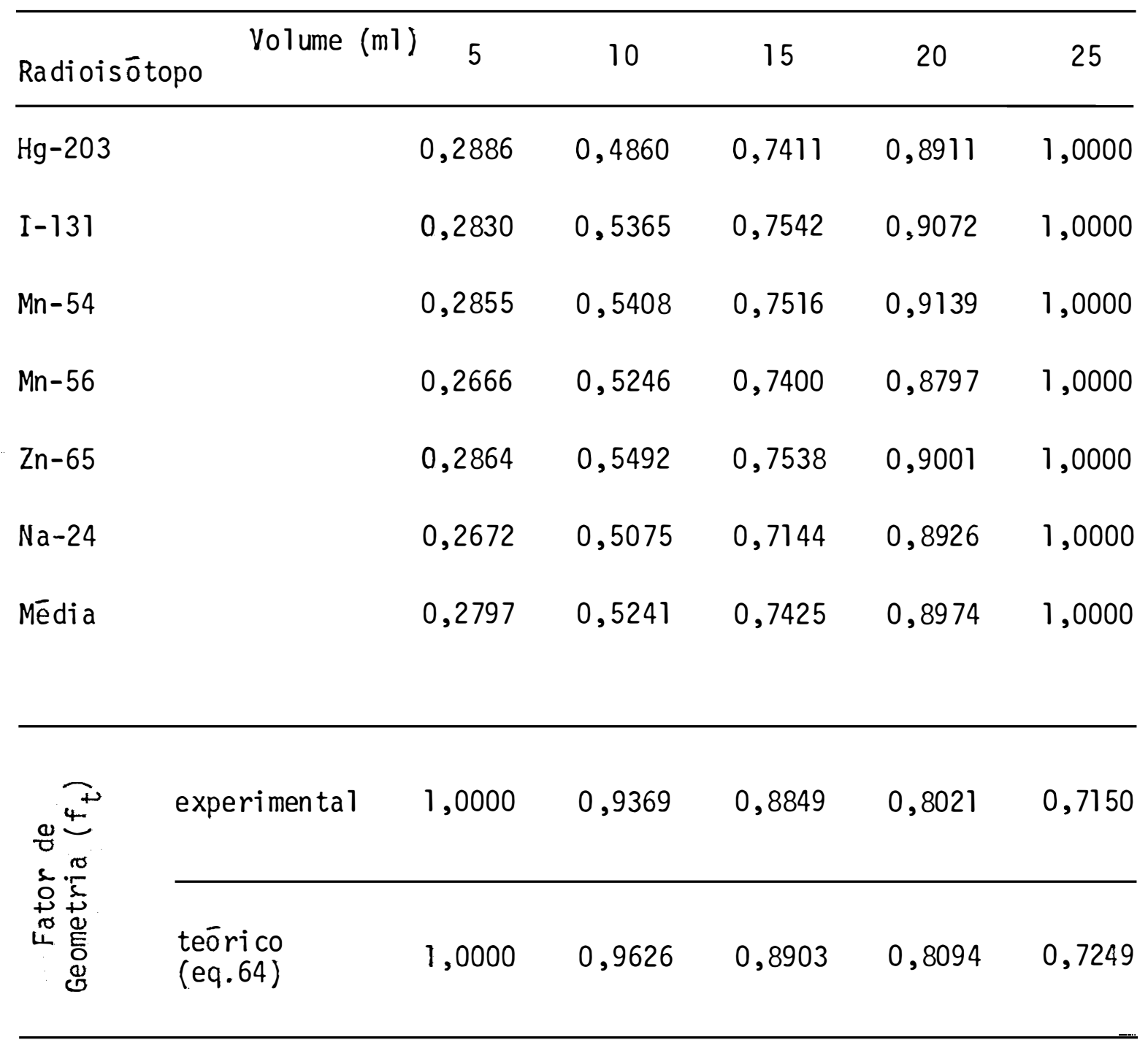




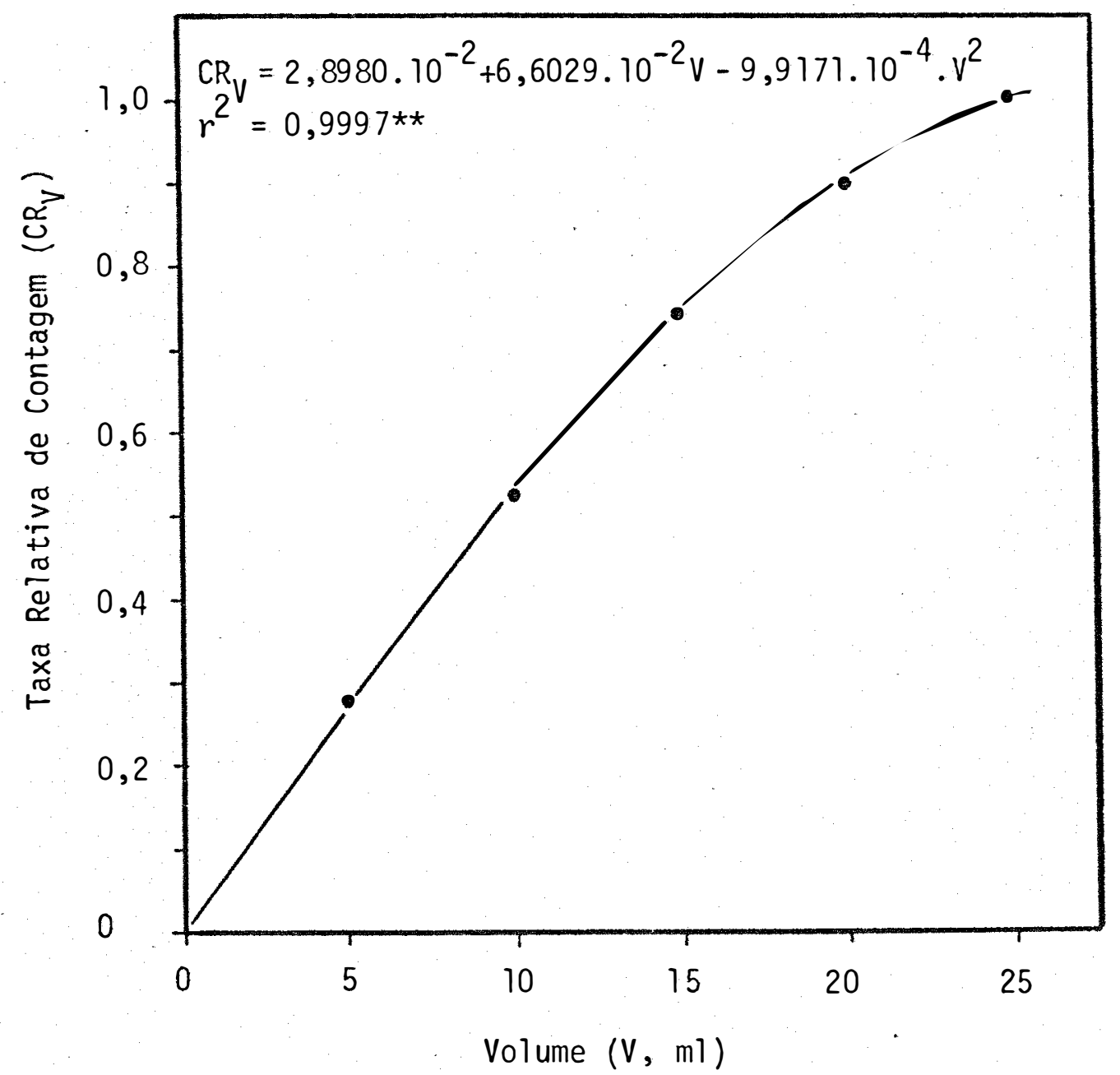

Figura 20 - Taxa relativa de contagem (média de sete radioisōtopos) em função do volume da amostra colocada em tubo de vidro, tomando-se como unitária a taxa de contagem obtida com o volume de $25 \mathrm{ml}$. 


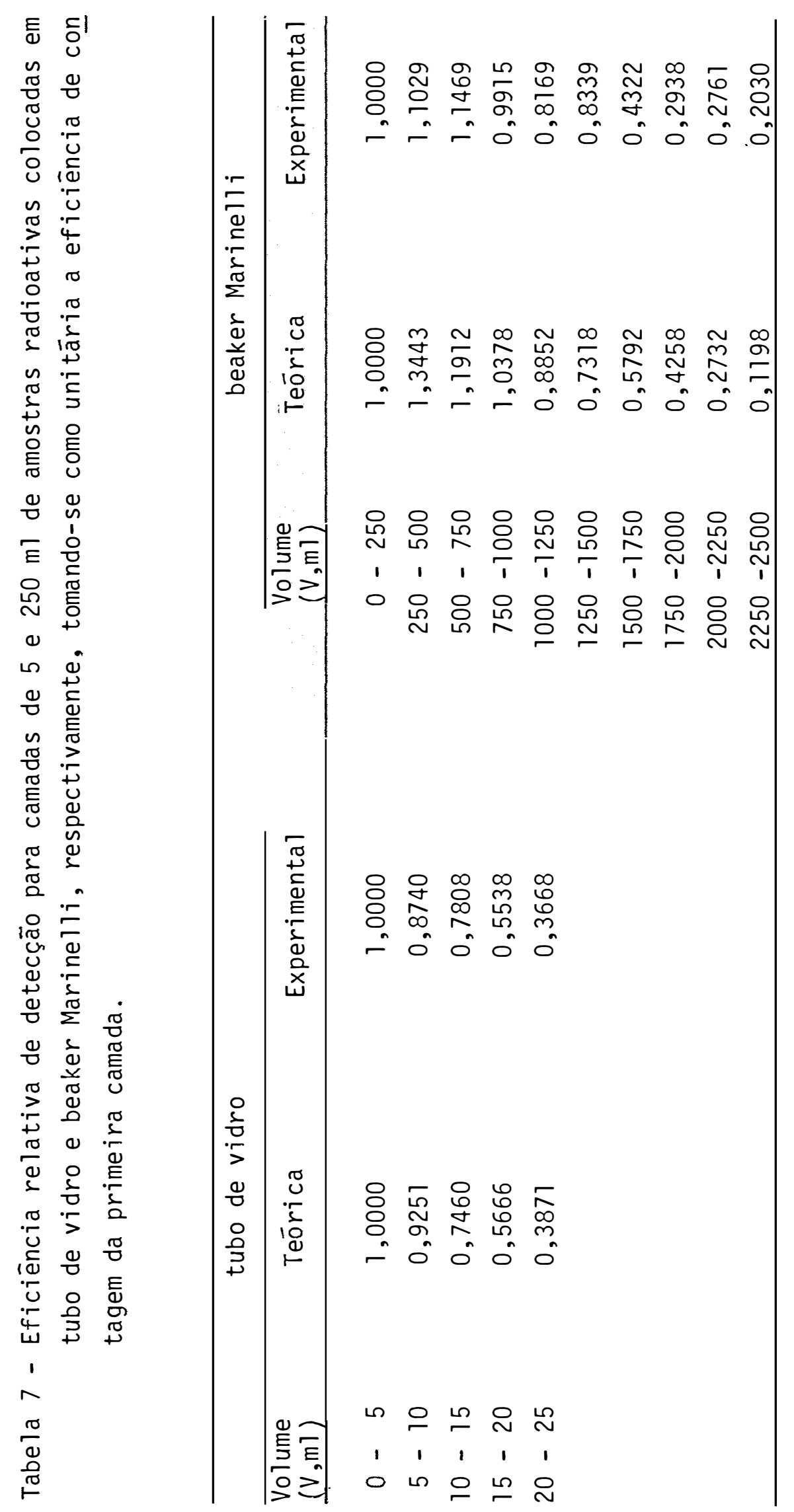




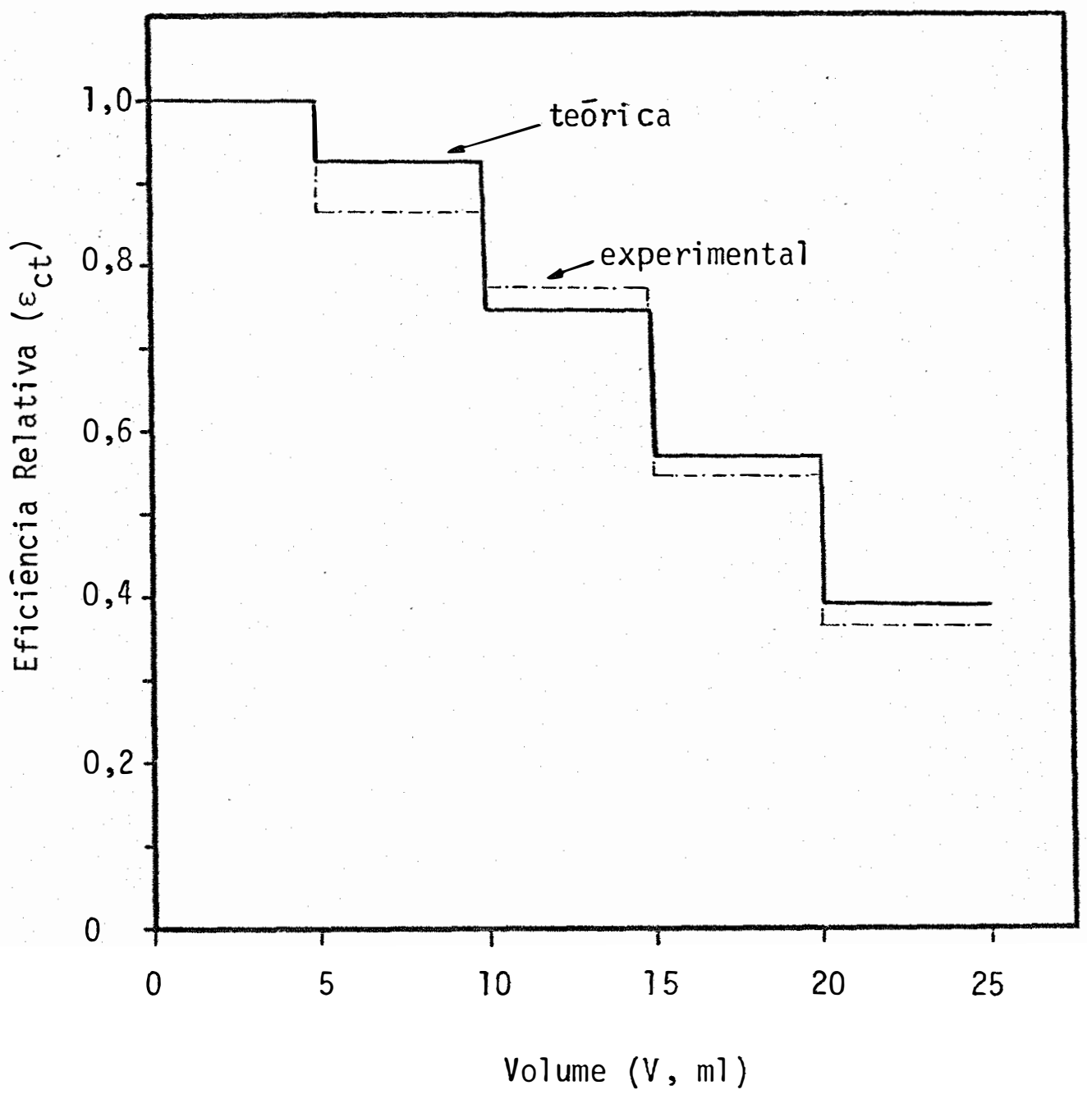

Figura 21 - Eficiência relativa de detecção $\left(\varepsilon_{c t}\right)$ para camadas de $5 \mathrm{ml}$ de amostras radioativas colocadas no tubo de vidro, tomando-se como unitāria a eficiência relativa de contagem da camada de 0 a $5 \mathrm{ml}$. 
nessa eficiência de deteç̧ão é de aproximadamente 18\% a partir da segunda camada, e sendo assim, a eficiencia de detecção para a camada de 25 a $30 \mathrm{ml}$ seria aproximadamente $20 \%$ e para a camada de 30 a $35 \mathrm{ml}$ seria praticamente desprezível em relação às anteriores. Esta diminuição de eficiência de detecção de cada camada, à medida que se aumenta o volume é devido à geometria de detec ção, pois os ātomos radioativos afastam-se do fundo do poço do cristal cintilador e a radiação gama emitida na desintegração tem maior chance de não sofrer interação com o detector, e com is to diminuindo a eficiēncia. Em outras palavras, à medida que se au menta o volume, diminui o āngulo sōlido para interação da radiação gama com o detector.

Com base na equação 62, o fator de geometria relativo ao tubo de vidro ( $f_{t}$, equação 39 ) pode ser dado pela equação:

$f_{t}=-5,2424.10^{-1} V^{-1}+1,1944-1,7940.10^{-2} \mathrm{~V}$

Os valores de $f_{t}$ em função do volume da amostra no tubo de vidro são mostrados na tabela 6 e visualizados na figura 22 . Pela figu ra observa-se que o fator de geometria, ou seja, a eficiência re. lativa de detecção $\left(\varepsilon_{R t}\right)$ diminui com o aumento do volume da amos tra radioativa, independentemente da energia da radiação gama.

Como foi mencionado, a eficiência de detecção em tubo de vidro para outros volumes $\left(\varepsilon_{t V}\right)$ pode ser calculada pela equação 40 . Substituindo o valor de $\varepsilon_{t 5}$, dado pela equação 61 , e $f_{t}$, dado pe la equação 64 , tem-se:

$$
\begin{aligned}
\varepsilon_{t V}= & \left(-5,2424 \cdot 10^{-1} V^{-1}+1,1944-1,7940 \cdot 10^{-2} V\right) . \\
& \cdot\left(1,08765+0,1111 E_{\gamma}\right) \cdot e^{-2,2255 E_{\gamma}}
\end{aligned}
$$

A tabela 5 e figura 23 apresentam a eficiēncia de detecção para alguns radioisōtopos em todos os volumes no tubo de vidro, e na figura 15 é mostrada a eficiência de detecção em função da energia da radiação gama, para a detecção em vários volumes dentro do tubo de vidro.

7.3. Eficiência de detecção de radioisōtopos em beaker Marinelli Os espectros de energia obtidos com $2500 \mathrm{ml}$ de solução radioativa no beaker Marinelli são apresentados nas figuras 11 - $203 \mathrm{Hg}$, 


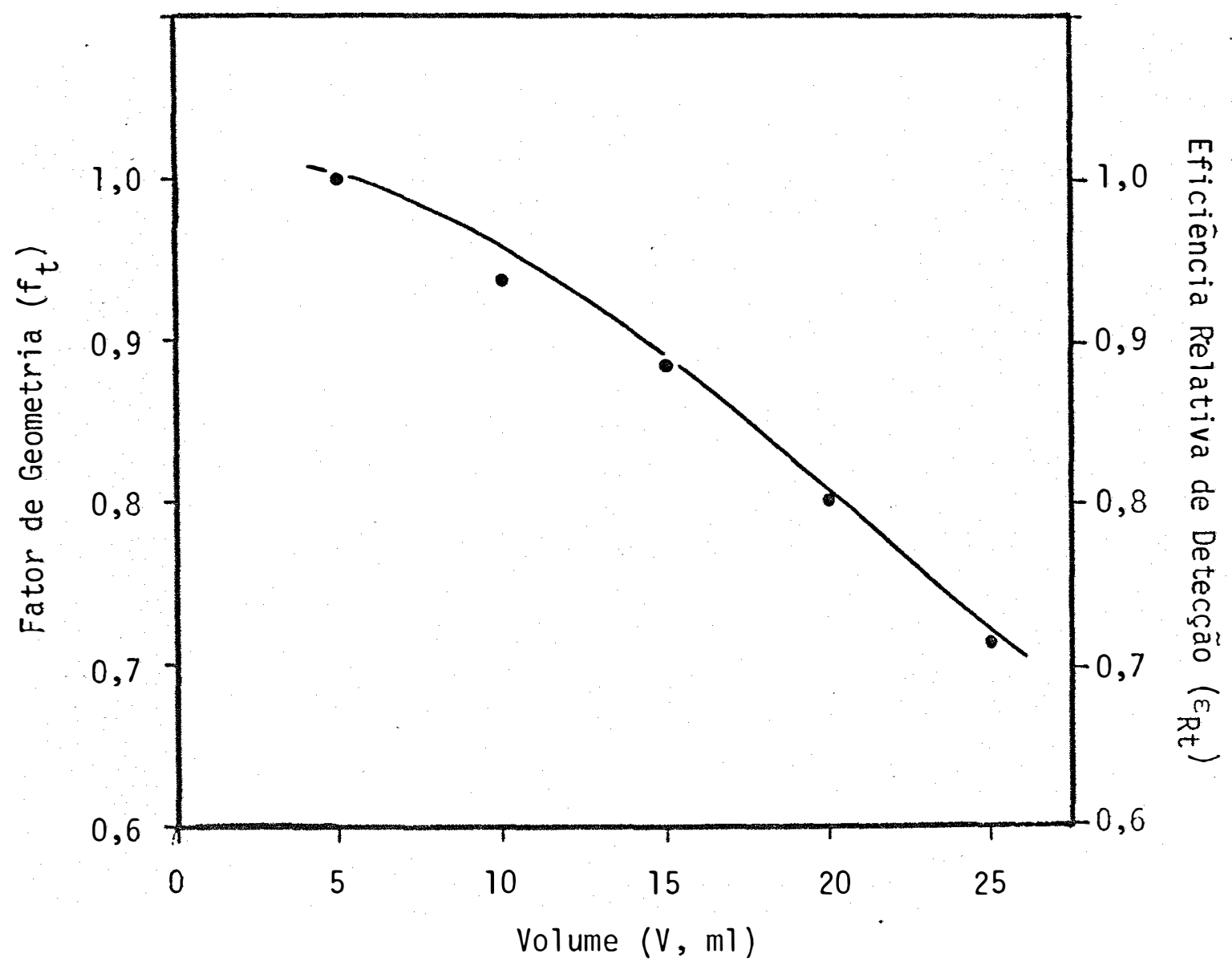

Figura 22 - Fator de geometria $\left(f_{t}\right)$ ou eficiência relativa de detecção $\left(\varepsilon_{R t}\right)$ em função do volume da amostra (V) colocada em tubo de vidro tomando-se como unitāria a eficiência relativa ob tida com $5 \mathrm{ml}$. 


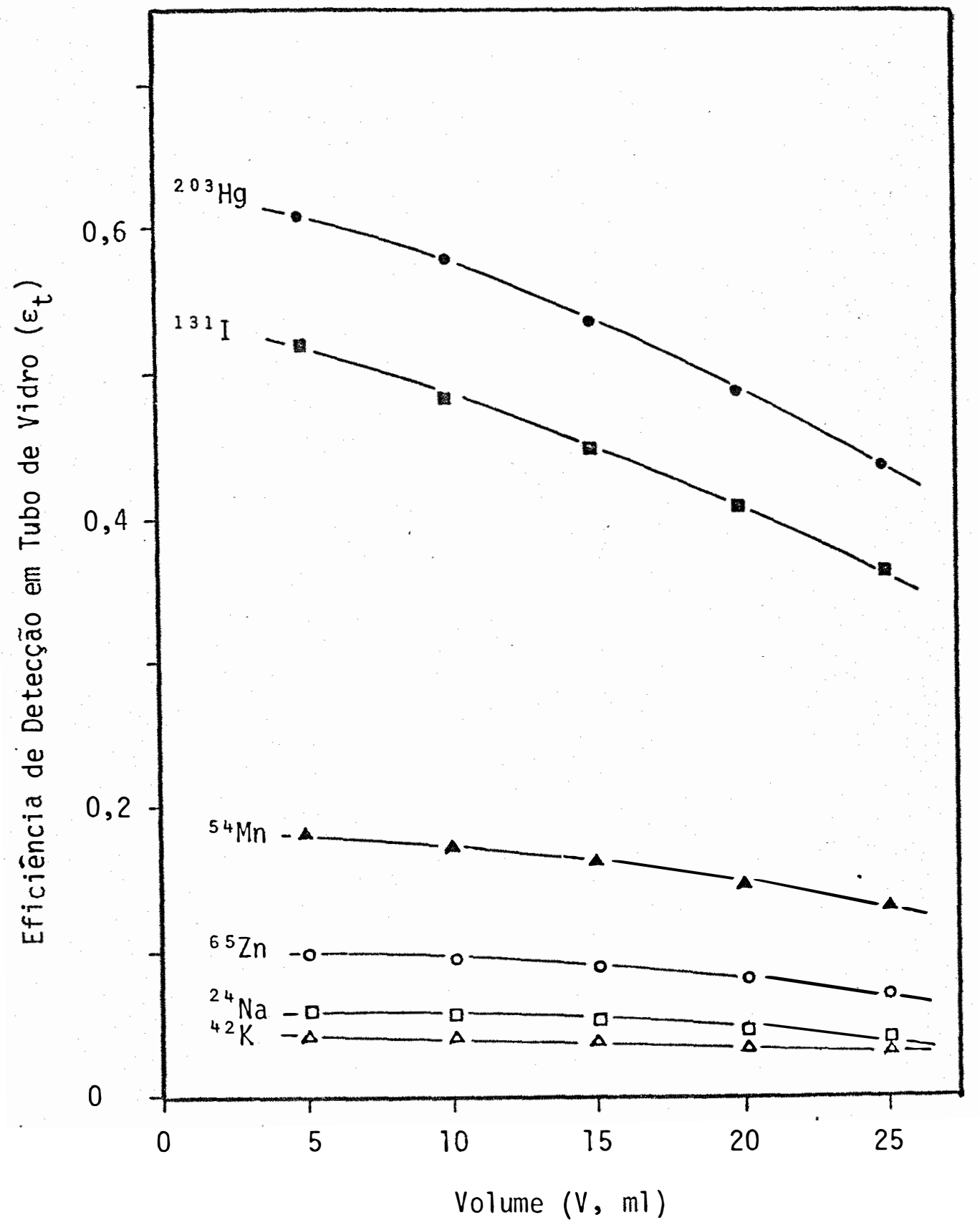

Figura 23 - Eficiência de deteç̧ão para alguns radioisōtopos em tubo de vidro $\left(\varepsilon_{t V}\right)$ em função do volume da amostra (V). 
$12-{ }^{54} \mathrm{Mn}, 13-{ }^{65} \mathrm{Zn}, 16-{ }^{131} \mathrm{I}, 17-{ }^{24} \mathrm{Na}$ e $18-{ }^{42} \mathrm{~K}$.

A tabela 8 e figura 24 apresentam os dados da razão $R^{\prime}$ (equação 44 ) entre as taxas de contagem líquida obtidas com amostras de mesma atividade no beaker Marinelli - $2500 \mathrm{ml}$ e no tubo de vidro $5 \mathrm{ml}$. A relação entre $R^{\prime}$ e a energia da radiação gama $\left(E_{\gamma}\right) \bar{e}$ da da pela equação:

$$
\begin{aligned}
& R^{\prime}=0,07897 \cdot e^{0,5039 E_{\gamma}} \\
& r=0,9741 \text { (sig. } 1 \%)
\end{aligned}
$$

Substituindo o valor de $R^{\prime}$ (equação 66) e $\varepsilon_{t 5}$ (equação 61) na equação 45, tem-se a eficiência de detecção no beaker Marinelliem função da energia da radiação gama, para o volume de $2500 \mathrm{ml}$ :

$\varepsilon_{M 2500}=\left(0,07897 \cdot e^{\left.0,5039 E_{\gamma}\right) \cdot\left(1,08765+0,1111 E_{\gamma}\right) \cdot e^{-2,2255 E_{\gamma}}}\right.$

ou

$$
\varepsilon_{M 2500}=\left(0,08589+0,008774 E_{\gamma}\right) \cdot e^{-1,7216 E_{\gamma}}
$$

Os dados das taxas relativas de contagem para os volumes de 250 a $2500 \mathrm{ml}$, de $250 \mathrm{em} 250 \mathrm{ml}$, são mostrados na tabela 9 e visuali zados na figura 25. Nota-se tambēm que as taxas relativas obtidas nos diversos volumes independem da energia da radiação gama, como na detecção em tubo de vidro. Com os valores médios de cada volume, foi obtida uma relação entre a taxa relativa de conta gem em função do volume da amostra colocada no beaker Marinelli:

$$
\begin{aligned}
& C R_{V}=-6,5168 \cdot 10^{-2}+8,2494 \cdot 10^{-4} V-1,6044 \cdot 10^{-7} V^{2} \\
& r^{2}=0,9990 \text { (sig. } 1 \% \text { ) }
\end{aligned}
$$

Do mesmo modo que o tubo de vidro, pode-se estimar a eficiência relativa de detecção de cada camada de $250 \mathrm{ml}$ adicionada ao beaker Marinelli, tomando-se como unitāria a dos primeiros $250 \mathrm{ml}$. Empregando-se uma equação simil ar à 63, tem-se:

$$
\varepsilon_{C M}=\frac{C R_{V}-C R_{V-250}}{C R_{250}}
$$

sendo: $\varepsilon_{C M}=$ eficiência relativa de detecção no beaker Marinelli 
Tabela 8 - Razão ( $R^{\prime}$ ) entre as taxas liquidas de contagem obtidas com amostras de mesma atividade, colocadas no beaker Marinelli - $2500 \mathrm{ml}$ e no tu bo de vidro - $5 \mathrm{ml}$, em função da energia da radiação gama $(E \gamma)$.

\begin{tabular}{ccc}
\hline Radioisōtopo & Energia da Radiação Gama $\left(E_{\gamma}, \mathrm{MeV}\right)$ & $\mathrm{R}^{\prime}$ \\
\hline $\mathrm{Hg}-203$ & 0,279 & 0,0903 \\
$\mathrm{I}-131$ & 0,364 & 0,0937 \\
$\mathrm{Mn}-54$ & 0,835 & 0,1162 \\
$\mathrm{Mn}-56$ & 0,847 & $.0,1372$ \\
$\mathrm{Zn}-65$ & 1,115 & 0,1277 \\
$\mathrm{Na}-24$ & 1,368 & 0,1563 \\
$\mathrm{Mn}-56$ & 1,811 & 0,1998 \\
\end{tabular}




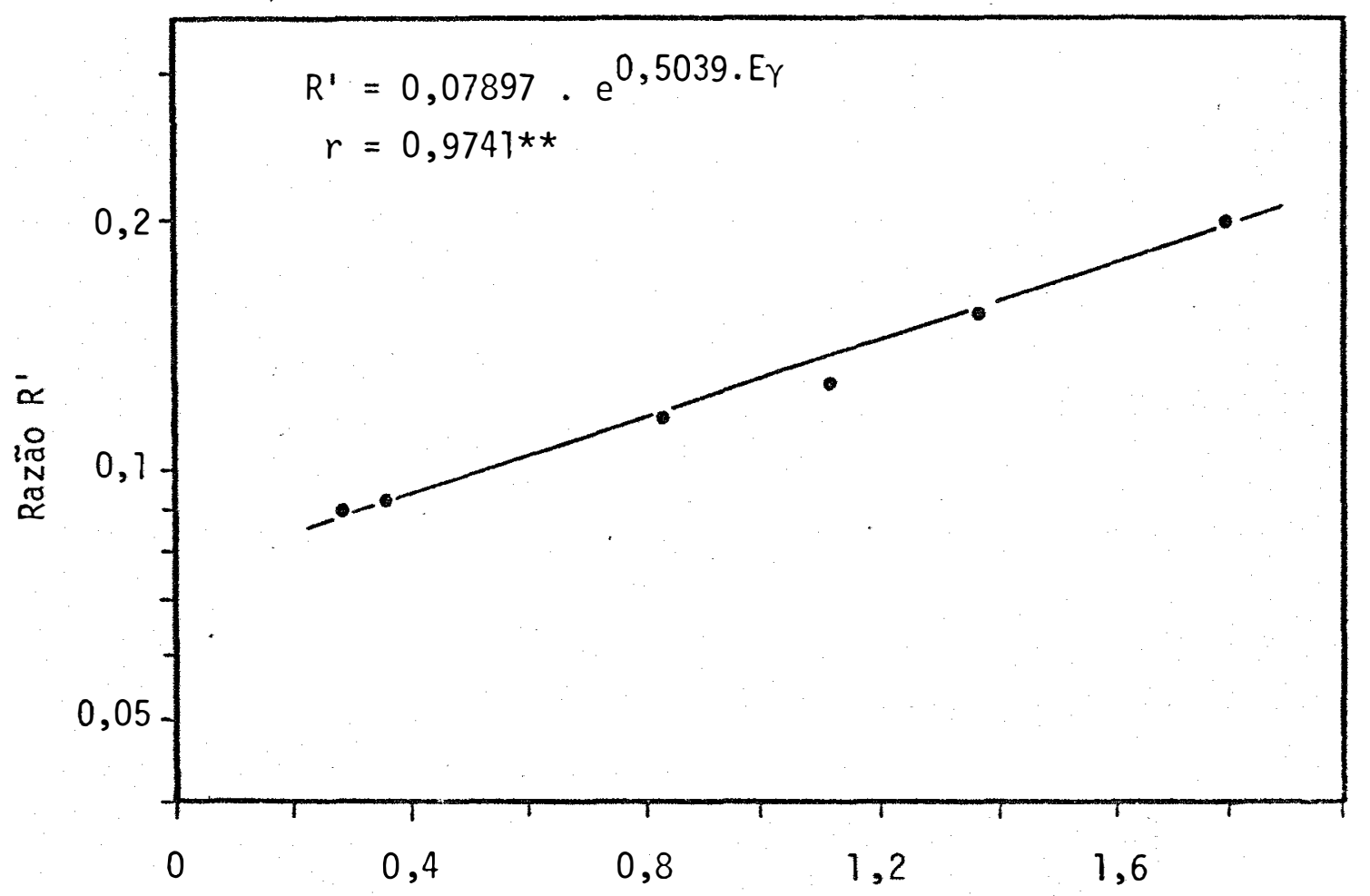

Energia da Radiação Gama (Eץ, MeV)

Figura 24 - Razão $\left(R^{\prime}\right)$ entre as taxas liqquidas de contagem obtidas com amostras de mesma atividade colocadas em beaker Marinelli $2500 \mathrm{ml}$ e em tubos de vidro - $5 \mathrm{ml}$, em função da energia da radiação gama $(E Y)$ : 


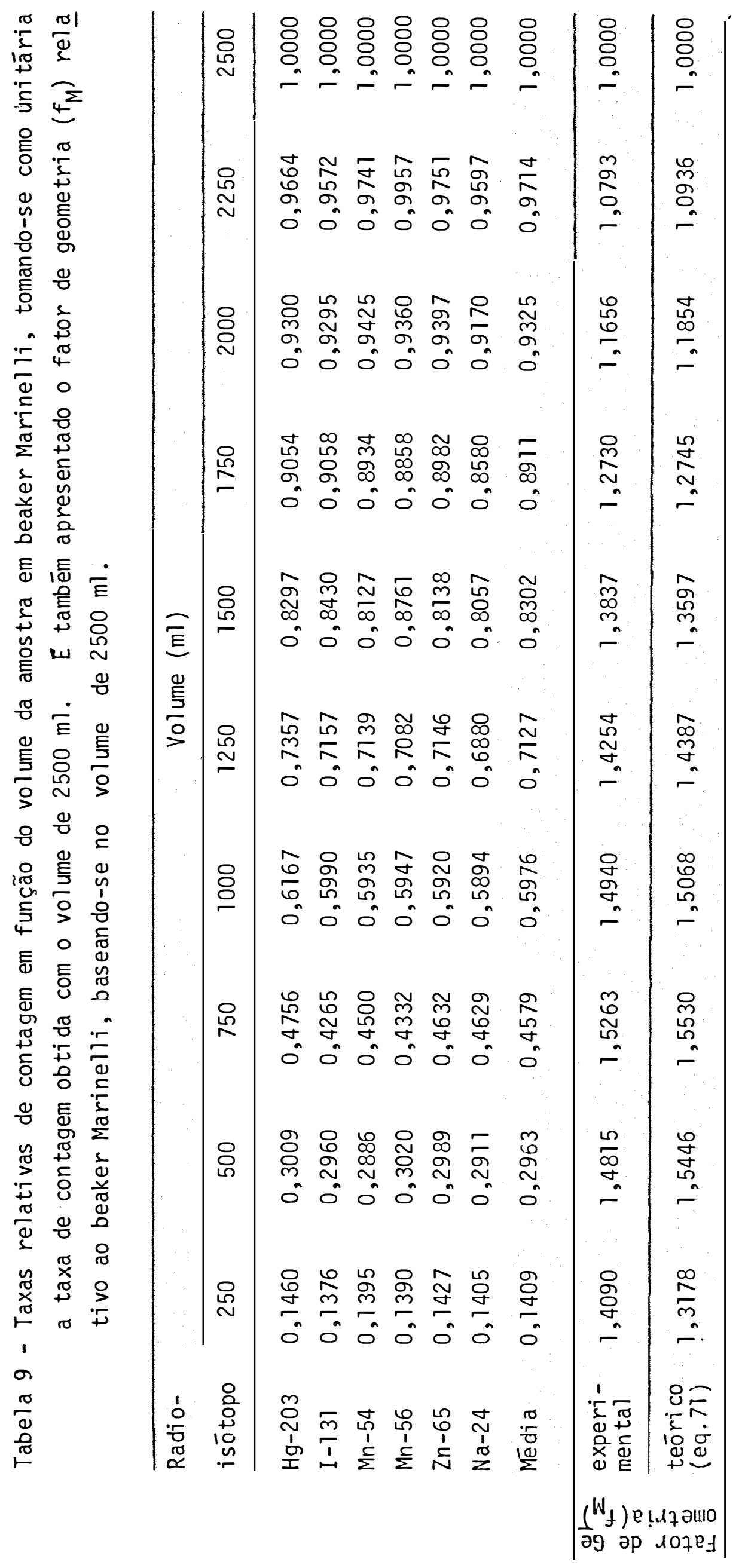




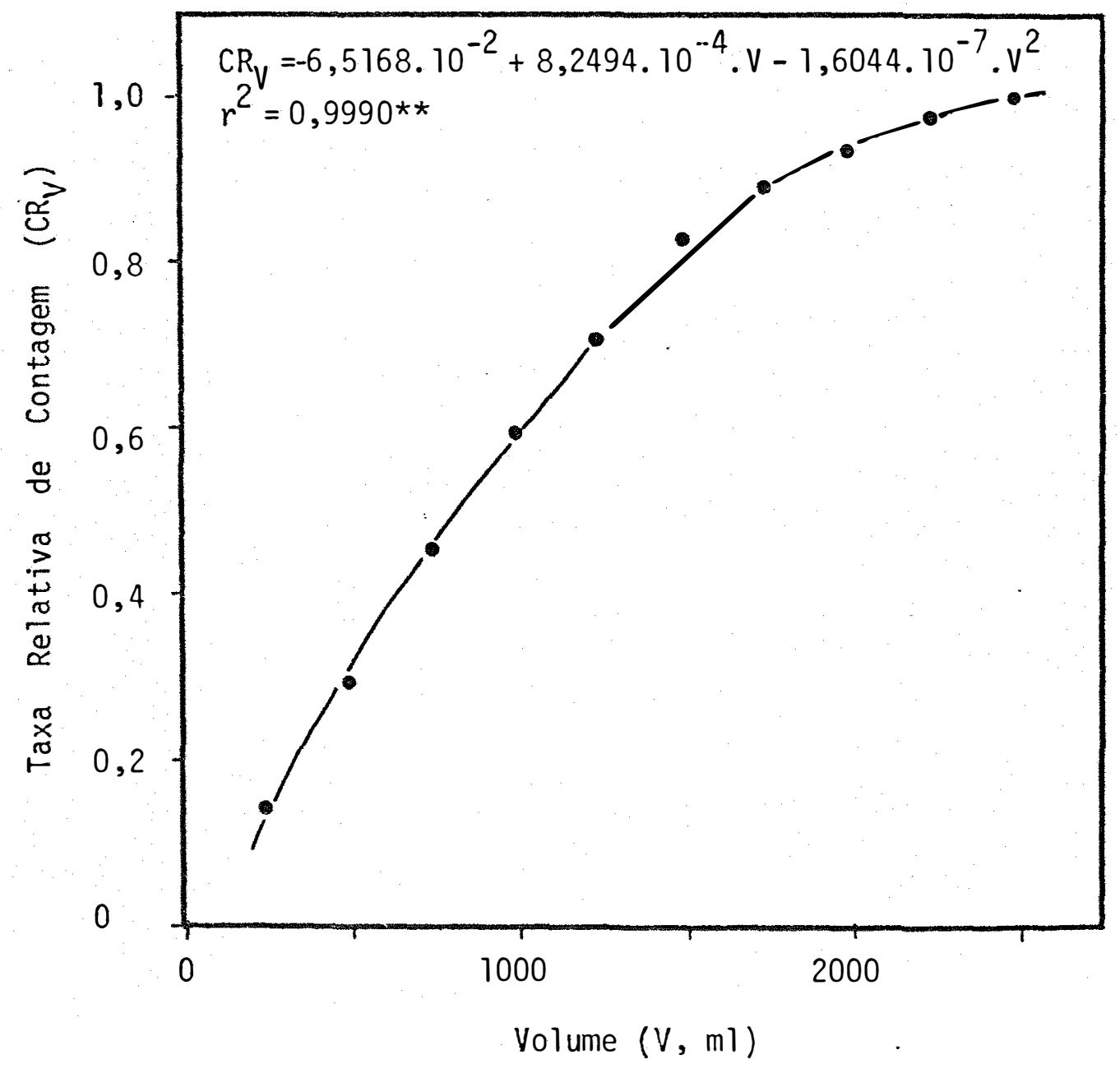

Figura 25 - Taxa relativa de contagem (média de sete radioisōtopos) em função do volume da amostra colocada em beaker Marinerli, tomando-se como unitária a taxa de contagem obtida com a amostra de $2500 \mathrm{ml}$. 
para camada de $250 \mathrm{ml}$, compreendida entre o volume de $\mathrm{V}$. e $\mathrm{V}-250 \mathrm{ml}$.

$C R_{V}, C R_{V-250}$ e $C R_{250}$ = taxas relativas de contagem devido aos vo lumes V, V-250 e $250 \mathrm{ml}$, respectivamente.

Os dados de eficiência de detecção de cada camada de $250 \mathrm{ml}$ são mostrados na tabela 7 e figura 26. Devido à reentrāncia existen te no fundo do beaker Marinelli; as primeiras quatro camadas de $250 \mathrm{ml}$ formam anēis, estando os primeiros $250 \mathrm{ml}$ em volta do cristal cintilador na sua parte inferior, enquanto que os anéis de 250 - 500 e 500 - $750 \mathrm{ml}$ estão mais simétricos ao detector, e o 40 anel (750 - $1000 \mathrm{ml})$ em volta do detector na sua parte supe rior. Com base nesta geometria de detecção era de se esperar, portanto, que as 2a. e 3a. camadas, 250 - 500 e 500 - $750 \mathrm{ml}$, res pectivamente, apresentassem valores maiores na eficiéncia relati va de detecção do que os do 10 e 40 anēis. E também notado que com o aumento de volume a ser detectado, a eficiência relativade cada camada diminui aproximadamente $15,3 \%$ a partir da $2 a$. cama da.

Com base na equação 69, o fator de geometria relativo ao beaker Marinelli ( $f_{M}$, equação 47) vale:

$f_{M}=-1,6384 \cdot 10^{2} V^{-1}+2,0740-4,0336 \cdot 10^{-4} \mathrm{~V}$

Os valores de $f_{M}$ em função do volume da amostra no beaker Mari nelli são mostrados na tabela 9 e representados na figura 26 . 0b serva-se pela figura que o fator de geometria $f_{m}$ ou a eficiencia relativa de detecção $\left(\varepsilon_{\mathrm{RM}}\right)$ tem um comportamento diferente do tubo de vidro. De modo independente da energia da radiação, a eficiência relativa aumenta até aproximadamente $750 \mathrm{ml}$, diminuindo em seguida.

E mais conveniente para discussão posterior, ter a eficiência re. lativa tomando-se como unitária a obtida com a amostra de $250 \mathrm{ml}$. Neste caso a eficiência relativa $\varepsilon_{R M}^{\prime} \bar{e}$ dada pela equação:

$$
\varepsilon_{R M}^{\prime}=\frac{\varepsilon_{M V}}{\varepsilon_{M 250}}=\frac{\varepsilon_{M V} / \varepsilon_{M 2500}}{\varepsilon_{M 250} / \varepsilon_{M 2500}}=\frac{f_{M V}}{f_{M 250}}
$$

onde $f_{M V}$ e $f_{M 250}$ representam os fatores de geometria para um da- 


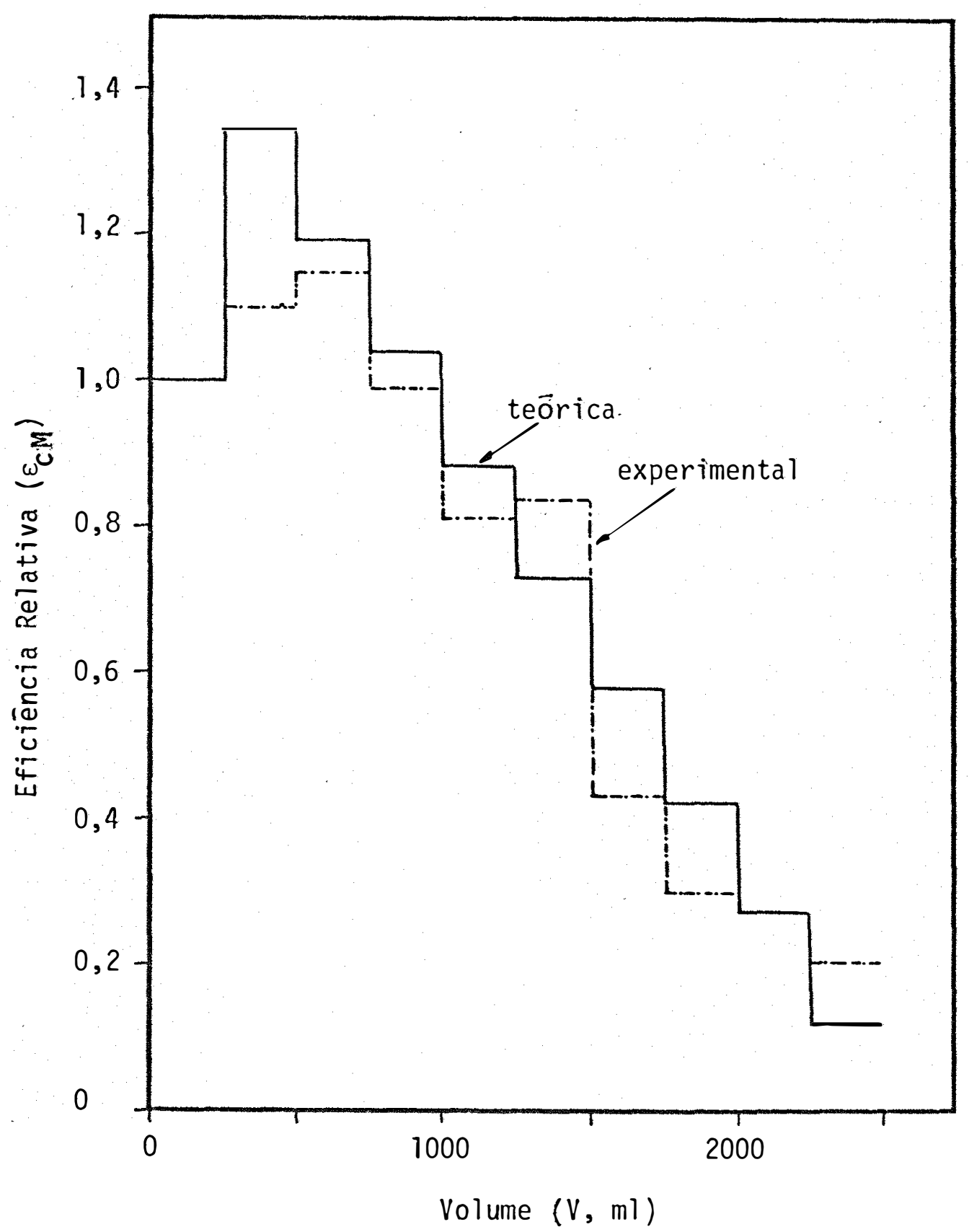

Figura 26 - Eficiência relativa de detecção $\left(\varepsilon_{c M}\right)$ para camadas de $250 \mathrm{ml}$ de amostras radioativas colocadas em beaker Marinelli, tomando-se unitária a eficiência relativa de contagem da camada de 0 a $250 \mathrm{ml}$. 
do volume $\underline{V}$ e para o volume de $250 \mathrm{ml}$, calculados de acordo com a equação 47 . Como comentado anteriormente, estes fatores $f_{M V} e$ $f_{\text {M250 }}$ representam, respectivamente, a eficiência relativa de deteç̧ão para um dado volume $\underline{V}$ e para o volume de $250 \mathrm{ml}$, tomandose como unitāria a eficiência de detecção obtida com $2500 \mathrm{ml}$, e são mostrados na figura 27.

Como jā foi mencionado, a eficiência de detecção para outros volumes em beaker Marinelli ( $\left.\varepsilon_{M V}\right)$ pode ser calculada pela equação 48. Substituindo o valor de $\varepsilon_{M 2500}$, dado pela equação 68 , e $f_{M}$, dado pela equação 71 , tem-se:

$$
\begin{aligned}
\varepsilon_{M V}= & \left(-1,6384 \cdot 10^{2} V^{-1}+2,0740-4,0336 \cdot 10^{-4} V\right) . \\
& \cdot\left(0,08589+0,008774 E_{\gamma}\right) \cdot e^{-1,7216 E_{\gamma}}
\end{aligned}
$$

A tabela 5 e figura 28 apresentam os valores da eficiência de de tecção para alguns radioisōtopos em função do volume no beaker Marinelli, e na figura 15 representa-se a eficiēncia de detecção em função da energia da radiação gama para a detecção em vārios volumes no beaker Marinelli.

7.4. Atividade específica mínima detectāvel

Fixando-se o tempo de detecção para a radiação de fundo $\left(t_{F}\right)$ em 100 e 1000 minutos, foram calculadas as atividades específicas mí nimas em função do tempo de deteç̧ão da amostra $\left(t_{B}\right)$ para se atingir os coeficientes de variação (CV) de 1 e 10\% para diferentes condições de detecção dos radioisōtopos ${ }^{20}{ }^{3} \mathrm{Hg},{ }^{131} \mathrm{I},{ }^{54} \mathrm{Mn}$, ${ }^{65} \mathrm{Zn},{ }^{24} \mathrm{Na}$ e ${ }^{42} \mathrm{~K}$. Para detecção em tubo de vidro foram fixados os volumes de 5 e $25 \mathrm{ml}$, enquanto que na detecção em beaker Mari nelli foram os de 500 e $2500 \mathrm{ml}$. As atividades específicas mí nimas nessas condições em função do tempo de detecção da amostra $\left(t_{B}\right)$ e para 100 e 1000 minutos de radiação de fundo, são dadas nas figuras 29 - 34 para coeficiente de variação de $1 \%$ e nas fí guras 35 - 40 para $10 \%$.

Para radioisótopos emissores de radiação gama de baixa energia $\left({ }^{20} \mathrm{Hg}\right.$, por exemplo), para se estimar com coeficiente de varia ção de $1 \%$ em 10 minutos de deteç̧ão da amostra e 100 minutos de detecção da radiação de fundo, as atividades específicas neces sārias são da ordem de $460 \mathrm{dpm} / \mathrm{ml}$ para tubos de vidro de $5 \mathrm{ml}$, 


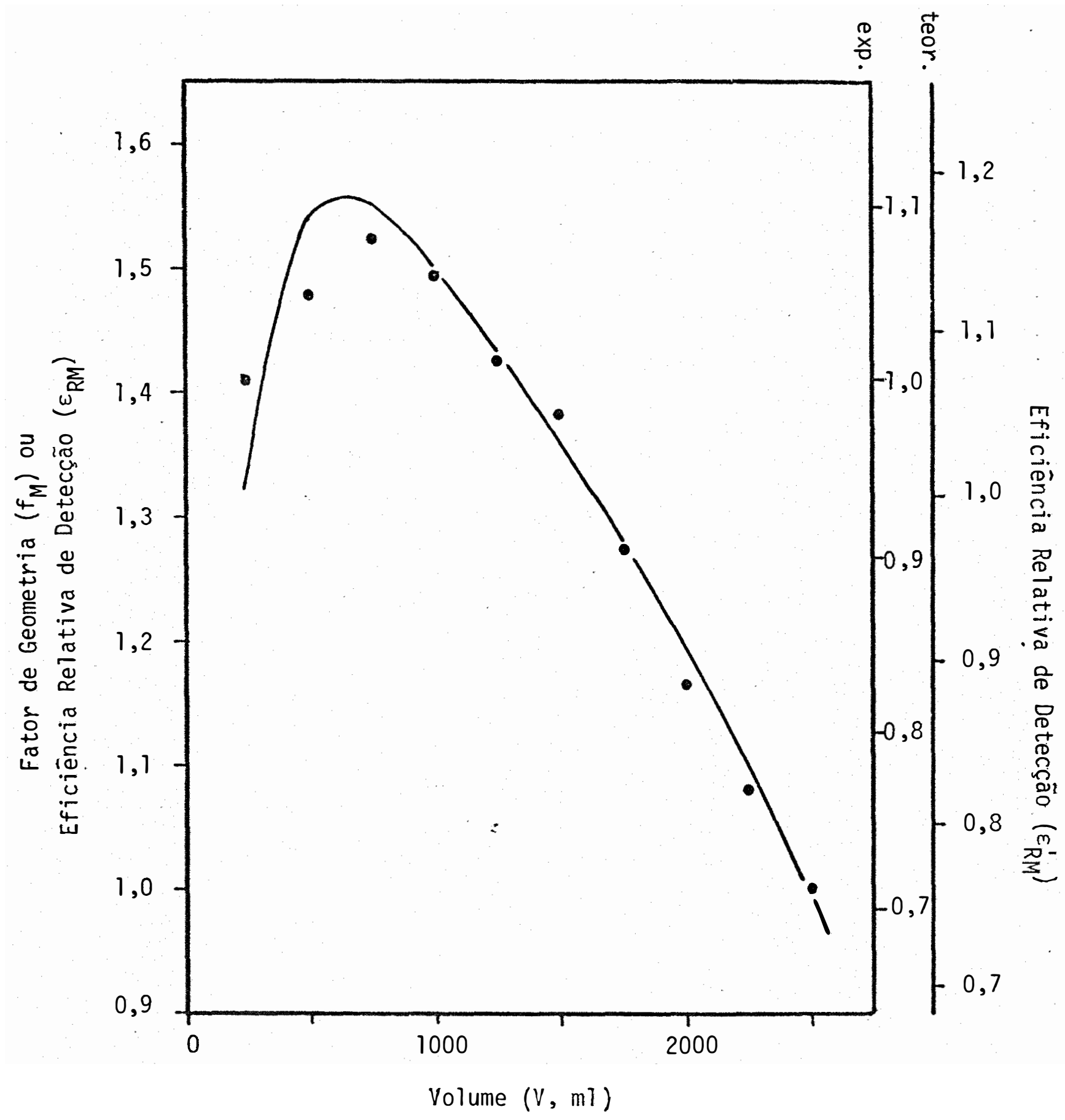

Figura 27 - Fator de geometria $\left(f_{M}\right)$ e eficiēncia relativa de detecção em função do volume da amostra colocada em beaker Marinelli, to mando-se como unitäria a eficiēncia relativa obtida com 2500 ml $\left(\varepsilon_{\mathrm{RM}}\right)$. E dada tambēm-a eficiēncia relativa de detecção tomando-se como unitäria a eficiēncia relativa obtida com amostra de $250 \mathrm{ml}\left(\varepsilon_{\mathrm{RM}}^{\prime}\right)$. 


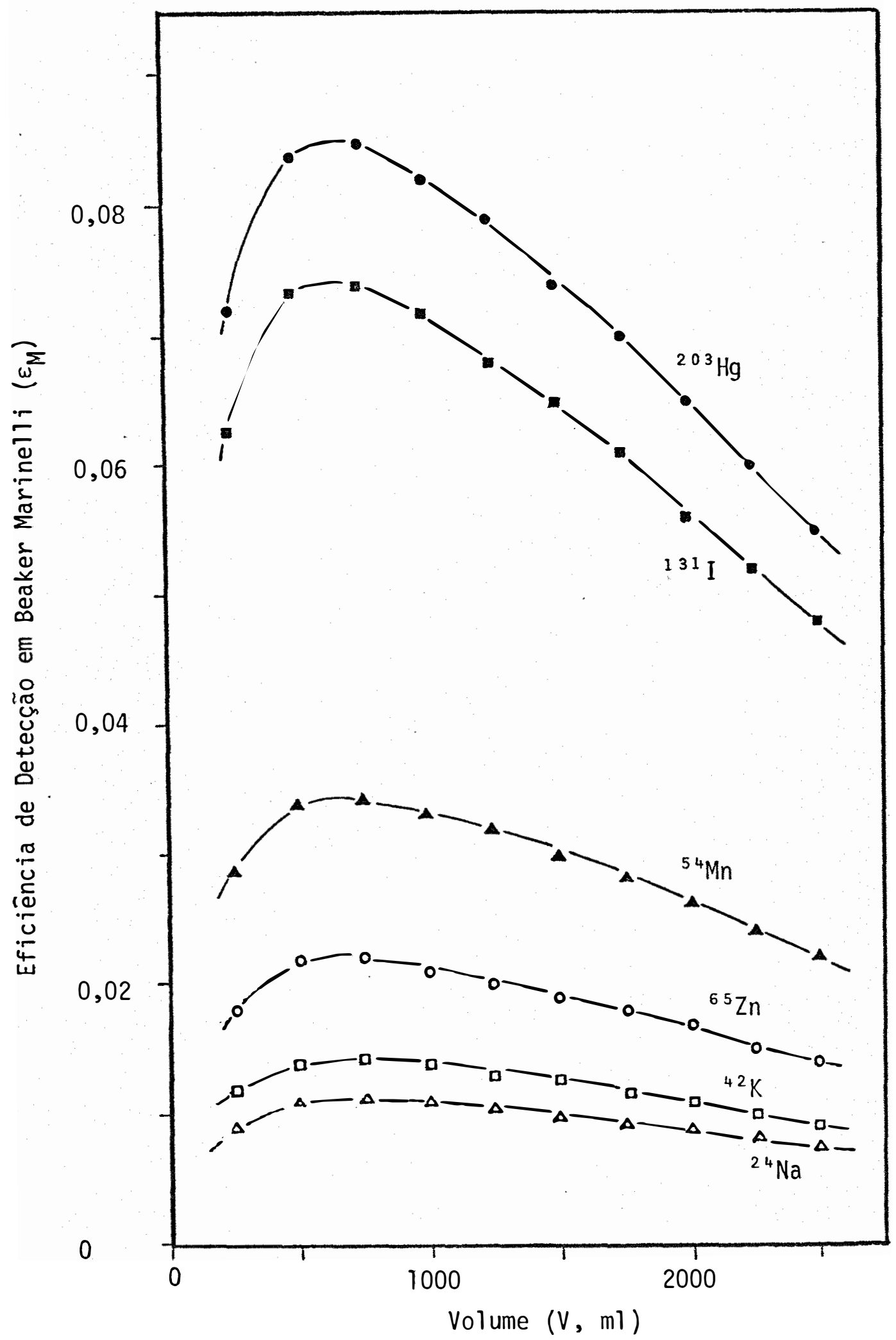

Figura 28 - Eficiēncia de detecção para alguns radioisōtopos em beaker Marinelli ( $\left.\varepsilon_{M V}\right)$ em função do volume da amostra. 


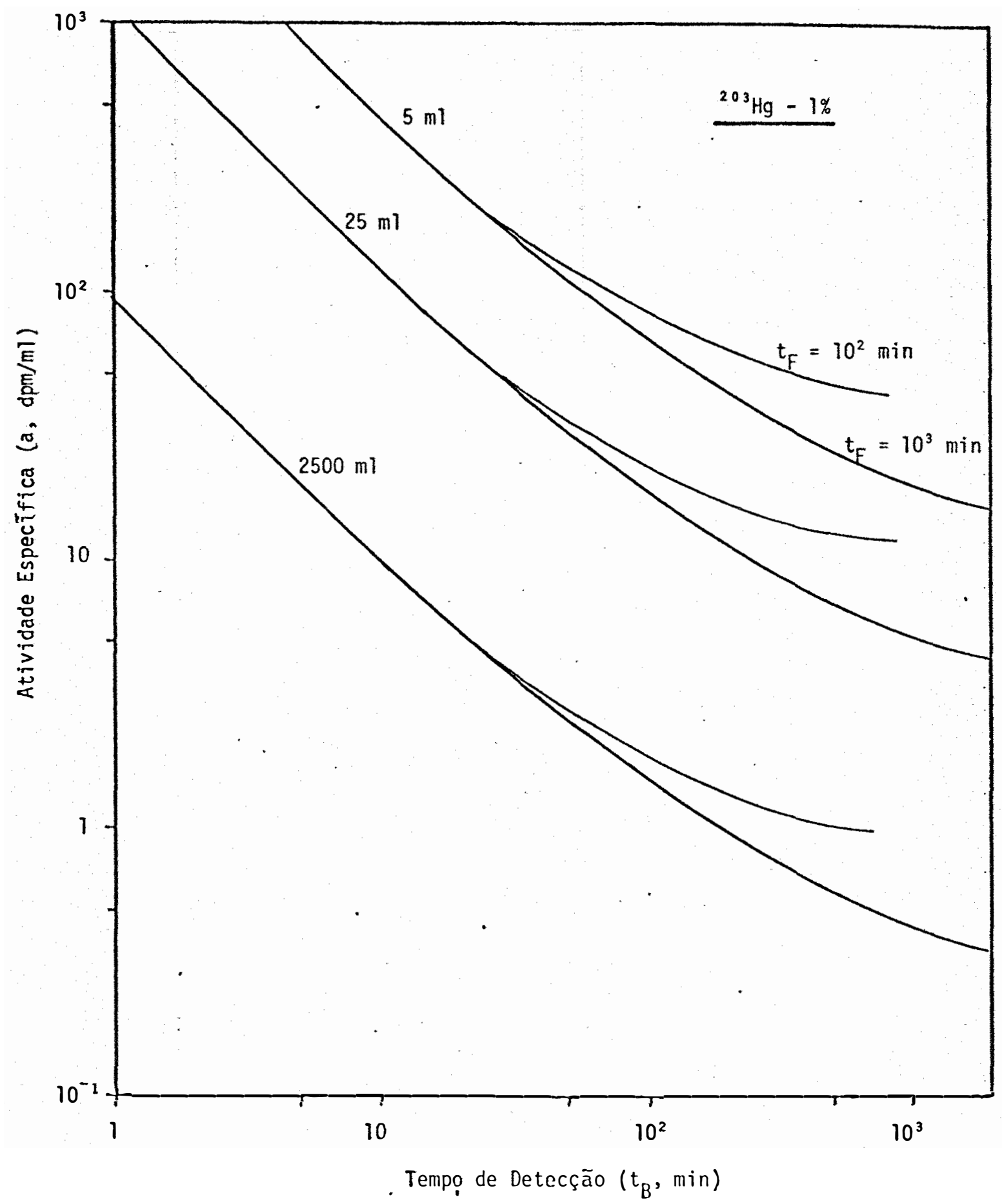

Figura 29 - Atividade especifica minima $(a, d p m / m l)$ para ${ }^{203} \mathrm{Hig}$, em função do tempo de detecção $\left(t_{B}, \min \right)$, para se atingir coeficiente de variação de $1 \%$, para amostras de 5 e $25 \mathrm{ml}$ colocadas em tubo de vidro, e de $2500 \mathrm{ml} \mathrm{em}$ beaker Marinelli. Tempo de contagem da radiação de fundo $t_{F}=100$ e 1000 minutos. 


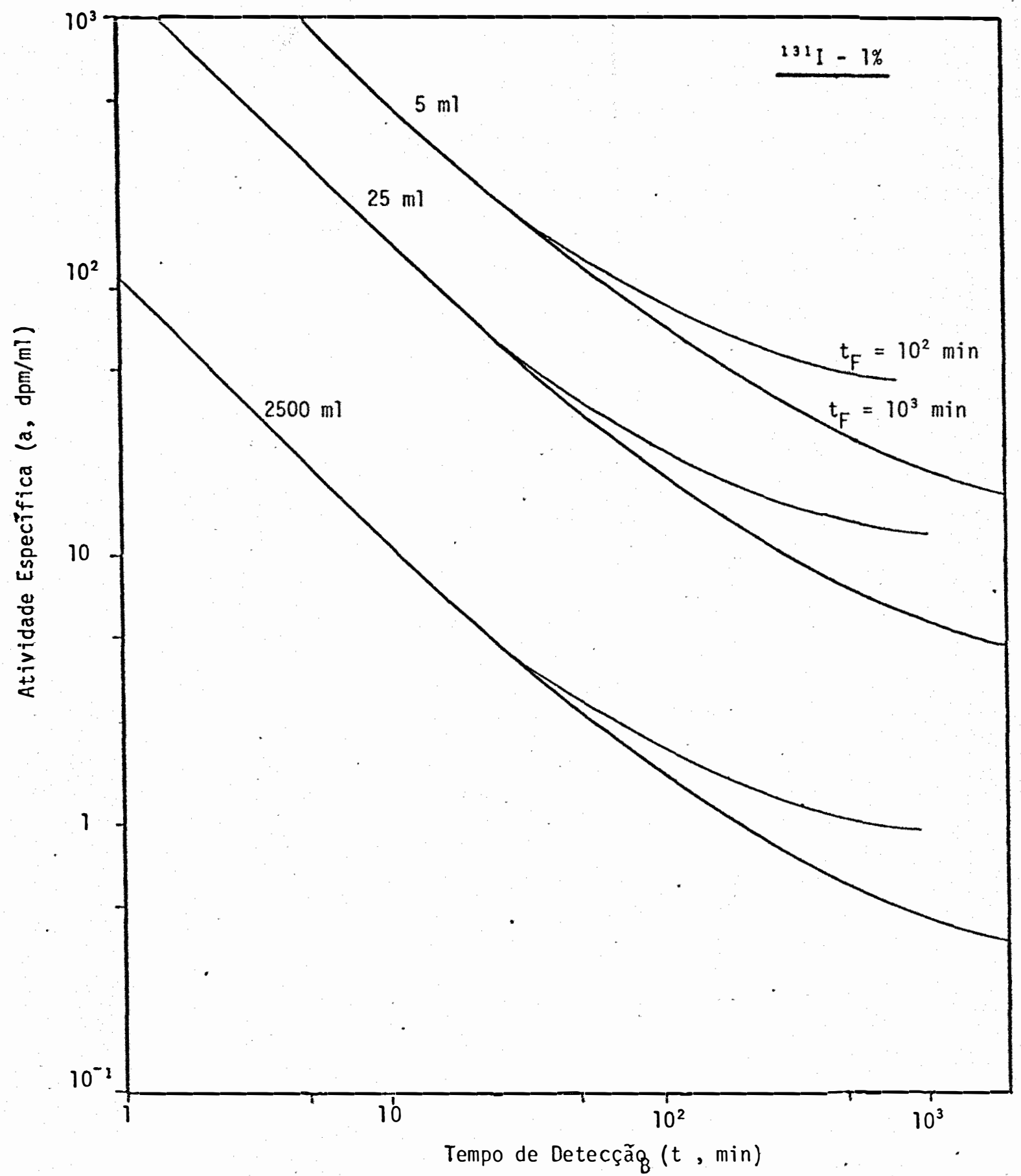

Figura 30 - Atividade especîfica mĩnima $(a, d p m / m l)$ para ${ }^{131} \mathrm{I}$ em função do tempo de detecção $\left(t_{B}\right.$, min $)$, para se atingir coeficiente de variação de $1 \%$, para amostras de 5 e $25 \mathrm{ml}$ colocada em tubo de vidro e de 500 e $2500 \mathrm{ml}$ em beaker Marinelli. Tempo de contagem da radiaçäo de fundo $t_{F}=100 \mathrm{e}$ 1000 minutos. 


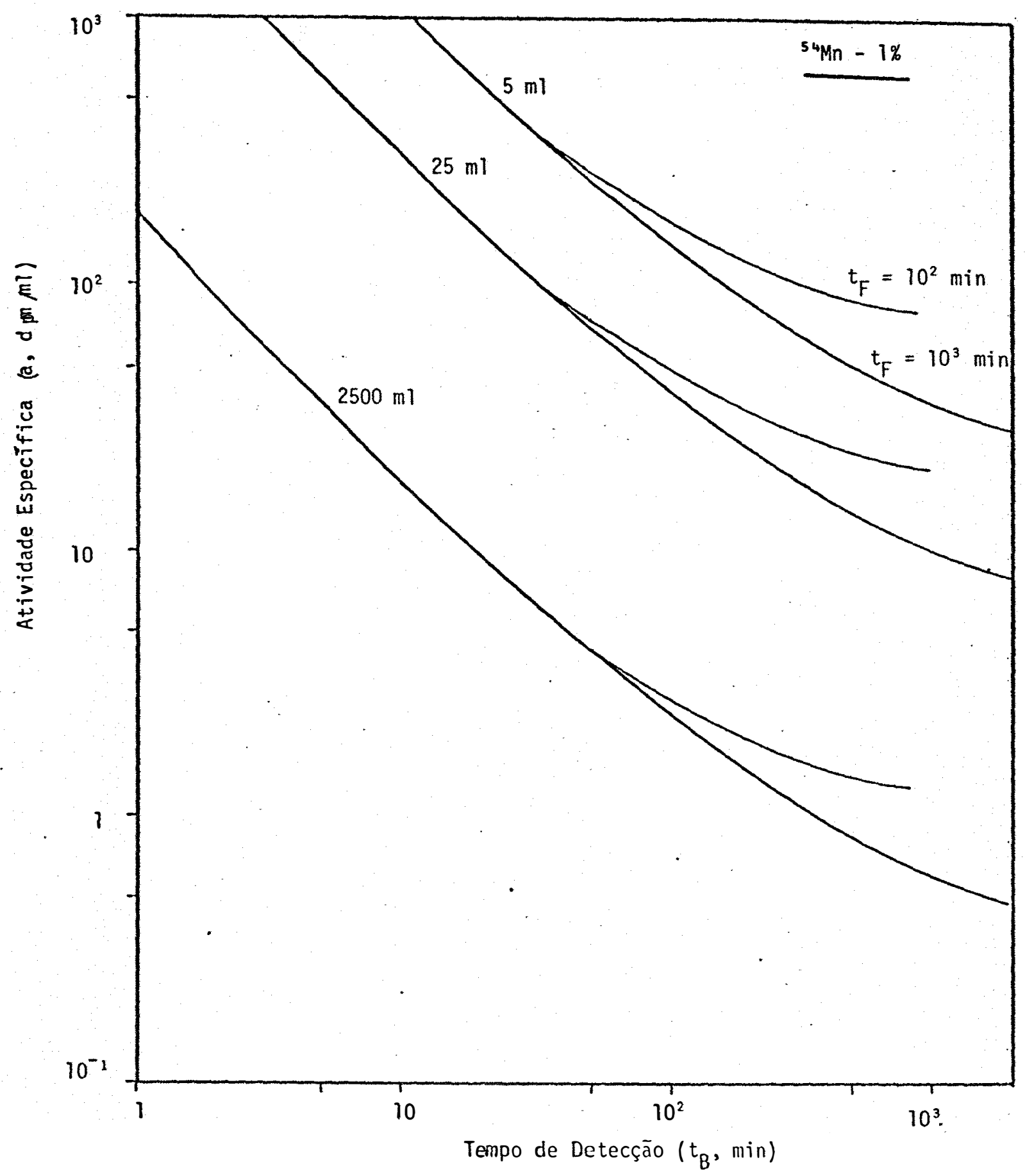

Figura 31 - Atividade específica minnima $(a, d p m / m l)$ para ${ }^{54} \mathrm{Mn}$ en função do tempo de detecção $\left(t_{B}\right.$, min), para atingir coeficiente de variação de $1 \%$, para amostras de 5 e $25 \mathrm{ml}$ colocada em tubo de vidro e de 500 e $2500 \mathrm{ml}$ em beaker Marinelli. Tempo de contagem da radiação de fundo $t_{F}=100 \mathrm{e}$ 1000 minutos. 


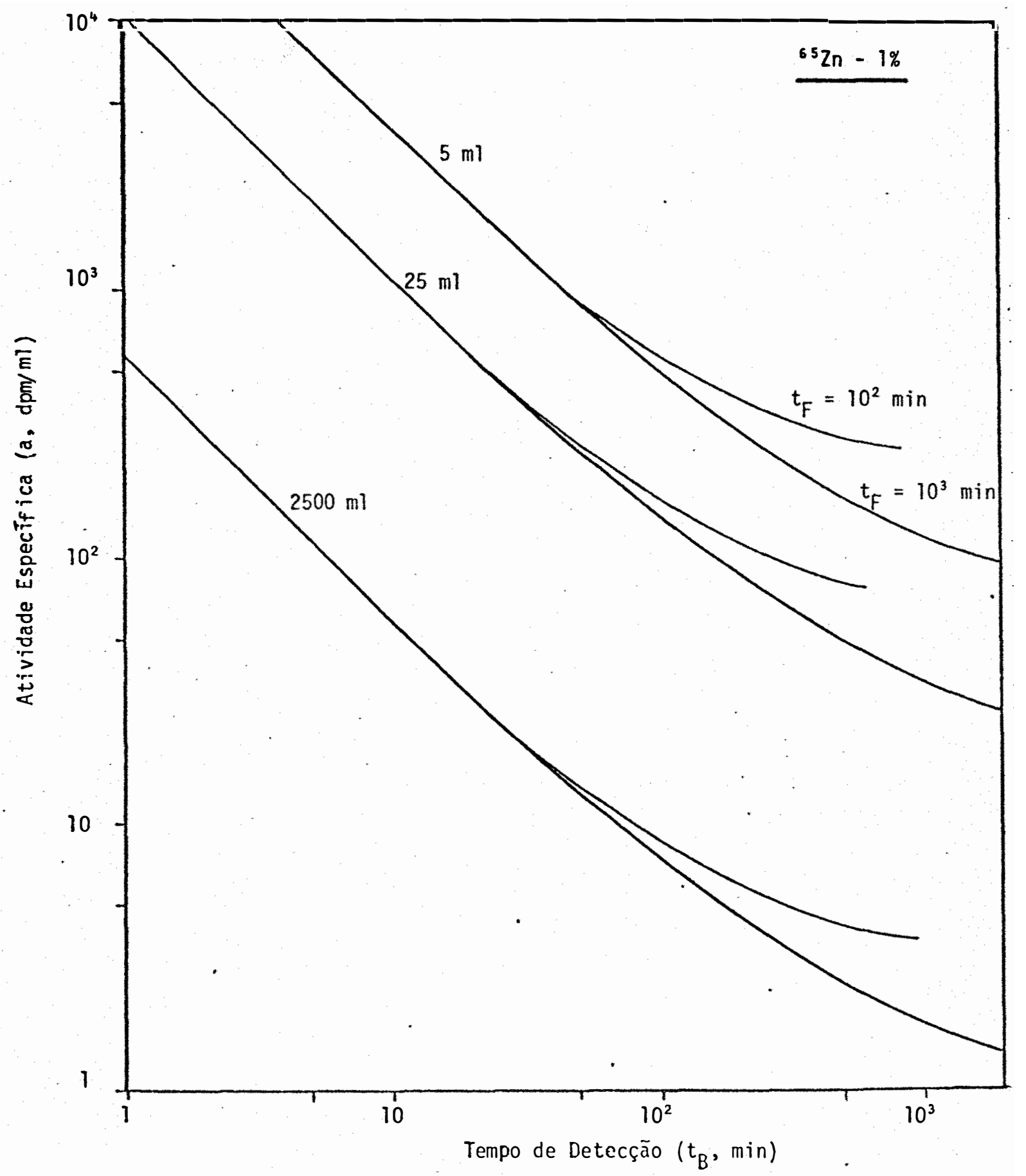

Figura 32 - Atividade específica minima $(a, d p m / m l)$ parą ${ }^{65} \mathrm{Zn}$, em função do tempo de detecção $\left(t_{B}, \min \right)$, para se atingir coeficiente de variação de $1 \%$ para amostras de 5 e $25 \mathrm{ml}$ colocada em tubo de vidro, e de $2500 \mathrm{ml} \mathrm{em}$ beaker Marinelli. Tempo de contagem da radiaçăo de fundo $t_{F}=100 \mathrm{e}$ 1000 minutos. 


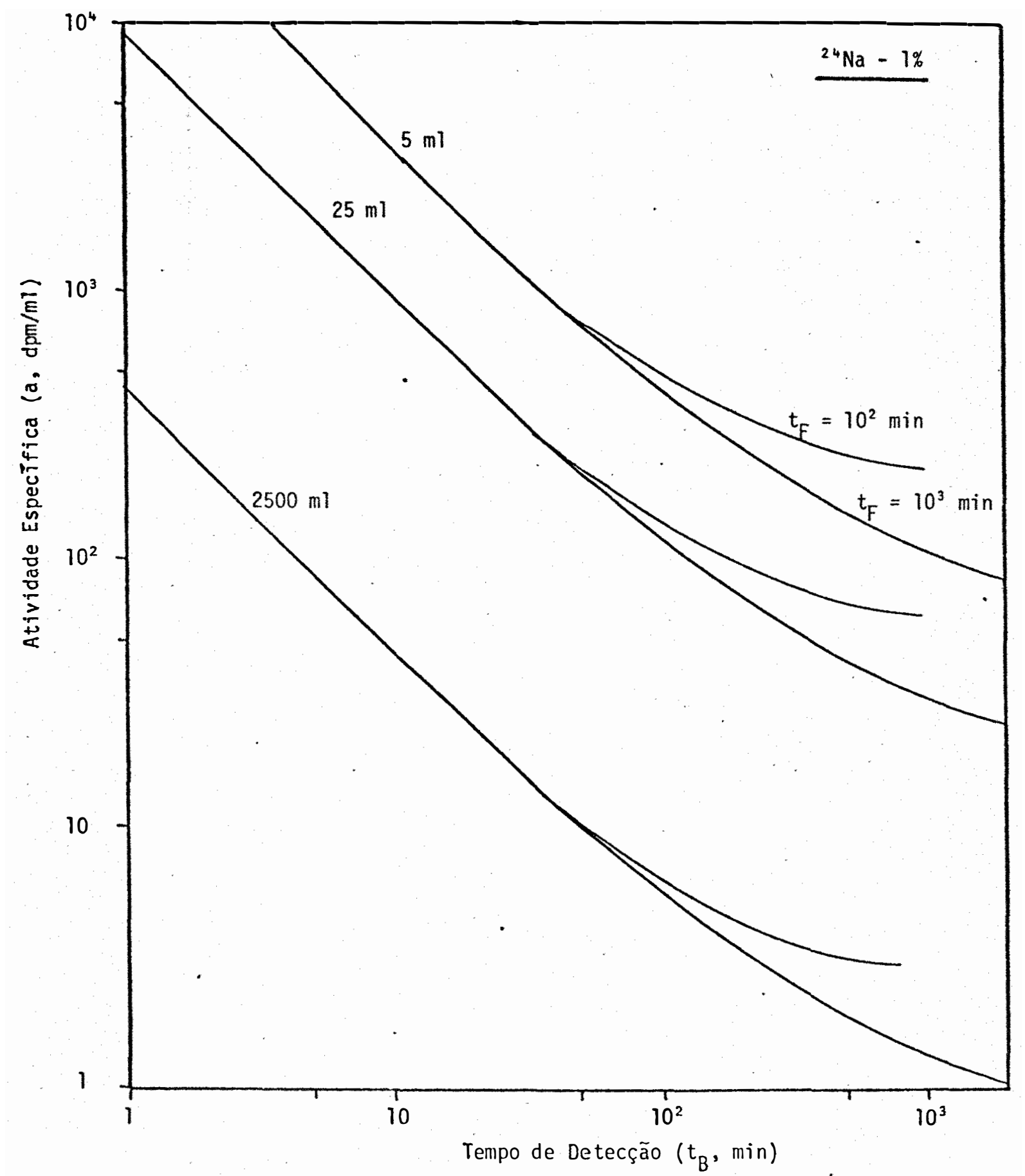

Figura 33 - Atividade especiffica mînima $(a, d p m / m l)$ para ${ }^{24} \mathrm{Na}$ em função do tempo de deteç̧ão $\left(T_{B}, \min \right)$, para se atingir coeficiente, de variação de $1 \%$, para amostras de 5 e $25 \mathrm{ml}$ colocada en tubo de vidro, e de 2500 $\mathrm{ml}$ en beaker Marinelli. Tempo de contagem da radiação de fundo $t_{F}=$ 100 e 1000 minutos. 


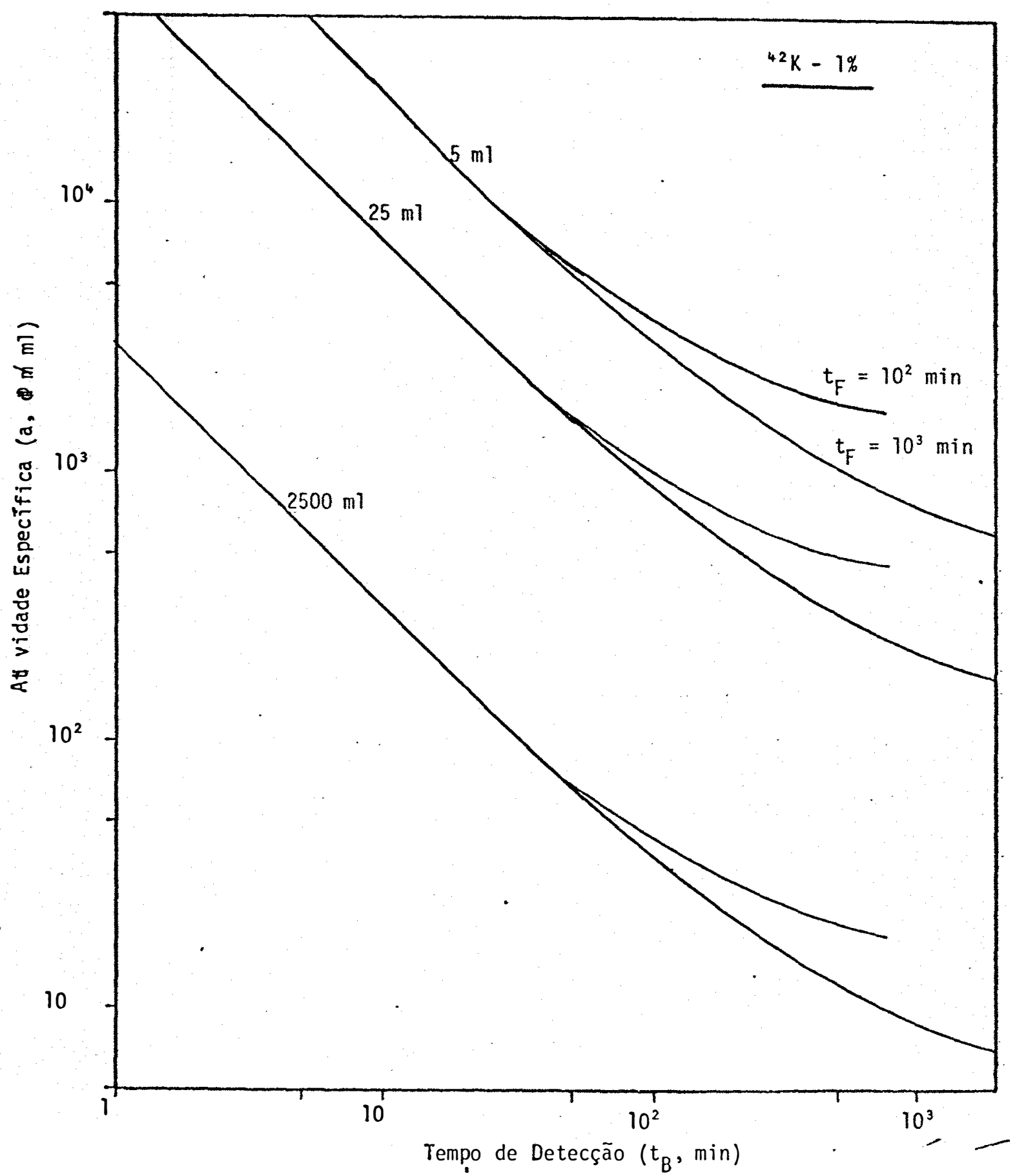

Figura 34 - Atividade especĩfica minima $(a, d p m / m l)$ para ${ }^{42} \mathrm{~K}$, em função do tempo de detecção $\left(t_{B}, \min \right)$, para se atingir coeficiente de variação de $1 \%$, para amostras de 5 e $25 \mathrm{ml}$ colocada em tubo de vidro, e de $2500 \mathrm{ml}$ em beaker Marinelli. Tempo de contagem da radiação de fundo $t_{F}=100 \mathrm{e}$ 1000 minutos. 


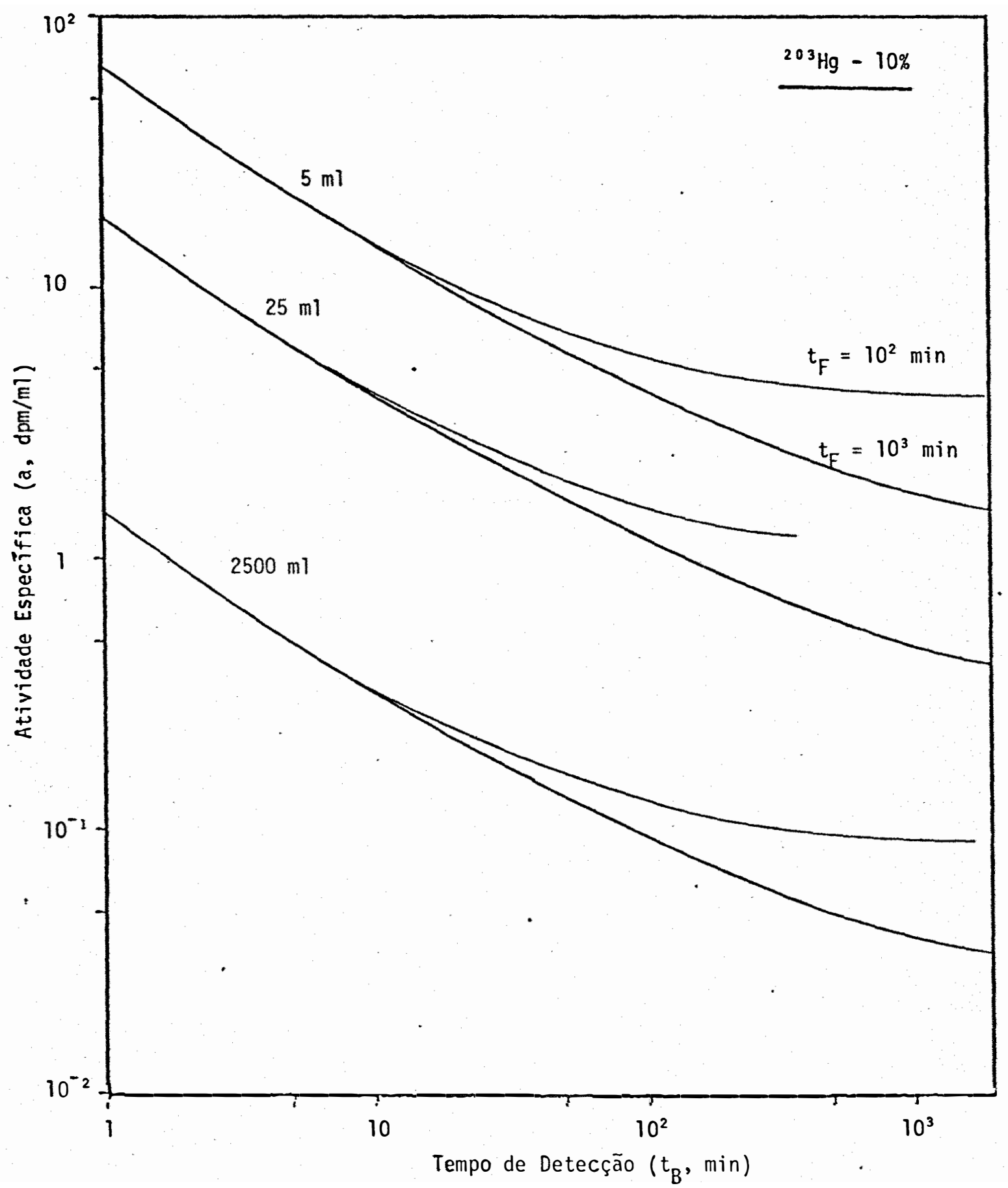

Figura 35- Atividade especîfica mīnima detectāvel (a, dpm/nl) para ${ }^{203} \mathrm{Hg}$ em função do tcmpo de detecção $\left(t_{B}\right.$, min) para se atingir coeficiente de variação de $10 \%$, para amostras de 5 e $25 \mathrm{ml}$ colocadas em tubo de vidro, e de 2500 mol em beaker Marinelli. Tempo de contagem da radiação de fundo $t_{F}=100$ e 1000 minutos. 


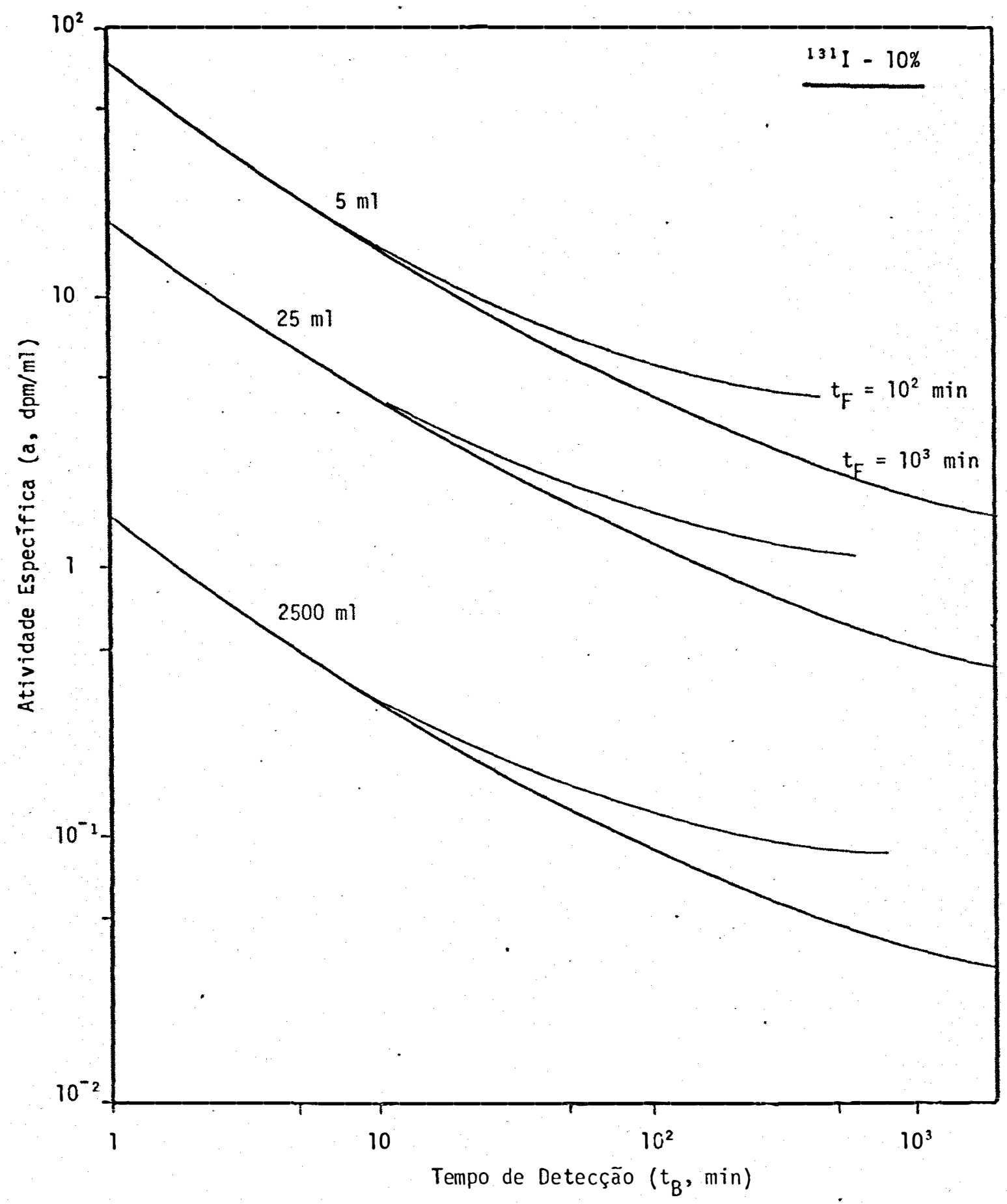

Figura 36 - Atividade especiffica minima detectāvel (a, dpm/ml) para ${ }^{131} 1$ en função do tempo de deteç̧ão $\left(t_{B}\right.$, min) para se atingir coeficiente de variação de $10 \%$, para amostras de 5 e $25 \mathrm{ml}$ colocadas em tubo de vidro, e de $2500 \mathrm{ml}$ em bcaker Marinelli. Tenipo de contagem da radiação de fundo $t_{F}=100$ e 1000 minutos. 


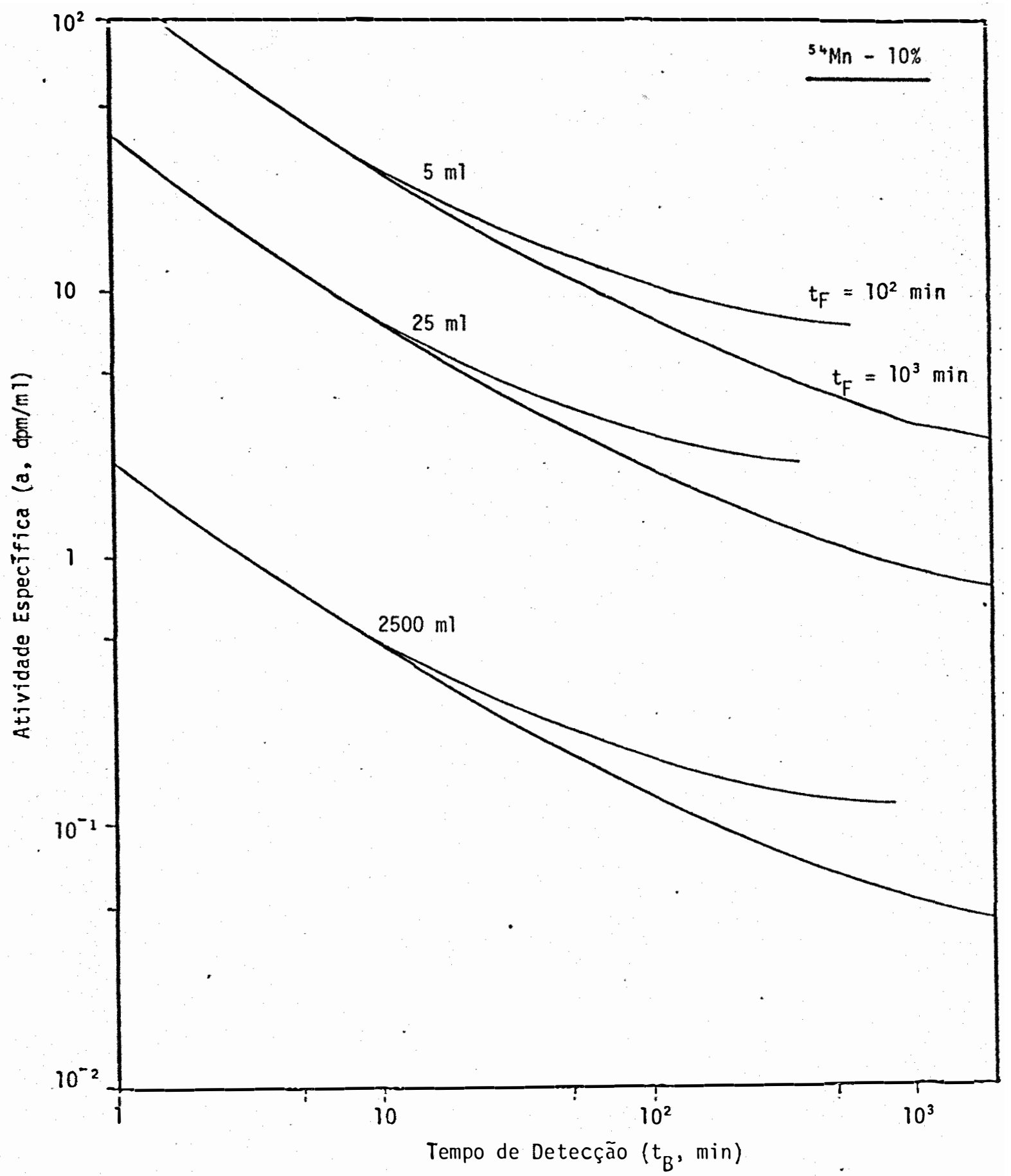

Figura 37 - Atividade especifica minnima detectāvel (a, dpm/ml) para ${ }^{54} \mathrm{Mn}$ em função do tempo de deteç̧ão $\left(t_{B}\right.$, min) para se atingir coeficiente de variação de 10\%, para amostras dc 5 e $25 \mathrm{ml}$ colocadas em tubo de vidro, e de $2500 \mathrm{~m}$ l em beaker Marinelli. Tempo de contagem da radiação de fundo $t_{F}=100$ e 1000 minutos. 


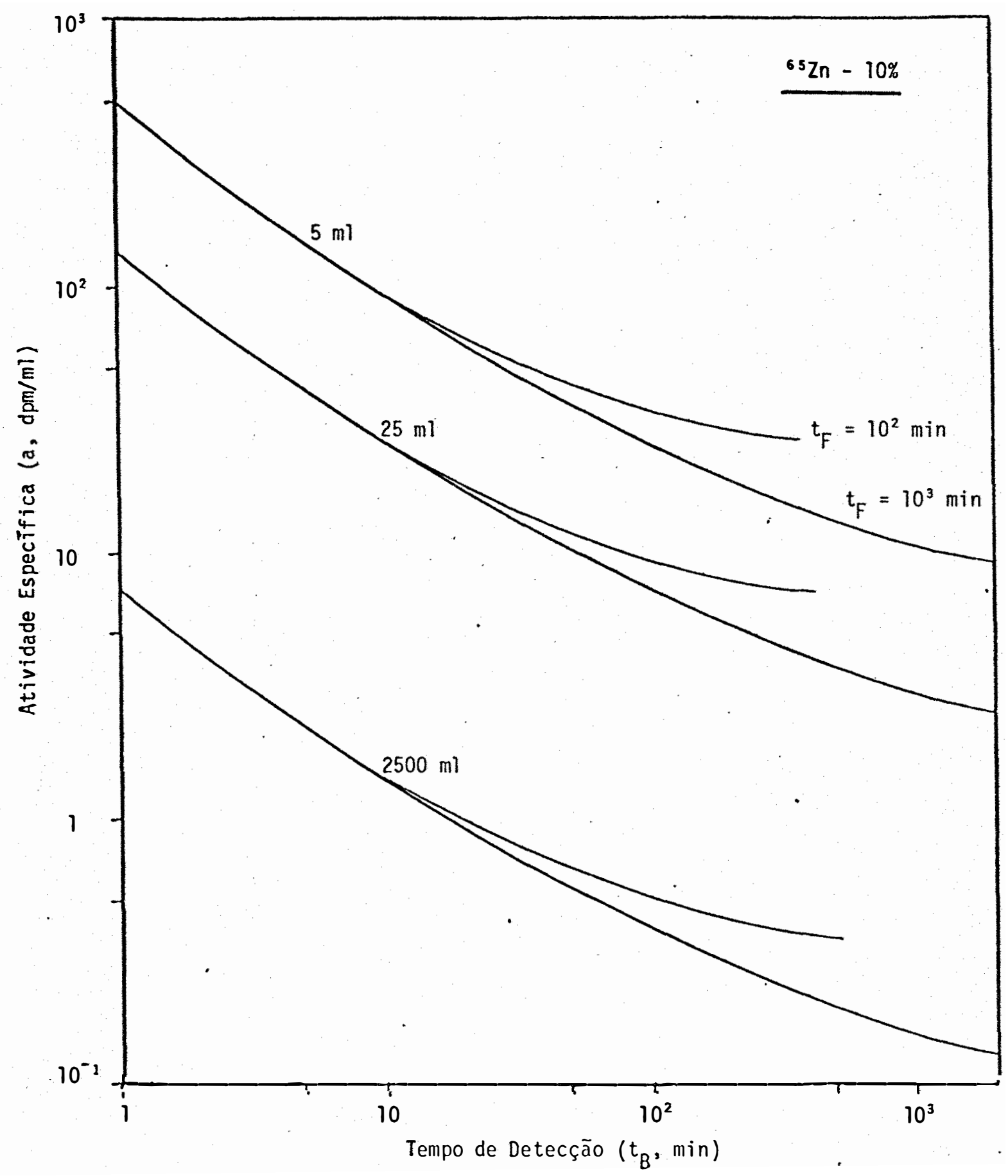

Figura 38 - Atividade especîfica minnima detectāvel (a, dpm/ml) para ${ }^{65} \mathrm{Zn}$ em função do tempo de detecção $\left(t_{B}\right.$, min) para se atingir coeficiente de variação de $10 \%$, para amostras de 5 e $25 \mathrm{ml}$ colocadas em tubo de vidro, e de $2500 \mathrm{ml}$ en beaker Marinelli. Tempo de contagem da radiação de fundo $t_{F}=100$ e 1000 minutos. 


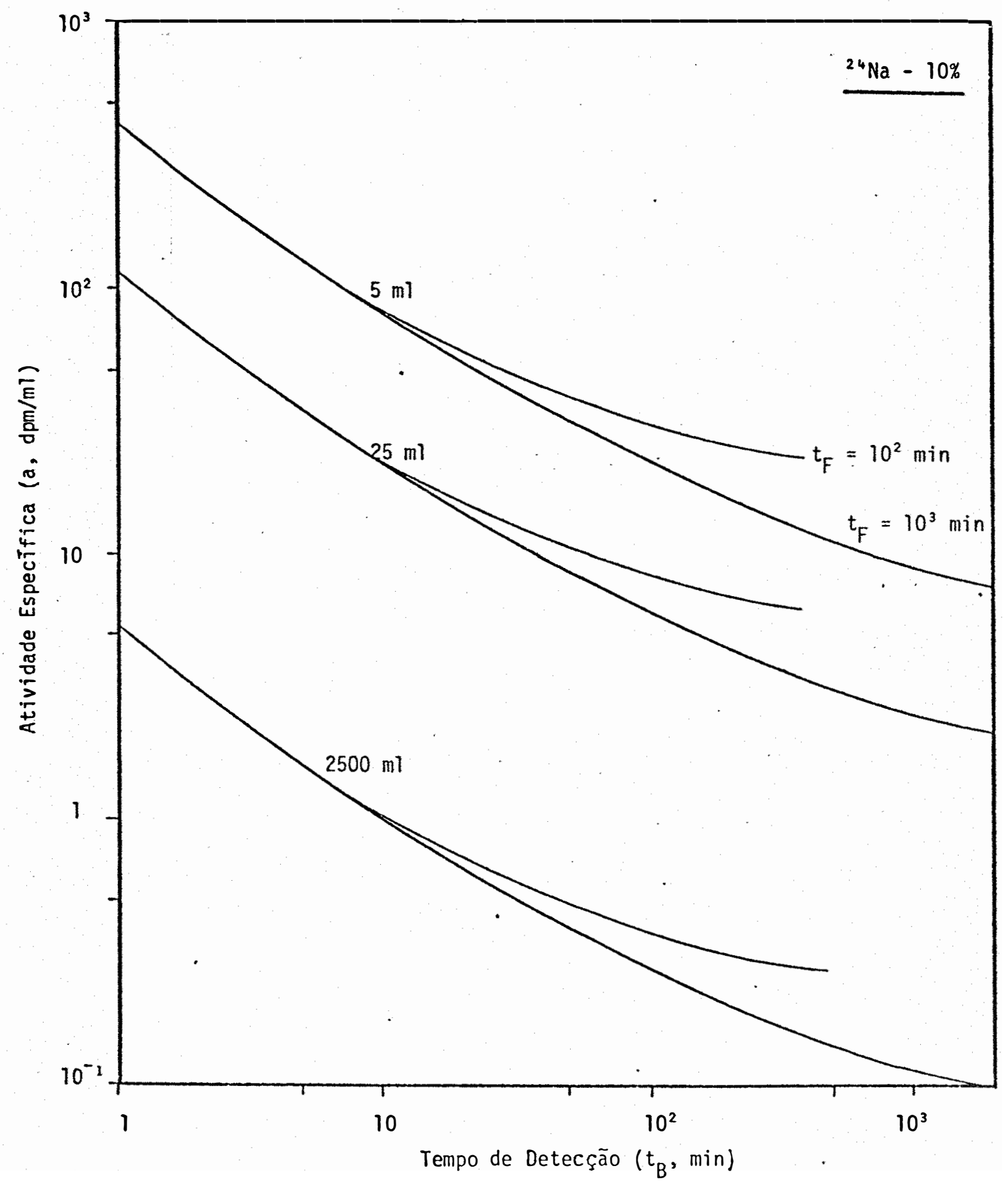

Figura 39 - Atividade especifica minina detectāvel (a, dpm/mI) para ${ }^{24} \mathrm{Na}$ em função do tempo de deteç̧ão $\left(t_{B}\right.$, nin $)$ para se atingir coeficiente de variação de .10\%, para anıostras de 5 e $25 \mathrm{mll}$ colocadas en tubo de vidro, e de $2500 \mathrm{ml}$ em beaker Marinelli. Tempo de contagem da radiação de fundo $t_{F}=100$ e 1000 minutos. 


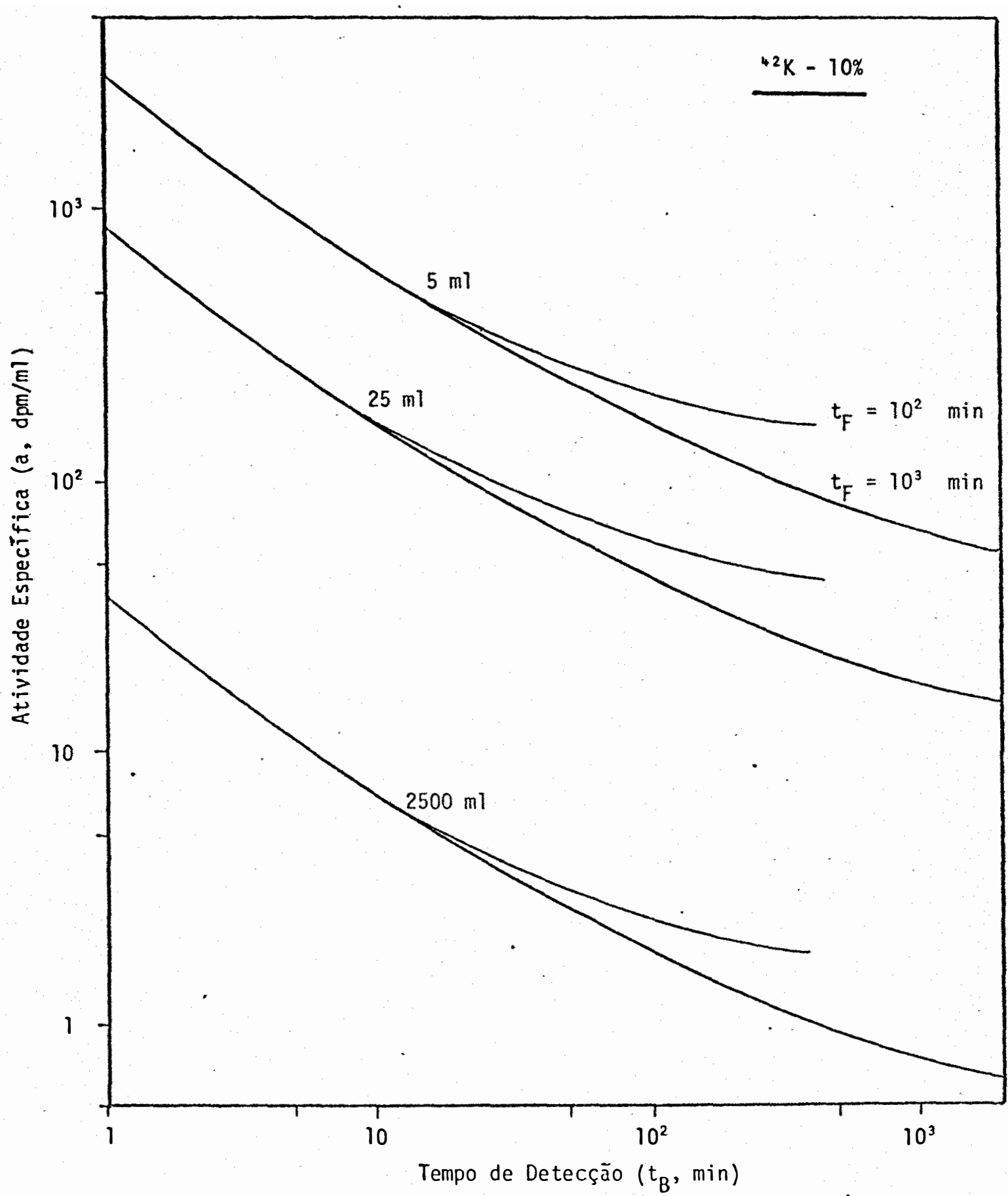

Figura 40 - Atividade específica mỉnima detectāvel (a, dpm/ml) para ${ }^{4}{ }^{2} \mathrm{~K}$ em função do tempo de detecção $\left(t_{B}\right.$, min) para se atingir coeficiente de varia ção de 10\%, para amostras de 5 e $25 \mathrm{ml}$ colocadas em tubo de vidro, e de $2500 \mathrm{ml}$ em beaker Marinelli. Tcmpo de contagem da radiação de fundo $t_{F}=100$ e 1000 minutos, 
$130 \mathrm{dpm} / \mathrm{ml}$ para $25 \mathrm{ml}$ e $10 \mathrm{dpm} / \mathrm{ml}$ para beaker Marinel1i. Em 100 minutos de detecção da amostra, para se atingir o mesmo coeficiente de variação, seriam necessārias 80,22 e 1,8 dpm/ml, respec tivamente, para tubo de vidro 5 e $25 \mathrm{ml}$, e beaker Marinelli $2500 \mathrm{ml}$. Para radioisōtopos emissores de raios gama de alta energia ( ${ }^{42} \mathrm{~K}$, por exemplo), a razão entre as atividades especificas é bem maior que para baixa energia. Considerando-se as mesmas condições anteriores, seriam necessārias 600, 165 e 7,2 dpm/ $\mathrm{ml}$ para se atingir o coeficiente de variação de 10\% com 10 minutos de detecção da amostra e 10 minutos da radiação de fundo. Pa ra 100 minutos de deteç̧ão da amostra, as atividades seriam de 210,58 e $2,4 \mathrm{dpm} / \mathrm{ml}$.

Por outro lado, para amostras de mesmas atividades específicas, o tempo necessário para detecção da amostra para se atingir um determinado coeficiente de variação, é da ordem de 100 vezes menor quando se utiliza o beaker Marinelli - 2500 do que tubo de vidro - $25 \mathrm{ml}$, como pode ser visto nas figuras 28 - 39 , considerando-se o mesmo tempo de detecção de radiação de fundo.

Apesar da eficiēncia de detecção em beaker Marinelli $2500 \mathrm{ml}$ ser 11,4 a 5,9 vezes menor que do tubo de vidro - $5 \mathrm{ml}$, ou de 8,3 a 4,3 em relação a $25 \mathrm{ml}$, na faixa de 0,2 a $1,5 \mathrm{MeV}$ (fig. 15), a atividade específica necessāria para atingir os coeficientes desejados são bem menores no beaker Marinelli. Em outras palauras, o baixo valor da eficiência do Marinelli é compensado pelo alto volume empregado na detecção. Isto pode ser evidenciado pelo em prego da equação 55, onde sob as mesmas condições, a razão entre as atividades minimas para beaker Marinelli e tubo de vidro pode ser dada por:

$$
\frac{a_{M 2500}}{a_{t}}=\frac{v_{t} \cdot \varepsilon_{t}}{V_{M \cdot \varepsilon_{M 2500}}}
$$

uma vez que a taxa de radiação de fundo é praticamente a mesma pa ra tubo de vidro e beaker Marinelli. Desse modo, em detecção com o beaker Marinelli, na faixa de 0,2 a 1,5 MeV, empregando-se nos mesmos tempos de deteç̧ão da amostra e radiação de fundo, consegue-se estimar com mesmo coeficiente de variação, atividades específicas 44 a 84 vezes menores que o tubo de vidro de $5 \mathrm{ml}$, e de 12 a 23 vezes para $25 \mathrm{ml}$ (figura 41 ). 


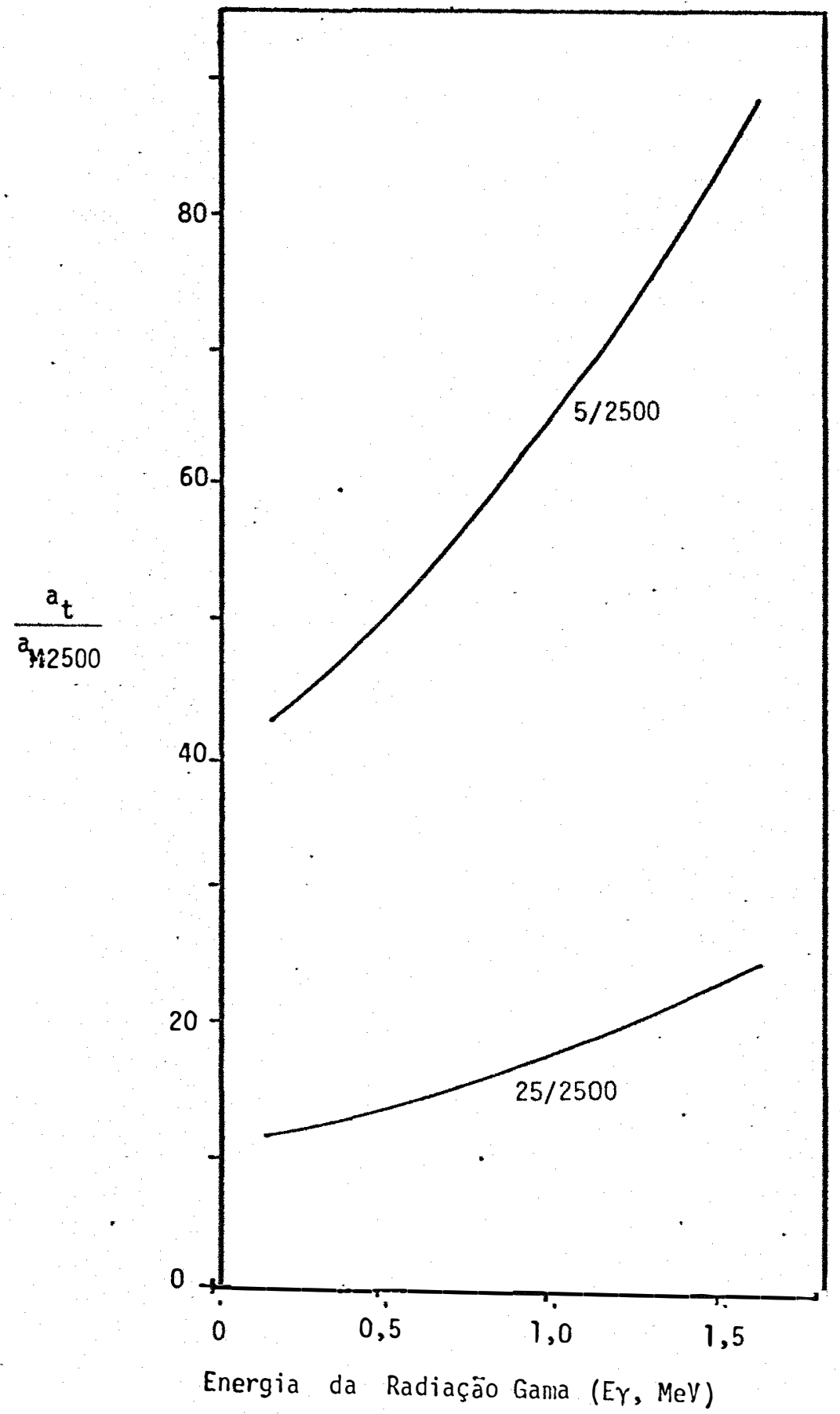

Figura 41 - Razão entre as atividades específicas minimas detectáveis para amostras colocadas em tubo de vidro $\left(a_{t}, 5\right.$ e $\left.25 \mathrm{ml}\right)$ e beaker Marinelli $(\mathrm{g}, 2500 \mathrm{ml})$. 
Para se detectar amostras de baixa atividade específica, poderia se empregar métodos químicos para concentração do volume da amos tra, como pur exemplo, resinas trocadoras de íons, precipitação, eletrodeposição, extração por solvente, etc. Neste caso, amos tras de grande volume poderiam ser reduzidas para 5 ou $25 \mathrm{ml}$, au mentando-se a atividade específica e detectando-a posteriormente em tubo de vidro com eficiēncia maior do que no beaker Marinel 1i. Em outras palavras, pela redução do volume de 2500 para 5 ou $25 \mathrm{ml}$, e empregando-se os mesmos tempos de detecção da amos tra e radiação de fundo poder-se-ia atingir atividades específicas menores com o mesmo coeficiente de variação. Poder-se-ia atingir 100 ou 500 vezes menor a atividade específica necessāria na deteç̧ão direta de 25 e $5 \mathrm{ml}$ da solução radioativa em tubos de vidro, respectivamente. Na faixa de 0,2 a 1,5 MeV, poder-seia atingir 11,4 a 5,9 vezes menor em relação à detecção direta em beaker Marinelli - $2500 \mathrm{ml}$, concentrando a amostra para $5 \mathrm{ml}$, e de 8,3 a 4,3 se a concentração fosse para $25 \mathrm{ml}$, como mostra a figura 42. Nos valores dados acima, foi considerado não haver perda de radioisōtopo no processo químico utilizado, ou seja,foi considerado que o processo químico de concentração tem uma efi ciēncia de $100 \%$.

Considerando que os métodos quîmicos de redução de volume exigem gastos com drogas, tempo de preparo e manuseio das amostras, tal vez fosse aconselhāvel a detecção por maior tempo diretamente em beaker Marinelli. 


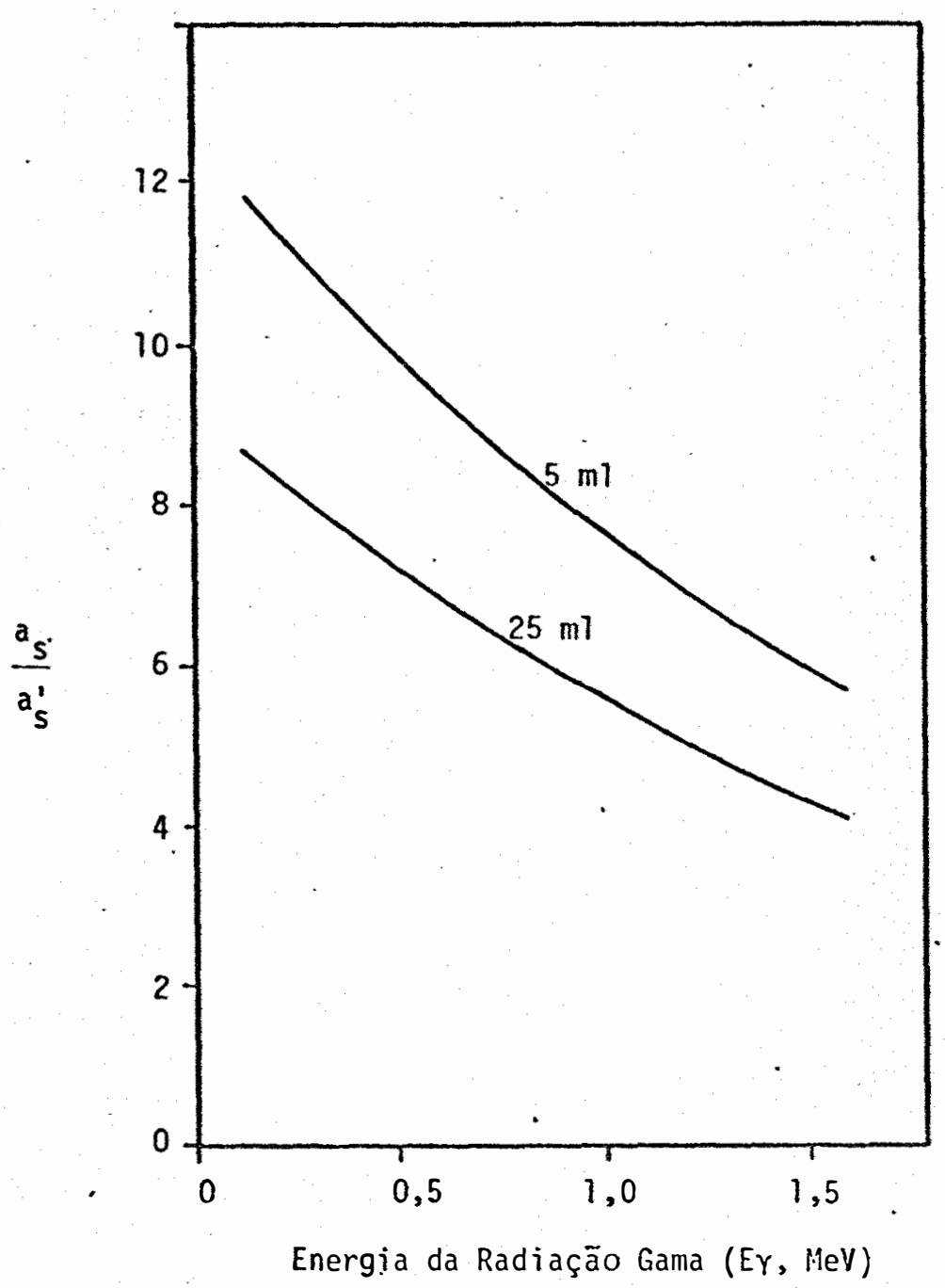

Figura 42 - Razão entre as atividades especĩficas minnimas detectäveis para amostras colocadas diretamente em beaker Marinelli $2500 \mathrm{ml}\left(\mathrm{a}_{\mathrm{s}}\right)$ e apōs extração colocadas em tubos de vidro $\left(a_{s}^{\prime}\right)$ de 5 ou 25 . mi . 


\section{CONCLUSOES}

Em face da discussão dos resultados obtidos pode-se con cluir que:

1) a eficiência relativa de detecção para fotopico em função do volume independe da energia da radiação gama, tanto na detecção em tubo de vidro como no beaker Marinelli;

2) a eficiēncia de detecção para amostras de $25 \mathrm{ml}$ coloca das em tubo de vidro é aproximadamente 1,4 vezes menor do que para amostras de $5 \mathrm{ml}$, independentemente da energia da radiação gama;

3) para radioisótopos de energia baixa $\left({ }^{20} \mathrm{Hg}-0,28 \mathrm{MeV}\right)$, a eficiēncia de detecção para amostras de $2500 \mathrm{ml}$ contida em beaker Mari nelli é aproximadamente 8 vezes menor que a obtida com $25 \mathrm{ml}$ em tubo de vidro, enquanto que para energia alta $\left({ }^{42} \mathrm{~K}-1,52 \mathrm{MeV}\right) \bar{e}$ aproximadamente 4 vezes; com relação a $5 \mathrm{ml}$ em tubo de vidro, é aproximadamente 11 a 6 vezes menor;

4) para se atingir um determinado coeficiente de variação o tempo necessārio para detecção da amostra quando se emprega beaker Marinelli - $2500 \mathrm{ml}$ è da ordem de 100 vezes menor do que tubo de vidro-25 $\mathrm{ml}$, considerando-se o mesmo tempo de detecção da radiação de fundo;

5 ) empregando-se mesmos tempos de detecção da amostra e radiação de fundo, na detecção de $2500 \mathrm{ml}$ da amostra em beaker Marinelli, as atividades específicas necessārias são 44 a 84 vezes menores do que em tubos de vidro de $5 \mathrm{ml}$, na faixa de 0,2 a 1,5 MeV, independentemente do coeficiente de variação desejado; com relação ao tubo de vidro contendo $25 \mathrm{ml}$, pode-se atingir atividades específicas 12 a 23 vezes menores;

6) empregando-se métodos quîmicos para concentração do ra dioisōtopo, com eficiēncia de 100\%, reduzindo-se o volume da amostra de 
2500 para $25 \mathrm{ml}$, pode-se atingir atividades específicas 8,3 a 4,3 vezes menores do que a detecção direta em beaker Marinelli, na faixa de 0,2 a $1,5 \mathrm{MeV}$; reduzindo-se 0 volume para $5 \mathrm{ml}$, poder-se-ia atingir níveis 11,4 a 5,9 vezes menores. 
9. SUMMARY: MINIMUM DETECTABLE ACTIVITY FOR RADIOISOTOPE GAMMA-RAY EMITTERS IN AQUEOUS SAMPLES

The photopeak detection efficiency was determined for aqueous samples from $5 \mathrm{ml}$ to $25 \mathrm{ml}$ in glass tubes and from $250 \mathrm{ml}$ to $2500 \mathrm{ml}$ in Marinelli beakers, as a function of gamma-ray energy within the 0.2 to $1.5 \mathrm{MeV}$ range, for a $3 \times 3^{\prime \prime}$ well type ( $7 / 8^{\prime \prime}$ diameter $\times 1$ 1/2" depth) NaI (Tl) scintillator crystal.

The detection efficiency for samples of $25 \mathrm{ml}$ in glass tubes was 1.4 times lower than that found for samples of $5 \mathrm{ml}$, independently of the gamma-ray energy. In Marinelli beakers, samples of $2500 \mathrm{ml}$ and $500 \mathrm{ml}$ showed similar results.

Within the gamma-ray energy range studied, the detection efficiency in Marinelli beakers of $2500 \mathrm{ml}$ is from 8 to 4 times lower than that for detection in glass tubes of $25 \mathrm{ml}$, and from 11 to 6 times lower in relation to the glass tube of $5 \mathrm{ml}$.

The Marinelli beaker lower detection efficiency when compared with the glass tube is compensated by the larger volume used in the measurement of this radioisotope activity. Based on the same background radiation times, the time necessary for detection of the sample in a Marinelli beaker of $2500 \mathrm{ml}$ to achieve a given variation coefficient, is of the order of 100 times lower than that achieved wi th a glass tube of $25 \mathrm{ml}$.

The specific activity needed to achieve a given variation coefficient is from 44 to 84 times lower when using a Marinelli beaker of $2500 \mathrm{ml}$ instead of a glass tube of $25 \mathrm{ml}$, with the same times for 
sample detection and back-ground radiation in both techniques. When comparing detection in a Marinelli beaker of $2500 \mathrm{ml}$ with that in a glass tube of $25 \mathrm{ml}$, the ratio is 12 to 23 times.

The use of chemical methods with $100 \%$ extraction efficiency to reduce the sample volume would be advantageous for radioisotopes which are low energy gamma-ray emitters. The volume reduction from 2500 to $25 \mathrm{ml}$, in the 0.2 to $1.5 \mathrm{MeV}$ range, would reach specific activities 8.3 to 4.3 times lower than the direct detection in a Marinelli beaker of $2500 \mathrm{ml}$; if the volume is reduced to $5 \mathrm{ml}$, it can be 11.4 to 5.9 times lower than direct detection. 
ADAMS, J.A.S. e P. GASPARINI, 1970. Gamma-ray Spectrometry for Rocks. Series Methods: - Geochemistry and Geophysics, vol. 10, Elsevier Publishing Co., $295 \mathrm{p}$.

BARATTA, E.J. e F.E. KNOWLES, Jr. 1973. Gamma spectroscopy determination of Cesium-137 in milk, using simultaneous equations: collaborative study. Jourm. of the AOAC, Bal timore, 56: 204-207.

BERGER, C.D. e R.E. GOANS, 1979. A rapid method of ${ }^{131} \mathrm{I}$ detection in milk. Health Phys., New York, 37: 783-784.

BRAUER, F.P.; J.H. KAYE e R.E. CONNALY, 1970. X-ray and beta-ganma coincidence spectrometry applied to radiochemical analysis of environmental samples. Adu. in Chemistry Series, no 93 Radioisotopes in the Environmental, p. 231-253.

BRAUER, F.P.; J.H. KAYE; J.E. FAGER; W.A. MI TZCAFF e H.G. RIECK, Jr., 1972. A dual $\mathrm{Ge}(\mathrm{Li})$-dual $\mathrm{NaI}(\mathrm{Tl})$ gamma-ray spectrometer. Nucl. Instr. Meth., Amesterdão, 102: 223-235.

BRAUER, F.P.; J.H. KAYE e J.E. FAGER, 1975. NaI(TI)-Ge(Li) coincidence gamma-ray spectrometry for radionuclide analys is of environmental samples. IEEE Trans. Nucl. Sci., Piscataway, NS-22: 661-670.

CHISTALLER, G., 1967. Experimental peak-total ratio of an $4 \times 4 " \mathrm{NaI}(\mathrm{Tl})$ crystal. Nucl. Instr. Meth., Ames terdão, 50: 173-175. 
COLBY Jr., L.J. e J.W. COBBLE, 1959. Precision calibration of large $4 \pi$ scintillation crystals for routine gamma counting. Nucleonics, Nova Iorque, 31: 789-799.

COSTRELL, L.; C. SANDERSON; D.E. PERSYK; G. WALFORD e F.J. WALTER, 1980. Germanium semiconductor detector efficiency determination using a standard Marinelli (reentrant) beaker geometry. Health Phys., Nova Iorque, 38: 229-232.

CROUTHAMEL, C.D.; F. ADAMS e R. DAMS, 1975. Applied Garma-Ray Spectromety. Nova Iorque, Pergamon Press, $752 \mathrm{p}$.

GUNNINK, R. e A.W. STONER, 1961. Photopeak counting efficiencies for $3 \times 3$ inch solid and well-type NaI scintillation crystals. Anaz. Chem., Washington, 33: 1311-1313.

GUSTAFSON, P.F. e S.S. BRAR, 1964. Measurement of ganma-emitting radionuclides in soil and calculation of the dose arising therefrom. In: ADAMS, J.A.S., e W.W. LOWDER, eds. The Natural Radiation Environment. Chicago, The University of Chicago Press, p. 449-512.

HANSEN, R.0., 1970. Radioactivity of a California terrace soil. Soil sci., Baltimore, 110: 31-36.

HANSEN, R.0. e G.L. HUNTINGTON, 1969. Thorium movements in morainal soils of High Sierra. Soil Sci., ' Baltimore, 108: 257-265.

HEATH, R.L., 1962. Scintillation Spectrometry Ganma-Ray Spectrum Catalogue. Idaho Falls, Philips Petrolium Company, Atomic Energy Division, IDO - 16408.

HEATH, R.L., 1964. Scintillation Spectromety. Vol. 2, 2nd. Edition, IDO-16880 - 2. I daho Operations Office.

HILL, R.F.; G.J. HINE e L.D. MARINELLI, 1950. The quanti tative determination of gamma-ray radiation in biological research. Amer. J. Roent. Radium Therapy and Nucl. Med., Wiston-Salem, 63:160-169. 
HOLMBERG, P. e R. RIEPPO, 1973. Monte Carlo calculations of efficiency values for well-type NaI - detectors with self-absorption in the source. Interm. J. Appl. Rad. Isotopes, Nova Iorque, 24: 99-105.

HOLMBERG, P. e R. RIEPPO, 1977. The effect of well dimensions on the efficiency values for well-type $\mathrm{NaI}$ - detectors. Interm. J. Appl. Rad. Isotopes, Nova Iorque, 28: 469-472.

HORWITZ, W., 1975. Official Methods of Analysis of the Association of Official Analytical Chemists. Washington, 12a. edição, 1094 p.

HUNT, G.J.; M.C. O'RIORDAN E P.D.J. WHETMATH, 1978. An anti-coincidenceshielded $\mathrm{Ge}(\mathrm{Li})$ gamma-ray spectrometer with high sensitivity for measurement of environmental radionuclides. Nucl. Instr. Meth., Amesterdão, 156: 573-589.

IDDINGS, F.A.; T.J. LIEBER e 0.W. WILLIAMS, 1979. Counting yield calibration of $\mathrm{NaI}(\mathrm{Tl})$ detectors for complex geometry samples by use of Cal iforni um-252. J. Radioanal. Chem., Amesterdão, 50:125-131.

LAZAR, N.H.; R.C. DAVIS e P.R. BELL, 1956. Peak efficiency of NaI. Nucleonics, Nova Iorque, 14: 52.

LLOYD, R.D.; R.L. AAMODT; W.W. WAGNER e R.C. PENDLETON, 1968. Calibration of a gamma-ray spectrometer for soils counting. Interm. J. Appl. Rad. Isotop., Nova Iorque, 19: 773-775.

MENZEL, R.G., 1968. Uranium, Radium and Thorium content in phosphate rocks and their possible radiation hazard. J. Agr. Food Chem., Washington, 16: 231-234.

MONTANHEIRO, M.N.S.; V.F. NASCIMENTO Fọ e F.A. PINTO, 1977. Introdução à espectrometria gama. BD-021, CENA, Piracicaba, $37 \mathrm{p}$.

MULLER, C.J. e F.J. HAASBROEK, 1969. Determination of total potassium in soil by means of radiometric analysis. Agrochemophysica, Johanesburgo, 1: 97-98. 
NASCIMENTO FO, V.F., 1977. Características físicas dos principais ra dioisōtopos utîlizados em ciências biológicas. BT-009, CENA. Piracicaba, $8 \mathrm{p}$.

NEW ENGLAND NUCLEAR, 1977. Certificate of radioactivity and calibration: ${ }^{57} \mathrm{Co},{ }^{133} \mathrm{Cs},{ }^{54} \mathrm{Mn}$ and ${ }^{60} \mathrm{Co}$ references sources. Boston, Massachusetts, $5 \mathrm{p}$.

NIELSEN, J.M. e H.A. KORNBERG, 1965. Multidimensional gamma-ray spectrometry and its use in biology. In: IAEA, ed., Radioisotope Scomple Measurement Techniques in Medicine and Biology. Viena, p. 3-15.

NIELSEN, J.M. e R.W. PERKINS, 1967. Anticoincidence shielded multidimensional gamma-ray spectrometers for low level counting. In: IAEA, ed., Radioactive Dating and Methods of Low Level Counting. Viena, p. 687-702.

PRICE, W.J., 1958. Nuclear Radiation Detection. Nova Iorque, McGraw Hi11, 382 p.

RIEPPO, R.; K. BLOMSTER e P. HOLMBERG, 1975. Calculated 10-150 keV gammaray efficiency values for well-types NaI-detectors. Intern. J. Appl. Rad. Isotopes, Nova Iorque, $26: 558-561$.

RIEPPO, R. e K. BLOMSTER, 1976. Calculated absolute photopeak efficiency values for $3 \times 3^{\prime \prime} \mathrm{NaI}$ - detector with cylindrical source geometry. Intern. J. App Z. Rad. Isotopes, Nova Iorque, 27: 365-367.

SONNTAG, C., 1967. Extremely low level scintillation spectrometer. In: IAEA, ed., Radioactive Dating and Methods of Low Level Counting. Viena, p. 675-685.

TAKAGI, S.; M. FUKUSHIMA e H. KOYAMA, 1978. Determination of extremely low-level radioiodine in milk. J. Nucl. Sci. Techn., Tóquio, 15: $145-151$.

TALIBUDEEN, 0. e Y. YAMADA, 1966. Total potassium in soils by radioactivity measurements. J. Soil Sci., Londres, 17: 107-120. 
VASSILAKY, M.; L. SALMON e J.A.B. GIBSON, 1965. Measurement of radioactivity in soil. AERE-R 4996, Harwell.

VERHEIJKE, M.L., 1962. Calculated efficiencies of a $3 \times 3^{\prime \prime} \mathrm{NaI}(\mathrm{TI})$ well-type scintillation crystal. Intern. J. Appl. Rad. Isotopes, Nova Iorque, 13: 583-585.

VERHEIJKE, M.L., 1970. Calculated efficiencies of NaI(TI) scintillation crystals for Marinelli beakers with aqueous sources. Interm. J. App 2. Rad. Isotopes, Nova Iorque, 21: 119-126.

WARD, G.M.; J.E. JOHNSON e D.L. WHELAN, 1968. Detection of Cesium-137 and related sampling problems of dairy cattle feeds, 1962-1967. Joum. of the AOAC, Baltimore, 51: 792-796.

WATT, D.E. e D. RAMSDEN, 1964. High Sensitivity Counting Techniques. Nova Iorque, MacMillan Co., 348 p.

WOGMAN, N.A., 1976. Current methods for laboratory analysis of environmental levels of radioactivity. IEEE Trons. Nucl. Sci., Piscataway, NS-23: 1214-1223.

WOGMAN, N.A.; R.W. PERKINS e J.H. KAYE, 1969. An all sodium iodide anticoincidence shielded multidimensional gamma-ray spectrometer for low-activity samples. Nucl. Instr. Meth., Amesterdão, 74.197-212. 